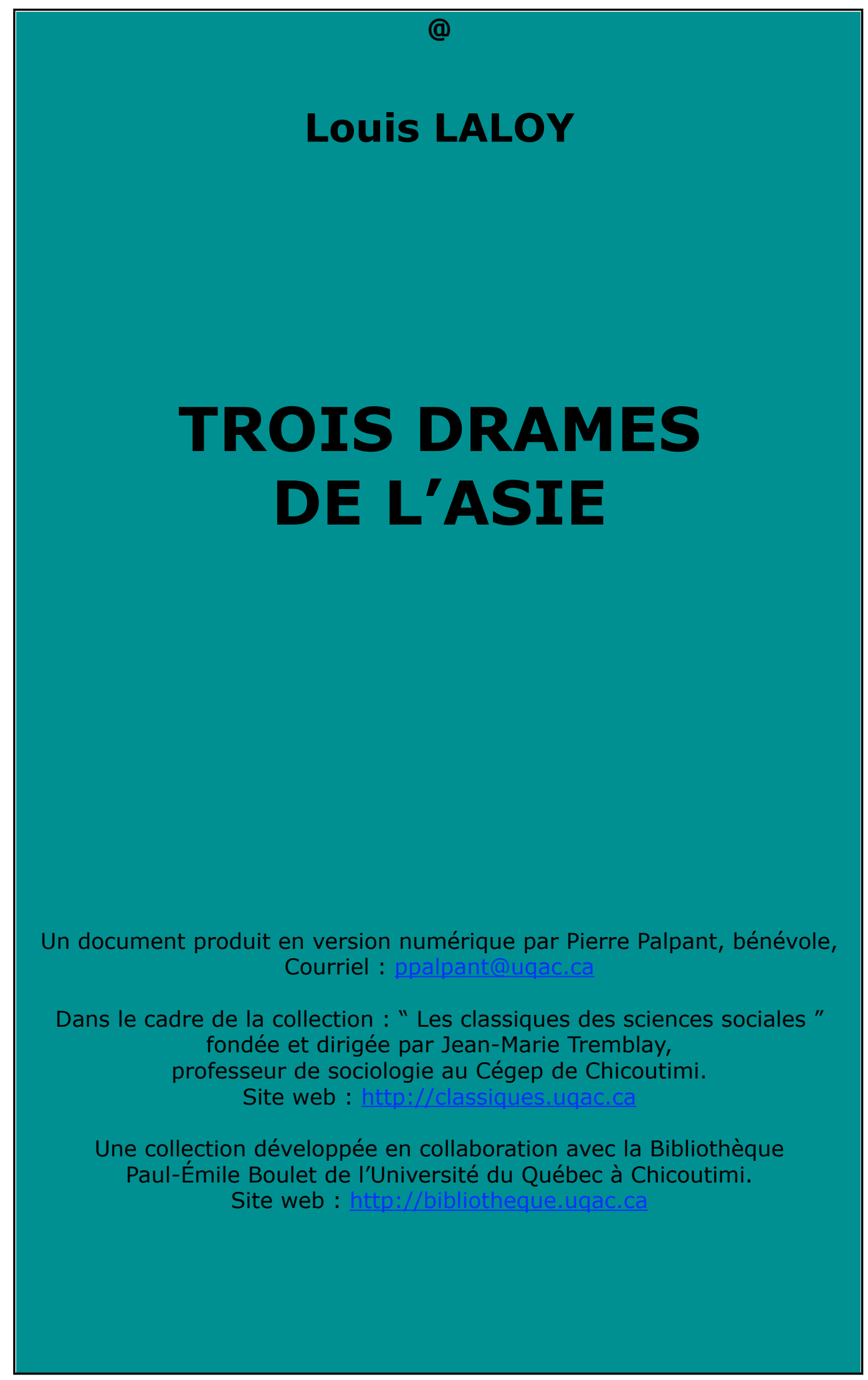


Un document produit en version numérique par Pierre Palpant, collaborateur bénévole,

Courriel : ppalpant@uqac.ca

à partir de :

\section{TROIS DRAMES DE L'ASIE,}

par Louis LALOY (1874-1944)

Editions de la Baconnière - Neuchatel, Décembre 1943, 146 pages.

Police de caractères utilisée : Verdana, 12 et 10 points.

Mise en page sur papier format Lettre (US letter), 8.5"x11"

[note : un clic sur @ en tête de volume et des chapitres et en fin d'ouvrage, permet de rejoindre la table des matières]

Édition complétée le 15 décembre 2006 à Chicoutimi, Québec. 


\section{Trois drames de I'Asie}

\section{TABLE DES MATIÈRES}

Préface

LE SONGE DE LA VIE, drame en quatre actes et un prologue.

Prologue I II III IV

VIKRÂMA ET OURVÂSI, ou le roi et l'apsâra, drame en cinq actes.

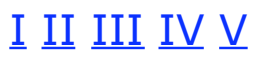

LE CHAGRIN AU PALAIS DE HAN, drame en cinq actes.

I II III IV $\underline{V}$ 


\section{PRÉFACE}

@

En 1755, Voltaire retiré « au pied des Alpes, et vis-à-vis des neiges éternelles », offrait à monseigneur le maréchal duc de Richelieu son nouvel ouvrage, l'Orphelin de la Chine, et après les compliments d'usage expliquait son dessein : "L'idée de cette tragédie me vint, il y a quelque temps, à la lecture de l'Orphelin de Tchao, tragédie chinoise, traduite par le P. Prémare, qu'on trouve dans le recueil que le $P$. du Halde a donné au public ».

Sans rechercher le patronage d'un si grand seigneur, le livre qui paraît aujourd'hui simplement se présente à qui garde encore en des temps si troublés le goût de la lecture, la force de penser ; le village du Jura qui abrite mes travaux ne contemple que de fort loin les neiges du Mont-Blanc, et je ne suis pas Voltaire, mais crois avoir autant que lui le droit de chercher mes héros hors de l'antiquité classique ou de l'Europe qui se dit chrétienne, et suivant son exemple de prendre avec les auteurs de la Chine ou de l'Inde, dans la mesure de mes moyens, les libertés que s'est permises Corneille à l'égard de Guilhen de Castro, Racine avec Euripide et Sénèque, et Goethe aux dépens de Marlowe.

Le premier de ces drames appartient à la religion taoïste et retrace la conversion d'un saint. Liù Yén ${ }^{1}$ est un des huit Immortels que I'on voit si souvent représentés sur les peintures

1 Les noms chinois sont transcrits selon la méthode des livres français d'enseignement, à cela près qu'une syllabe sans accent est censée au premier ton dans le cas ordinaire, au cinquième si un $\mathrm{h}$ la termine. 


\section{Trois drames de I'Asie}

et les objets d'art de la Chine, avec leurs attributs signalétiques : pour Liù Yên, l'épée rappelant son passage aux armées, qui lui fut si funeste ; pour Tchoung-lî K'iuên, l'éventail, insigne du haut commandement qu'il exerçait sur terre ; la gourde et la béquille de fer de Li T'ieh-koài réincarné dans le corps d'un boiteux ; les castagnettes du solitaire Ts'âo Kouoh-kiou, le panier de fleurs que porte le joyeux Lân Ts'aì-houô, la boîte où Tchang Kouò enferme son âne de papier, la flûte de Hân Siang-tzè, la fleur de lotus cueillie par la dévote Hô Sien-kou.

Le taoïsme est une doctrine purement chinoise en son principe et déjà constituée par ses éléments essentiels avant l'introduction du bouddhisme qui est venu des Indes et n'a commencé d'être connu en Chine qu'au deuxième siècle de l'ère chrétienne. Mais ensuite les deux religions ont réagi l'une sur l'autre et le bouddhisme de la Chine s'est imprégné de la pensée taoïste pendant que le taoïsme admettait plusieurs divinités du bouddhisme.

La philosophie taoïste pousse plus loin que Kant la critique de la raison dont elle n'accepte aucune notion, pas même celle de l'existence, et la religion taoïste prêche une morale de renoncement, analogue à celle du bouddhisme mais beaucoup plus absolue, détachée de toutes les œuvres et sous sa forme la plus haute réduite à la contemplation pure. Il n'y a que la foi qui sauve, la foi dans le táo, mot qui signifie la voie, la route. Cette route est celle que suit l'univers ou plutôt, car l'univers n'est luimême qu'une apparence encore, le grand Tout insondable dont nous n'apercevons jamais que l'ombre et le reflet. Celui qui a su 


\section{Trois drames de I'Asie}

se confondre avec le grand Tout a trouvé le chemin du salut. Quelques-uns y parviennent d'eux-mêmes, par la seule puissance de leur méditation. A d'autres il faut des épreuves pour renoncer au monde. Celles qui par l'intervention de Tchoung-lî déjà élevé au céleste séjour seront proposées à Liù Yên encore retenu sur la terre ont ceci de particulier qu'elles se produisent en rêve.

Les philosophes de la Chine, comme aussi ceux de l'Inde, ont très tôt remarqué que dans le rêve les objets sont pour nous aussi vrais et nos sensations aussi fortes qu'à l'état de veille. Rien ne prouve donc, si l'on veut bien y réfléchir, que le monde que nous appelons réel ne soit pas lui aussi un rêve. C'est une des idées fondamentales de la philosophie hindoue; elle conduit à la conviction, développée surtout par le bouddhisme, que tout ce que nous voyons autour de nous est illusoire. Parler d'illusion, c'est affirmer encore qu'une réalité existe ou peut exister. Pour le taoïsme chinois, qui voit plus haut, il n'y a, au sens absolu du mot, ni illusion ni réalité. Tout dépend du point de vue et du moment. Le rêve quand on rêve est réel, et devient illusoire au réveil. Ce que nous apercevons les yeux ouverts cesse d'exister quand nous prend le sommeil. Le héros de ce drame vivra sa vie en rêve mais en recevra des impressions aussi fortes que si ce n'était pas un rêve, et c'est par leur action qu'il sera sauvé. En peu d'instants il aura vécu, ou ce qui revient au même, il aura cru vivre plusieurs années. C'est que le temps n'a pas la même valeur dans ces deux univers sans commune mesure. Nous avons rencontré tant de personnes différentes, fait un si long chemin et vu se succéder tant d'images, qu'il nous semble avoir 


\section{Trois drames de I'Asie}

dormi longtemps, mais notre montre ou les témoins nous apprennent que c'est à peine si notre assoupissement a duré quelques minutes. Réalité du rêve et relativité du temps : telles sont les deux idées qui expliquent ce drame et lui impriment son mouvement.

La légende de Liù Yên et du rêve d'épreuve est narrée, non sans notables variantes, par un conte fantastique qui date du huitième siècle de notre ère, plusieurs Vies des saints taoïstes dont aucune n'est antérieure au quatorzième siècle, et elle forme le sujet d'un drame de la même époque. J'ai donné jadis la traduction littérale de l'un de ces récits hagiographiques ${ }^{1}$, et un peu plus tard celle du drame 2. Ainsi aura-t-on les moyens, si I'on estime que le problème en vaille la peine, de confronter les textes pour mesurer ma part, bonne ou mauvaise, de responsabilité.

Le roi Vikrâma et l'apsâra Ourvâsi apparaissent fréquemment, jusqu'à nos jours, dans les drames sacrés de l'Inde et les opéras-ballets du Siam, du Cambodge et de Java, qui en sont dérivés. La religion nationale de l'Inde s'appelle le brahmanisme et aussi, dans les temps modernes, I'hindouisme. Le bouddhisme s'y est formé, vers le sixième siècle avant l'ère chrétienne, par un mouvement de réaction analogue à celui qui en Europe a produit la Réforme. Il a passé de là au Tibet, à la Chine, au Japon et aux autres pays de l'Asie orientale, mais a été presque complètement expulsé des Indes. L'islam, introduit par la

\footnotetext{
${ }^{1}$ Légendes des Immortels. Paris, Messein, 1922.

${ }^{2}$ Le rêve du millet jaune. Paris, Desclée, 1935.
} 


\section{Trois drames de I'Asie}

conquête musulmane au douzième siècle, a encore de nombreux adhérents, mais est resté complètement étranger au théâtre comme aux autres arts figurés. Il n'est pas malaisé de reconnaître dans la religion des brahmanes plusieurs traits de ressemblance avec la mythologie antique : Indra brandit la foudre comme le Zeus des Grecs, le Jupiter romain ; et l'un des principaux incidents de la pièce sera une métamorphose pareille à celles qui donnent leur titre à un poème d'Ovide. Mais la croyance hindoue est loin de s'enfermer en des contours aussi nets et aussi limités. Elle touche d'un côté à la philosophie la plus haute, de l'autre au sentiment direct de la nature. Indra est le maître du monde et même des trois mondes où sont répartis les dieux, les hommes et les êtres doués de la vie animale, végétale ou minérale. C'est précisément en raison de cette fonction qu'il réside dans le ciel inférieur et n'est pas éternel ; il passera, comme toutes les formes déterminées qu'il gouverne, n'étant comme elles que l'émanation d'un principe universel et inconnaissable, celui qui sera invoqué par le brahmane à la fin de ce drame. D'autre part on verra les animaux et les fleurs de la forêt écouter la voix qui les implore et compatir à la douleur d'un homme, ce qui dans le paganisme des Grecs leur était rigoureusement interdit. Enfin, la grâce féminine reçoit ici une vertu rédemptrice dont l'antiquité gréco-romaine n'a jamais eu l'idée ; il a fallu le christianisme pour la lui restituer. Les apsaras sont les danseuses du ciel où les contemplent Indra et les dieux qui l'accompagnent; elles sont préposées non pas à leurs plaisirs, mais à la mission de signifier leurs pensées. Et c'est l'une d'elles qui en exil sur terre va conduire le roi, loin du 


\section{Trois drames de I'Asie}

monde terrestre, sur la voie du salut. La fiction répond ici à la réalité. Il n'y a pas de pays, hors de la chrétienté, où la femme ait été comme dans I'Inde des brahmanes honorée, respectée, adorée.

La première version de ce drame est attribuée à Kalidâsa, qui semble avoir vécu au quatrième siècle de l'ère chrétienne, et c'est elle que j'ai suivie, mais seulement pour les lignes principales de l'action.

Le Chagrin au palais de Hán est un drame historique. Mais il contient aussi sa leçon de vertu, car en Chine la politique ne peut pas se séparer de la morale dont elle n'est qu'un chapitre et une application. Cette morale n'est pas celle du taoïsme ni du bouddhisme, qui l'une et l'autre conduisent au détachement et à la contemplation. Il faut à l'homme d'État une doctrine qui lui permette et même lui ordonne d'accepter son emploi et d'y développer son activité. Cette doctrine a été procurée à la Chine par l'enseignement de Confucius, qui en trouvait les éléments dans les croyances et les coutumes de ses contemporains. Ce n'est pas, au sens où nous prenons ce terme, une morale laïque. La religion en est l'appui inébranlable ; mais c'est une religion très simple, qui assure l'invisible solidité des fondations, et ne va pas plus loin ; la raison et le cœur font le reste, achevant au grand jour l'édifice. L'hommage aux ancêtres d'une part, de l'autre le culte du ciel et des forces de la terre, montagnes, fleuves, dieux du sol, génie du foyer, maintiennent l'homme en contact avec les morts à qui il doit la vie, en harmonie avec I'univers dont il doit vénérer la grandeur et de son mieux imiter 


\section{Trois drames de I'Asie}

l'ordre souverain. La société humaine a son ordre, elle aussi, déterminé et conservé par le système rigoureux des obligations réciproques, où chacun, sans aucune exception de race, de rang ni de naissance, trouve à la place qui lui est assignée le décret qui lui prescrit son devoir et confère sa dignité. Et de même en son âme passions, intérêts et sentiments vivent en paix, contenus entre leurs limites et soumis à l'autorité des vertus supérieures qui s'appellent justice et humanité.

La dynastie des Hán a régné sur la Chine durant les deux siècles qui ont précédé et les deux qui ont suivi l'ère chrétienne. C'est une belle dynastie qui eut comme toute autre ses défaillances passagères, sa grandeur et sa décadence, mais a donné à la nation, durant ces quatre siècles, une gloire et une prospérité dont témoignent les œuvres littéraires et les monuments de l'époque, particulièrement les sculptures, d'un style robuste et magnifique, qui sont parvenues jusqu'à nous.

Il y a dans cette assurance, cette majesté aisée, cette plénitude de vie, quelques traits qui rappellent notre siècle de Louis XIV. Comme la France de ce temps-là, la Chine bénéficiait alors d'un régime solide, d'un ordre bien établi, d'un souverain prestige. Le seul danger lui venait de ses voisins tartares du nord et de l'ouest, tribus nomades et guerrières dont les incursions étaient toujours à redouter. C'est pour s'en préserver qu'un souverain de la dynastie antérieure avait bâti la Grande muraille. Sous les Hán les armées chinoises eurent souvent à lutter contre ces redoutables adversaires qui leur infligèrent plus d'un échec, mais finalement elles parvinrent à les tenir en 


\section{Trois drames de I'Asie}

respect. C'est alors que sous le nom de Huns et conduits par Attila, les hordes refluèrent vers l'ouest, et moins heureuse que la Chine, l'Europe fut envahie.

L'empereur qui apparaît en cette pièce a pour nom Yuên-tí et son règne a duré de l'an 48 à l'an 32 avant notre ère. Il a laissé dans I'histoire le souvenir d'un prince délicat et raffiné, ami des lettres et des arts, soucieux avant tout de maintenir la paix. Un traité d'alliance ou plutôt, comme nous dirions aujourd'hui, un pacte de non-agression avait été conclu avec le chef ou grand khan des Tartares, qui devait recevoir pour épouse une princesse du palais impérial. Celle qui lui fut envoyée avait pour nom de famille Wâng, pour prénom Tchao-kiun. L'histoire ne nous dit rien de plus, mais l'infortune de cette jeune femme, accoutumée au luxe de la cour et obligée d'aller vivre sous la tente de feutre, dans la steppe sauvage, a laissé un long souvenir dans la mémoire populaire. Quatre siècles plus tard, des complaintes qui nous ont été conservées déplorent son malheur, et les poètes de l'époque des T'âng, qui est le huitième siècle de notre ère, se plaisent à évoquer sa beauté, son regret, sa résignation. Il était réservé à l'un des plus grands poètes dramatiques de la Chine, qui vivait sur la fin du treizième siècle, de mettre ce sujet si simple à la scène et d'en tirer par d'ingénieuses péripéties, jointes à la profonde connaissance du cœur humain, les plus émouvants effets. C'est lui qui a introduit le personnage du ministre infidèle Maô Yên-chéou, auteur de tout le mal ; son nom lui a été suggéré par l'histoire où il désignait un peintre célèbre de l'époque. 


\section{Trois drames de I'Asie}

C'est principalement de cet ouvrage que je m'étais inspiré pour un drame donné en 1912 au Théâtre des Arts que dirigeait alors M. J. Rouché. Une musique de scène de M. Gabriel Grovlez l'accompagnait, le rôle de l'empereur y fut créé par M. René Rocher, et eut ensuite pour interprète M. Charles Dullin. J'ai gardé de ces représentations le plus beau souvenir, mais on ne sera pas surpris qu'à trente ans de distance je donne de mon œuvre une version nouvelle.

Aux Indes comme en Chine, la règle du théâtre est que le chant alterne avec le dialogue parlé. Il ne pouvait être question d'employer ici un tel procédé, qui fut celui de la tragédie grecque et des mystères du moyen âge, mais n'a été adopté après la Renaissance que par l'opéra-comique du dix-huitième et du dixneuvième siècle, et de nos jours par l'opérette. Restreint volontairement aux moyens littéraires, l'auteur s'est efforcé d'obtenir une modulation analogue par le passage du poème en vers cadencés à la prose.

Le théâtre des Chinois, pareil en cela encore à celui des anciens Grecs, se joue sur une scène, mais sans aucune machinerie, le décor et les accessoires réduits aux éléments indispensables, tout le reste indiqué par le texte et le jeu des acteurs. C'est ainsi que dans le premier de ces drames, s'il paraissait en Chine, on verrait au premier et au dernier acte le fourneau de l'auberge, le lit de camp et l'oreiller, points de repère que l'action exige, mais non la barque à la troisième scène du deuxième acte, ni la rivière, ni même le linge de la lavandière : les gestes de celle-ci suffiraient et plus tard on 


\section{Trois drames de I'Asie}

reconnaîtrait, aux mouvements des personnages et à leurs réactions pour garder l'équilibre, l'embarcation où ils sont portés. Quant au théâtre des Hindous, plus frugal encore, il se passe de scène et n'a aucun décor ; la pièce est jouée sur la Place du village ou dans la cour d'un temple. Pas plus que les lecteurs, les spectateurs n'apercevraient ce char ailé qui à la première scène du second drame déposera le roi légendaire sur un sommet proche du ciel, ni plus tard la liane qui va reprendre figure humaine entre ses bras. Il leur suffirait d'écouter les paroles, comme à nous de les lire.

De nos jours, le progrès de la science rend possible une autre méthode d'interprétation, orale comme au théâtre, mais qui laisse à l'imagination de chacun aussi libre jeu que la lecture : c'est la transmission par les ondes. L'expérience en a été faite pour ces drames, avec un succès qui de beaucoup a passé mon espoir.

Je ne croyais pas possible, sans aucun secours visuel, d'atteindre à cette intensité de l'émotion, à cette qualité du style, et tiens à dire ici toute la reconnaissance que je dois à $M$. Pierre Sabatier, directeur des programmes à la Radiodiffusion nationale de France, qui m'a rallié à cette idée, ainsi qu'aux artistes dont on lira les noms plus loin et qui furent, chacun en son emploi, admirables de conviction, d'intelligence, de caractère et de puissance évocatrice. A eux tous je dédie cet ouvrage qui sans l'encouragement précieux qu'ils m'ont donné n'aurait pas vu le jour.

Rahon (Jura), 5 avril 1943. 
Trois drames de I'Asie

@ 


\section{LE SONGE DE LA VIE}

Drame en quatre actes et un Prologue donné pour la première fois

par la Radiodiffusion nationale de France

le 30 octobre 1942.

\section{PERSONNAGES}

Liù Yên, bachelier,

puis préfet et commandant militaire

Tchoung-lî, I'un des Immortels

Le Docteur

Le grand Chambellan

Le vieux Serviteur

Le Bûcheron

Wèi-ché, secrétaire du palais impérial

Le Greffier

Le Sergent

Mà Soéi, général de cavalerie

Fong Liûn, général de cavalerie.

Yuh-ts'ing, fiancée de Liù Yên.

Tsoéi-ngô, fille du grand Chambellan

La Patronne

La Vieille

Deux enfants.
MM. Roger GAILLARD.

Louis SEIGNER, Jean BRUNEL. Léon BÉLIÈRES. André BACQUÉ. Henri BEAULIEU.

R. MAXIME. CUEILLE.

J. HEUZÉ.

$\mathrm{X}$.

Y.

$M^{\text {mes }}$ Gisèle PARRY.

Denise BOSC. Yvonne KERVA. Gabr. DU MESNIL.

Mise en ondes de Georges COLIN. 


\section{PROLOGUE}

Entre ciel et terre, sur une montagne si haute qu'elle échappe au regard des hommes. Elle est située aux confins du monde, à l'Orient. La divinité qui y règne s'appelle le Prince-empereur de la Floraison orientale. Là sont réunis sept bienheureux qui par leurs vertus ont mérité d'être affranchis des lois de la matière :ils sont devenus Immortels.

L'un d'eux paraît : il porte la robe flottante et le bonnet rabattu des sages taoïstes, mais tout blancs l'un et l'autre.

\section{SCÈNE UNIQUE}

\section{TCHOUNG-LÎ.}

Sur les pentes du Mont invisible, résidence du Princeempereur de la Floraison orientale,

Ecoutant le chant du phénix, respirant l'air céleste et contemplant de loin la terre,

Les Immortels s'élèvent et descendent comme de blancs nuages.

Mon nom terrestre est Tchoung-lî, et je n'ai accédé à la félicité suprême que depuis quatre cents ans, le plus jeune des sept Immortels réunis sur la montagne qui touche au ciel. D'abord fonctionnaire civil, j'avais passé ensuite à la carrière militaire, pour combattre les tribus nomades qui menaçaient nos frontières. Devenu général d'armée, j'allais de victoire en victoire quand un jour, faute de précautions, je me suis laissé surprendre. Enveloppés de tous côtés, la retraite coupée, mes guerriers se sont fait tuer jusqu'au dernier homme. Laissé pour mort sur le champ de bataille, quand j'ai rouvert les yeux ce fut pour voir un tel carnage qu'il me fut impossible d'affronter le regard d'un homme vivant. Retiré dans la forêt sauvage, reclus 


\section{Trois drames de l'Asie}

dans la méditation, c'est ainsi que j'ai fait mon salut. Je viens d'apercevoir dans la province occidentale, sur la route qui mène à la capitale de l'empire, une traînée de vapeur bleue, qui monte droit jusqu'au ciel. C'est signe que le voyageur qui est là, prêt à entrer dans une auberge au bord de la route, est de nature à devenir un Immortel. Mais je vois dans son cœur les sept passions humaines : la joie, la colère, le chagrin, la crainte, I'amour, la haine et le désir. Elles l'occupent et détournent son attention de I'unique vérité. Je vais prendre un habit terrestre, afin de le convertir et le conduire sur la Voie éternelle. Dès qu'il y sera parvenu, le chaud ni le froid n'atteindront plus son corps, les jours et les mois ne vieilliront plus son visage. Le roi des enfers sur ses tablettes l'exemptera de la vie et de la mort. Les secrétaires d'immortalité sur leurs livres inscriront ses nom et prénom. A la pointe de la mer ils lui montreront du doigt le bord du ciel et conduiront l'homme égaré jusqu'au Mont invisible où il sera reçu parmi les Immortels.

(Il disparaît.) 


\section{Trois drames de I'Asie}

\section{ACTE PREMIER}

Devant l'auberge, sur la route de la capitale, et ensuite dans l'auberge, celle-ci indiqués par une table avec deux chaises, un lit de camp d'un cédé, un fourneau de l'autre.

\section{SCÈNE PREMIÈRE}

(Le bachelier Liù Yên apparaît sur la route.)

LIÙ YÊN.

Fouettant ma rosse sur la route de la capitale Sans répit du matin au soir, Je n'aperçois encore, jusqu'au bout de I'horizon, que l'ombrage des ormes.

Comment n'aurais-je pas l'impatience au cœur ?

Je m'appelle Liù Yên, et suis né dans l'ouest, au village de Lohtsién, non loin de la frontière. Mon père, simple cultivateur, ayant remarqué mon goût pour la lecture, m'a envoyé à la ville pour y faire mes études. J'y ai bien réussi. Reçu premier à l'examen dans ma province, j'ai été désigné pour me rendre à la capitale de l'empire où va avoir lieu le grand concours, celui qui donne accès aux emplois supérieurs. En route depuis plusieurs jours, j'en ai pour longtemps encore. C'est l'heure de midi : personne dans les champs. La chaleur m'accable, la fatigue et la faim me pressent. J'aperçois une auberge et vais $y$ entrer pour faire une légère collation. Je m'approche de la porte, je descends, j'attache ma monture et prends dans mon sac de voyage deux cents sapèques pour qu'on me fasse une bouillie de millet. 


\section{Trois drames de I'Asie}

\section{SCÈNE II}

Dans l'auberge.

LIÙ YÊN, puis TCHOUNG-Lî et la patronne.

(Liù Yên est entré, Tchoung-lî paraît à son tour sur la route. Il a le même costume qu'à la scène précédente, mais en noir, et porte un sac de voyage.)

TCHOUNG-LÎ. - La vie est ma porte de droite et la mort ma porte de gauche. Longue vie, mort précoce, immortalité, tout dépend de nous-même.

LIÙ YÊN. - Quelqu'un me suivait donc sur la route ?

TCHOUNG-Lî.

Bien qu'il n'ait que sa demeure d'herbes et sa hutte de joncs un adepte,

Compagnon du vent calme et de la lune claire

Ne saura même plus discerner l'automne du printemps,

La dynastie qui règne ou celle qui va venir.

LIÙ YÊN. - C'est le chant d'un adepte.

(Tchoung-lî entre à son tour dans l'auberge, c'est-à-dire dans le périmètre formé par le lit de camp, la table et le fourneau. Il salue le voyageur qui est déjà là.)

TCHOUNG-LÎ. - Monsieur le bachelier, je vous présente mes félicitations.

LIÙ YÊN. - Seigneur maître de la doctrine, j'en suis trop honoré. Vous savez donc où je vais ?

TCHOUNG-Lî. - Mais ce n'est pas de cela que je vous fait compliment.

LIÙ YÊN. - J'étais entré pour un instant. 


\section{Trois drames de I'Asie}

TCHOUNG-Lî. - Je sais. Holà ! madame I'aubergiste ! Monsieur désire une bouillie de millet bien chaude et cuite à point, pour réparer ses forces. Hâtez-vous. Le voyageur a faim de dévorer la route. Qu'attendez-vous?

LA PATRONNE. - Vous êtes impatients, messeigneurs. Il faut tout de même que j'allume le feu.

TCHOUNG-LÎ. - Je ne demande rien pour moi, que cette chaise pour m'asseoir, et causer avec lui, pendant qu'il va attendre.

LIÙ YÊN. - La faveur d'un entretien avec votre sagesse me sera plus précieuse qu'un monceau d'or.

TCHOUNG-Lî.

Un grand de ce monde est celui qui se livre au caprice sauvage,

S'abandonne aux apparences trompeuses.

Ces gens riches du siècle

Ne sont devant mes yeux que brouillard et fumée.

LIÙ YÊN. - Ce qui m'a incité à l'étude n'est pas l'attrait des richesses mais le goût du savoir.

TCHOUNG-Lî. - Renoncez au savoir et vous connaîtrez le bonheur.

LIÙ YÊN. - Si j'avais renoncé au savoir, je serais laboureur dans la maison de mon père.

TCHOUNG-LÎ. - N'aviez-vous pas de quoi vivre auprès de lui ?

LIÙ YÊN. - C'est ce que mes parents souhaitaient. Même ils m'avaient choisi déjà une fiancée, la fille de nos voisins, d'une famille très honorable. Elle s'appelle Yuh-ts'ing, Pureté du jade, et mérite ce prénom. 


\section{Trois drames de l'Asie}

TCHOUNG-Lî. - Le jade pur se rencontre dans les solitudes sauvages et non pas sur les grandes routes.

LIÙ YÊN. - Elle ne perdra rien pour attendre. Je reviendrai pour l'épouser.

TCHOUNG-Lî. - Bientôt ?

LIÙ YÊN. - Sitôt que j'aurai un bel emploi. Nous prendrons alors nos parents avec nous, pour le repos de leurs vieux jours.

TCHOUNG-Lî. - Autrefois un puissant ministre se trouvant en voyage aperçut au bord de la route une ornière où restait un peu d'eau. Il lui sembla qu'un voix très fine l'appelait : «Monsieur le puissant ministre ! monsieur le puissant ministre ! » Il fit arrêter sa litière et s'approcha. Une ablette se débattait dans l'eau bourbeuse. «Ablette, petite ablette, que faites-vous ici ? - Je suis née dans les flots du lac Oriental. Pardonnez mon audace de vous avoir appelé. N'auriez-vous pas une pinte d'eau pour me sauver la vie ? - Bien volontiers et de bon cœur. Je m'en vais justement vers le fleuve du Sud et rien ne me sera plus facile que d'en faire détourner le cours pour l'amener ici. » Mais l'ablette répondit, toute rouge de colère : «Je suis sortie de mon élément et tout près de mourir. Avec une pinte d'eau vous pouvez me sauver et voilà ce que vous trouvez à m'offrir. Passez-moi donc tout de suite dans une ficelle pour me porter au marché du poisson sec, cela vaudra bien mieux. »

LIÙ YÊN. - Secourir sa famille est une bonne œuvre. Secourir le peuple est une belle action. Si je deviens ministre, je pourrai veiller à la justice des sentences et à l'intégrité des 


\section{Trois drames de I'Asie}

fonctionnaires, augmenter par une meilleure exploitation les richesses de l'empire.

TCHOUNG-LÎ. - C'est quand disparaît la sagesse qu'on a recours à la justice. C'est quand la convoitise règne que l'intégrité devient la vertu principale. Et quand la richesse abonde, la corruption se répand.

LIÙ YÊN. - Si je ne réussis pas dans I'administration civile, je passerai au service militaire, car j'ai étudié aussi l'art de la guerre. Les Barbares de I'Ouest sont toujours menaçants. N'estce pas notre devoir de les contenir et de les soumettre, pour leur faire connaître les bienfaits de la paix et garantir la sécurité de nos frontières ?

TCHOUNG-Lî. - Les armes sont toujours instruments de malheur. Le général victorieux a pour escorte en son triomphe un cortège funèbre.

LIÙ YÊN. - J'ai terminé mes études pour la paix et la guerre, et je resterais sans emploi ?

TCHOUNG-Lî.

Voyez ce ministre en son palais, donnant ses ordres du matin au soir,

Ce général qui veille avec ses hommes, guettés par l'adversaire,

Comment serait-il, comme moi, indépendant des êtres, seul maître de soi-même?

LIÙ YÊN. - Seigneur docteur, veuillez considérer que je suis convoqué à la capitale, pour le grand concours. Comment désobéir? 


\section{Trois drames de I'Asie}

TCHOUNG-LÎ. - Celui qui a quitté ce monde échappe aux lois humaines.

LIÙ YÊN. - Je n'en suis pas capable.

TCHOUNG-LÎ. - C'est que vous vous ignorez vous-même ; vous n'êtes pas né pour l'activité vulgaire. J'ai reconnu en vous les traits d'un Immortel.

LIÙ YÊN. - Pourtant la terre est belle, avec la charrue dans les champs, la montagne aux creux d'ombre et l'arbre au bord de la rivière.

TCHOUNG-Lî.

Où je suis, le sol est sans poussière, L'herbe n'a qu'un long printemps,

Aux quatre saisons les fleurs s'épanouissent, toujours délicates et douces.

J'ai la montagne bleue pour paravent devant ma porte à claire-voie,

La pluie humecte les feuillages des bambous,

La rosée nourrit la fraîcheur des simples,

J'écoute la plainte des singes sauvages sur les arbres anciens,

Et contemple l'eau qui enveloppe de son cours ma retraite solitaire.

LIÙ YÊN. - Plus beau encore, le sourire des hommes qui remercient pour un bienfait.

TCHOUNG-Lî.

Le bienfait dépend du sort et non de notre volonté.

La gratitude s'attache au nom plus qu'à la chose.

LIÙ YÊN. - Je ne puis pas vous suivre. Oh ! quelle lassitude !

TCHOUNG-Lî. - En route depuis I'aurore, il faut vous reposer.

Prenez mon oreiller que je tire de mon sac, et étendez-vous là. Je vous réveillerai. L'eau ne bout pas encore. Il dort déjà. Liù 


\section{Trois drames de I'Asie}

Yên, sur cet oreiller enchanté je vais vous promener en songe dans les espaces indéfinis de l'avenir, parcourant en dix minutes de sommeil dix années d'existence. A votre retour dans le moment présent vous saurez ce que valent le plaisir et la gloire, le talent, la science, la volonté humaine et la faveur de vivre. Ne faites pas de bruit, madame. Il dort profondément. Je dirige son rêve.

(Liù Yên est étendu, endormi, sur le lit de camp, la nuque appuyée à l'oreiller chinois, de forme quadrangulaire. Tchoung-lî le tient sous son regard.)

@ 


\title{
Trois drames de I'Asie
}

\section{ACTE II}

\author{
SCÈNE PREMIÈRE \\ LE GRAND CHAMBELLAN, LIÛ YÊN. \\ Une salle dans le palais du grand Chambellan.
}

\section{LE GRAND CHAMBELLAN.}

C'est la vertu du souverain qui fait le salut de l'empire, Car elle se répand, entre les quatre mers, jusqu'aux bornes du monde,

Et tous viennent à lui comme les enfants à leur père.

Je suis le grand chambellan du palais, ces enfants sont mes petits enfants. Ma femme était très jeune et ne m'avait donné encore qu'une fille quand elle a quitté ce monde. Je n'ai pas voulu me remarier, fidèle au souvenir et pour ne pas donner une marâtre à notre enfant. Je l'ai élevée de mon mieux mais les soins d'un père ne peuvent remplacer l'amitié, la confiance et la clairvoyance maternelles. A quinze ans je l'ai mariée à un jeune docteur, d'origine modeste, dont j'avais remarqué, étant I'un des examinateurs du grand concours, les talents rares. Je ne m'étais pas trompé, car il n'a cessé de s'élever, depuis lors, porté par son mérite, et soutenu aussi, il faut le dire, par mon autorité ; il a été chef du personnel administratif, secrétaire historiographe, et depuis I'an passé préfet du territoire de la capitale. Il habite avec nous, puisque je n'ai pas de fils, et me traite comme un père adoptif. Depuis neuf ans qu'il est mon gendre, il ne m'avait jamais causé aucune peine, non plus qu'à ma fille, du moins je le suppose. Elle s'appelle Tsoéi-ngô. Il s'appelle Liù Yên. Et voici 


\section{Trois drames de l'Asie}

leurs deux enfants, que volontiers on me confie, comme si j'étais leur père. Je les garde aujourd'hui, pendant qu'ils se font leurs adieux, car il va, hélas ! nous quitter. Je l'attends et ne le laisserai pas partir sans lui dire ce que j'en pense.

(On entend au dehors la voix de Liù Yên.)

LIÙ YÊN

Qui recourt à la force appelle la force contre lui.

Le sang répandu crie vengeance.

Voué jusqu'à ce jour aux arts de la paix,

La lance au poing je cours à la frontière, pour le service de l'empire

Et le châtiment des rebelles

(Liù Yên entre en scène et salue son beaupère.)

LE GRAND CHAMBELLAN. - Ainsi vous changez de carrière ?

LIÙ YÊN. - Vous savez le danger de l'empire.

LE GRAND CHAMBELLAN. - Je sais que les Barbares de l'Ouest, ayant trompé la vigilance de nos postes-frontière, ont fait des incursions sur notre territoire. Je sais aussi qu'après de fortes études dans l'art militaire vous n'avez jamais cessé de vous instruire ni de vous exercer, si bien que vous êtes aujourd'hui à la fois un des meilleurs stratèges et un des plus beaux cavaliers de l'empire. Cependant vous aviez préféré jusqu'ici, et avec raison selon moi, les fonctions civiles.

LIÙ YÊN. - Vous ne savez pas tout. La frontière est ouverte sur une large étendue et des hordes nombreuses ont envahi le territoire.

LE GRAND CHAMBELLAN. - Nous en viendrons à bout. Ce n'est pas la première fois que ces cavaliers du désert tirent avantage 


\section{Trois drames de I'Asie}

de la surprise, mais ils n'ont jamais pu tenir devant nos forces régulières. Ce n'est qu'un accident qui sera bientôt réparé. Mais ici, les heureux résultats de votre administration vous avaient désigné à la confiance de l'empereur, à la reconnaissance des populations.

LIÙ YÊN. - Et à la calomnie de mes rivaux.

LE GRAND CHAMBELLAN. - Et à la calomnie qui est la plus fidèle compagne des éminents services. Mais j'étais là pour déjouer les intrigues de cour. Vous étiez en passe de devenir ministre et là c'est tout le peuple à qui, prêtant l'oreille, vous deviez rendre la justice. Faut-il renoncer à un aussi grand ouvrage pour courir sus à quelques bandits à peine dignes du nom d'hommes ?

LIÙ YÊN. - Vous ne savez pas tout encore. Parmi les districts envahis se trouve celui où je suis né. Je me suis renseigné auprès de mon collègue le gouverneur de la province et viens de recevoir, par un courrier spécial, sa réponse. Ils ont passé par mon village et selon leur coutume n'y ont laissé âme qui vive.

LE GRAND CHAMBELLAN. - Vos parents ?

LIÙ YÊN. - Mes vieux parents n'ont pas échappé au massacre.

LE GRAND CHAMBELLAN. - Excusez donc, mon enfant, mes remontrances intempestives et mes maladroites paroles. $\mathrm{Ce}$ n'est pas moi qui vous retiendrai maintenant car je connais la maxime du Sage : le fils ne peut vivre sous le même ciel que le meurtrier de son père. 


\section{Trois drames de I'Asie}

LIÙ YÊN. - Je suis heureux de vous apprendre que je viens de recevoir mon brevet de général de brigade, pour commander la cavalerie du corps expéditionnaire.

LE GRAND CHAMBELLAN. - Je m'empresse de vous offrir mes félicitations. Permettez cependant à ce vieux raisonneur de puiser encore quelques conseils au fond de sa longue expérience. Connaissant votre ardeur et le noble sentiment qui vous anime, je crains que vous ne perdiez la prudence, cédant à la colère. Ménagez vos soldats, ne les exposez pas plus qu'il n'est indispensable, et surtout arrêtez l'effusion du sang dès que ce sera possible. Ne cherchez pas à porter la guerre sur le territoire ennemi. Il suffit que soit libéré le nôtre.

LIÙ YÊN. - Je vous écoute avec respect et vos conseils seront suivis, car les instructions que j'ai reçues m'enjoignent de m'arrêter à la frontière. En mon absence, je vous confie ce que j'ai de plus précieux au monde : ma femme et mes enfants.

LE GRAND CHAMBELLAN. - Je veillerai sur eux dans toute la mesure de mes forces et jusqu'à mon dernier souffle.

LIÙ YÊN. - Je vous souhaite bonheur et longue vie.

LE GRAND CHAMBELLAN. - Je vous souhaite victoire et prompt retour.

(Liù Yén s'éloigne en chantant.)

LIÙ YÊN.

Les rebelles sans fin se soulèvent, Leurs cris de mort ébranlent la terre, heurtent le ciel. Au secours de l'empereur en cette calamité Si je ne suis vainqueur, je jure de ne pas revenir. 


\section{Trois drames de I'Asie}

(Le grand Chambellan, seul en scène, prend par les mains les deux enfants.)

\section{LE GRAND CHAMBELLAN.}

Me voici donc, grand Chambellan avec ma tête blanche et mon visage gris,

Sans autre postérité devant mes yeux que vous, enfants jolis et innocents.

Rien n'est plus douloureux, à mon âge, que la séparation.

\section{SCÈNE II}

\section{LIÙ YÊN, MÀ SOÉI, FONG LIÛN.}

Près d'une année plus tard. En Mongolie, à quelques lieues de la frontière, la tente de Liù Yên, général commandant le corps de cavalerie. C'est la nuit. Une table et trois chaises. Sur la table une lampe, une carte étalée. Liù Yên d'abord est seul, en tenue de campagne, cuirasse et jambières. Il soulève un instant la tenture au fond de la tente, écoute, puis revient.

LIÙ YÊN.

La flèche siffle et l'arc bourdonne, Les chevaux piétinent et hennissent.

La bataille a duré tout le jour.

Sur le terrain conquis le guerrier dort sans rêves, Dans le silence de la nuit le fracas se prolonge.

Parce que je sors de l'administration civile on se méfiait de mes avis en nos conseils de guerre. J'avais raison pourtant, l'événement l'a montré. Liù Yên, le général ministre, le commandant des livres, le chef des écritures, c'est ainsi qu'ils m'appelaient, trop fiers de leur prudence. Malgré l'avantage du nombre et celui de combattre sur notre territoire, d'intelligence avec ce qui restait de la population, l'armée se traînait à petites journées. La cavalerie à chaque étape devait attendre 


\section{Trois drames de I'Asie}

I'infanterie, et celle-ci attendait ses convois de ravitaillement. L'ennemi sur ses chevaux rapides nous attaquait à l'improviste et tournait bride, les détachements lancés à sa poursuite le perdaient de vue ou tombaient dans une embuscade. Chaque jour nous perdions des hommes, des chevaux, des voitures. Rien n'est pénible au combattant comme de recevoir des coups qu'il ne peut rendre. Mécontent de ses chefs, il perd le courage de vivre et mourir avec eux. Autour des feux de camp on entendait des murmures, et parfois un chant séditieux. Inquiet, le commandant en chef m'a enfin laissé libre, comme je le proposais depuis longtemps, de jeter sur l'ennemi mon corps de cavalerie, sans soutien et sous mon entière responsabilité, pour le surprendre à notre tour. La manœuvre a parfaitement réussi. (Deux coups sont frappés sur un gong invisible, à l'entrée de la tente.) Qui vient?

MÀ SOÉI. - Mon collègue Fong Liûn me suit. Nous sommes convoqués auprès du général.

LIÙ YÊN. - C'est exact. Entrez donc, je suis seul. (Les deux généraux entrent et saluent.) Général Mà Soéi, général Fong Liûn, permettez-moi d'abord de vous féliciter. Vous m'avez secondé aujourd'hui avec autant d'intelligence que de bravoure.

MÀ SOÉI. - Général Liù Yên, c'est vous qui aviez conçu cette heureuse manœuvre.

FONG LIÛN. - C'est vous qui chargeant le premier, à la tête de vos escadrons, nous donniez l'exemple du courage. 


\section{Trois drames de I'Asie}

LIÙ YÊN. - L'un à I'aile droite, I'autre à I'aile gauche, vous avez su toujours conserver vos distances, pour le vaste mouvement qui en débordant l'ennemi lui a coûté si cher.

MÀ SOÉI. - Bien peu ont échappé.

FONG LIÛN. - Ce fut un beau carnage.

LIÙ YÊN. - Pas assez grand encore.

MÀ SOÉI. - Sans doute, mais est-il possible de les exterminer jusqu'au dernier?

FONG LIÛN. - Ils ne seront jamais assez punis pour leurs crimes, mais est-il souhaitable de les pousser au désespoir?

LIÙ YÊN. - C'est ce que nous allons examiner. Veuillez prendre place à ma droite et à ma gauche, comme sur le champ de bataille. Voici la carte du pays, sommaire mais exacte, à ce qu'il semble. (Ils s'assoient et regardent la carte étalée sur la table.)

LIÙ YÊN. - Vous avez reconnu ici notre point de départ, auprès de ce village en ruines où I'ennemi venait de passer. Un premier bond nous a portés à quinze lieues vers le sud, un autre à dix lieues plus loin, sans rencontrer de résistance sérieuse. C'est ici seulement, tout près de la frontière, que s'est engagée ce matin la bataille décisive.

FONG LIÛN. - De combien avons-nous progressé ?

LIÙ YÊN. - Qu'en pensez-vous ?

MÀ SOÉI. - De six lieues environ.

LIÙ YÊN. - C'est aussi mon avis. 


\section{Trois drames de I'Asie}

FONG LIÛN. - Nous aurions dépassé de cinq lieues au moins la frontière ?

MÀ SOÉI. - De cinq lieues, du nord au sud. Mais voyez, elle s'infléchit ensuite et dans la direction de l'est nous n'en sommes guère qu'à deux lieues.

FONG LIÛN. - La retraite serait possible par là, en cas de malheur.

MÀ SOÉI. - Je ne crois pas. La carte indique ici une ligne de marécages.

LIÙ YÊN. - Je les connais. Ils ont au moins une demi-lieue de largeur, sous des fourrés de joncs et de roseaux où nos chevaux ne peuvent passer.

MÀ SOÉI. - Ils bordent le fleuve Jaune.

LIÙ YÊN. - Le fleuve Jaune, oui.

FONG LIÛN. - Vous semblez en souci. Qu'y a-t-il donc ?

LIÙ YÊN. - Excusez ma faiblesse. C'est là que se trouvait mon village natal.

MÀ SOÉI. - Excusez ma sottise. Je devais y penser. Le militaire est rude.

FONG LIÛN. - Pieusement nous rendons hommage à vos parents défunts.

(Tous trois se lèvent, les mains jointes, et s'inclinent en silence.)

LIÙ YÊN (se rasseyant, et faisant signe aux autres de reprendre leur place).

- Nous disions donc, messieurs, que nous sommes ici, dans cette plaine herbue, l'ennemi en retraite dans la direction du sud 


\section{Trois drames de I'Asie}

ou du sud-ouest peut-être. Général Fong Liûn, vous êtes devant nous, de ce côté. Qu'avez-vous observé ?

FONG LIÛN. - Rien, général.

LIÙ YÊN. - Vous n'êtes pas curieux.

FONG LIÛN. - Je ne mérite pas ce reproche. Sitôt le combat terminé, j'ai envoyé sur les traces de l'ennemi mes éclaireurs, des cavaliers d'élite. Ils viennent de rentrer mais ils n'ont rien pu voir. Sur la terre des herbes le pas des chevaux ne laisse aucune empreinte. Ils n'ont rencontré âme qui vive, pas même un chien perdu, une brebis égarée. Le pays brusquement s'est changé en désert.

LIÙ YÊN. - Et vous en concluez ?

FONG LIÛN. - Qu'il nous faut prendre garde. Voilà vingt ans que je fais la guerre contre les sauvages et j'ai appris à mes dépens quelques-unes de leurs ruses.

LIÙ YÊN. - Et vous, général Mà Soéi, quelles dispositions avec vous prises?

MÀ SOÉI. - Sitôt rendu à mon poste d'arrière-garde, j'ai fait allumer les signaux de feu indiquant où nous sommes, et l'ennemi en retraite.

LIÙ YÊN. - Et la réponse ?

MÀ SOÉI. - Pas de réponse. Ils sont loin en arrière. Mais les oiseaux sont venus en grand nombre.

LIÙ YÊN. - Oiseaux de nuit, attirés par la flamme. 


\section{Trois drames de l'Asie}

MÀ SOÉI. - Il y avait aussi des corbeaux et des pies qui venaient du nord.

LIÙ YÊN. - Ce qui signifie, selon vous ?

MÀ SOÉI. - Qu'ils avaient été tirés de leur sommeil par une troupe en marche. Je crains d'être pris à revers.

LIÙ YÊN. - Général Fong Liûn, général Mà Soéi, merci pour vos renseignements. Ils me sont précieux pour la décision à prendre. MÀ SOÉI. - Mais y a-t-il une décision à prendre ?

LIÙ YÊN. - Vous faites allusion aux instructions reçues quand nous sommes entrés en campagne. Je ne les oublie pas. Il nous a été prescrit de libérer le territoire de l'empire, mais sans aller plus loin.

FONG LIÛN. - Désobéir à l'empereur est une chose grave.

LIÙ YÊN. - Désobéir, pour mieux obéir.

FONG LIÛN. - Que voulez-vous dire?

LIÙ YÊN. - Nous ne dépassons pas la frontière, c'est elle qui se déplace et s'avance avec nous. Honte à qui cède un pouce du terrain conquis. Et nous irons plus loin encore, à la poursuite de l'ennemi, pénétrant chaque jour plus avant sur ses terres, pour les annexer à l'empire.

MÀ SOÉI. - L'ennemi est vaincu, mais non pas anéanti.

LIÙ YÊN. - C'est pourquoi il faut l'exterminer.

FONG LIÛN. - Ses réserves n'ont pas donné encore.

LIÙ YÊN. - Nous avons aussi des réserves, et elles sont inépuisables ; c'est le courage de nos soldats, leur dévouement à 


\section{Trois drames de I'Asie}

l'empereur, leur juste ressentiment pour tant d'atrocités, leur ardeur au combat que la victoire exalte. L'occasion est favorable ; si je la laissais échapper, je serais le dernier des lâches, le plus ingrat des fils.

FONG LIÛN. - Quels sont les ordres ?

LIÙ YÊN. - Demain, dès l'aube, nous reprenons notre formation de combat, avec ma place au centre, et vous sur les deux ailes.

Je compte sur vous pour que le mouvement s'exécute aussi promptement que possible. Et nous fonçons droit devant nous, dans la direction de l'ouest, balayant tout sur notre passage. Sommes-nous d'accord?

MÀ SOÉI. - Puisque la décision est prise, nous n'avons plus à discuter.

FONG LIÛN. - Et vous pouvez compter sur nous.

LIÙ YÊN. - Pour vaincre.

MÀ SOÉI. - Ou pour mourir.

\section{SCÈNE III}

\section{YUH-TS'ING, LIÙ YÊN.}

Sur la rive occidentale du fleuve Jaune, quelques jours plus tard. Une jeune fille lave du linge au bord de l'eau.

YUH-TS'ING.

Comme la flèche le temps vole,

Comme la navette du tisserand les jours passent et repassent.

De l'existence humaine quelle est donc la raison ? 


\section{Trois drames de I'Asie}

Peu m'importe la richesse. Mais le bonheur?

Le bonheur! Je ne l'aurai plus en cette vie. Quelles fautes ai-je pu commettre dans une précédente existence, pour être ainsi punie ? J'étais promise à un ami d'enfance, le fils de nos voisins, mais il a quitté le pays quand j'avais treize ans à peine, appelé à la capitale, et n'en est jamais revenu. Je n'ai pas voulu épouser un autre que lui et suis restée chez mes parents, jusqu'à l'année dernière où les Barbares ont envahi notre pays. Ils ont détruit notre village. Ils ont tué mon père. Ma mère et moi avons pu nous enfuir jusqu'ici. On nous a prêté une barque pour passer les voyageurs, mais ils sont rares en ce temps de misère. Je gagne un peu d'argent en faisant métier de lavandière. Il a fait une belle carrière. L'an passé il était gouverneur de la capitale. On dit que depuis lors il a passé dans l'armée, avec un commandement important. On dit aussi qu'il a épousé I'héritière d'une famille illustre. Devenu un si gros personnage, qu'aurait-il fait d'une pauvre fille comme moi ?

(Derrière elle, sans qu'elle puisse le voir d'abord, se montre Liù Yên. Il porte le costume militaire, mais déchiré et souillé de boue, avec l'insigne de son grade, qui est un sceau d'or, pendu à son ceinturon, et le sabre au côté, mais il est à pied, l'air recru de fatigue.)

LIÙ YÊN. - Où suis-je ? Après le désastre où mon armée a succombé, j'ai marché devant moi, au hasard. Jeté à bas de mon cheval, étourdi par la chute, je m'étais éveillé sous un monceau de morts. J'ai appelé. Personne n'a répondu. Ils étaient tous là cependant, mes vaillants guerriers, étendus sur la plaine, et ne pouvaient m'entendre. Alors je me suis enfui, sans tourner la tête, me sentant poursuivi par une armée de fantômes. J'ai 


\section{Trois drames de I'Asie}

traversé les fondrières, cherchant ma route sous les fourrés de roseaux et de joncs, trébuchant dans la boue. Mais je commence à me reconnaître. N'est-ce pas le bord du fleuve Jaune ?

$$
\begin{aligned}
& \text { (Il s'approche et Yuh-ts'ing aperçoit son } \\
& \text { ombre sur l'eau.) }
\end{aligned}
$$

YUH-TS'ING. - Mes yeux ont vu sur l'eau passer l'ombre d'un homme.

LIÙ YÊN. - Une jeune fille lave la toile au bord de I'eau. Une barque est auprès d'elle. Madame ! mademoiselle !

YUH-TS'ING (répond sans le regarder). - Je ne suis qu'une lavandière, j'habite chez ma mère veuve et n'ai pas de mari. Je ne puis rien pour vous.

LIÙ YÊN. - Ce qui reste de mon armure ne doit pas vous faire peur. Je ne suis plus qu'un malheureux, seul survivant de mon armée. Tous mes guerriers sont morts, ils sont morts par ma faute, et leurs fantômes me poursuivent.

YUH-TS'ING. - Votre armée ?

LIÙ YÊN. - Je commandais la cavalerie du corps expéditionnaire et après une longue campagne nous tenions la victoire, mais j'ai voulu pousser plus loin nos avantages, et malgré les instructions qui m'avaient été données j'ai poursuivi l'ennemi sur son territoire. C'est là que nous avons été surpris, enveloppés, anéantis. Je mérite la mort et cherche le chemin de la capitale pour dire adieu à ma famille et ensuite me remettre à la justice impériale.

YUH-TS'ING. - A vous entendre, comment ne pas vous plaindre ? 


\section{Trois drames de I'Asie}

LIÙ YÊN. - Ma seule excuse est que j'avais à venger la mort de mes parents.

YUH-TS'ING. - Ils ont tué vos parents ?

LIÙ YÊN. - Dans le village de Loh-tsién.

YUH-TS'ING. - Dans le village de Loh-tsién ?

LIÙ YÊN. - Vous paraissez émue.

YUH-TS'ING. - Ils ont tué mon père, dans le même village.

LIÙ YÊN. - Dans le même village ! Les deux maisons voisines. Oh ! comment ai-je pu ne pas vous reconnaître ?

YUH-TS'ING. - C'est que vous m'avez oubliée, seigneur Liù Yên. LIÙ YÊN (à voix basse). - J'étais un insensé.

YUH-TS'ING. - Monsieur le général, permettez à votre humble servante de vous offrir le peu dont elle dispose, cette barque pourrie pour vous passer sur l'autre rive. Vous trouverez à peu de distance la route de la capitale.

LIÙ YÊN. - Voilà donc le service que vous étiez appelée à me rendre.

YUH-TS'ING. - Je n'espérais pas tant. La barque est au rivage. Voulez-vous y monter ? Je vais prendre les rames. Il faut connaître le cours du fleuve.

$$
\begin{aligned}
& \text { (Ils sont tous deux dans la barque et } \\
& \text { voguent sur le fleuve.) }
\end{aligned}
$$

LIÙ YÊN. - Vous ne pouvez rester à faire ce métier.

YUH-TS'ING.

L'eau répandue ne se ramasse pas.

La pluie tombée ne remonte plus au nuage. 


\section{Trois drames de I'Asie}

LIÙ YÊN.

On trouve l'or dans le sable du fleuve,

Le jade pur au milieu des cailloux.

YUH-TS'ING.

L'hirondelle ignore la pensée de l'aigle,

La tourterelle ne peut être unie au phénix.

LIÙ YÊN. - Pourquoi passer sur l'autre rive ?

YUH-TS'ING. - Le courant est fort dans le milieu du fleuve, mais il s'apaise près des îlots.

LIÙ YÊN. - Que ne suis-je demeuré en mon village ?

YUH-TS'ING. - Le vent du nord s'élève et le fleuve s'agite. Hâtez-vous de descendre, que je ramène la barque avant la tempête.

(Lin Yên descend à terre.)

LIÙ YÊN. - Comment vous témoigner ma reconnaissance ?

YUH-TS'ING. - Nous ne devons plus nous revoir en ce monde.

LIÙ YÊN. - Comment vous laisser ainsi ?

YUH-TS'ING. - Ne me voyez-vous pas au comble du bonheur ?

LIÙ YÊN. - Adroitement elle a repoussé la barque et la dirige dans le courant. J'entends sa voix encore.

YUH-TS'ING. - L'heure vient où le jade se brise et la perle retourne au fleuve.

LIÙ YÊN. - Que dit-elle ? Le vent siffle, les flots se rident et les vagues accourent. Puisse-t-elle arriver à bon port. 


\section{Trois drames de I'Asie}

YUH-TS'ING (de loin). - Mes vœux sont exaucés, mon destin se termine. $\mathrm{O}$ ma mère, pardon pour le chagrin que je vous donne.

LIÙ YÊN. - Elle a disparu dans les flots. Elle a sacrifié son existence ! La pluie tombe en bourrasque et je ne vois plus rien. Tout cela par ma faute. Tout cela par ma faute!

(Il reprend sa marche péniblement.) 


\section{ACTE III}

Le palais du grand Chambellan.

La scène se passe dans un salon de réception dont une porte donne sur la cour d'entrée, l'autre sur les appartements intérieurs réservés à la famille. Deux tables, dont une porte un service à thé, l'autre est une table de toilette avec un miroir. Un vieux serviteur dispose des fleurs dans des vases. Le devant de la scène est vide et plus tard représentera, hors du palais, la route.

\section{SCÈNE PREMIÈRE}

Le vieux Serviteur, TSOÉI-NGÔ.

\section{LE VIEUX SERVITEUR.}

Dans le jardin les fleurs pressées, Dans la maison la beauté solitaire. Les fleurs me parlent et j'entends leur langage. Mais une femme, qui peut déchiffrer sa pensée?

Je suis le jardinier en chef du jardin aux fleurs, le plus ancien des serviteurs de la maison. Le vieux seigneur me connaissait depuis sa jeunesse et m'accordait sa confiance. Voilà six mois bientôt qu'il est mort, mais avant de mourir il m'a chargé de veiller sur sa fille et les deux enfants, pendant I'absence du mari, qui est parti pour la guerre. Je fais de mon mieux mais le jardin est de l'autre côté du palais. Et puis, comment m'y prendre ? Si je risque un conseil, la jeune dame répond en me donnant un ordre. Aujourd'hui elle me dit d'apporter les plus belles fleurs de mon jardin, pivoines et chrysanthèmes. Je sais pourquoi, mais silence. Les histoires des appartements intérieurs ne doivent pas être divulguées. Tout de même, que dirait le vieux seigneur, s'il revenait au monde ? Que dirait le seigneur général, s'il savait ? 


\begin{abstract}
(Tsoéi-ngô, fille du grand Chambellan et femme de Liù Yên, entre par la porte des appartements intérieurs. Elle est vêtue de blanc, couleur du deuil, mais c'est un deuil très élégant. Elle interpelle le vieux Serviteur.)
\end{abstract}

TSOÉI-NGÔ. - Est-ce fini ?

LE VIEUX SERVITEUR. - Que madame prenne la peine de voir, si elle est satisfaite.

TSOÉI-NGÔ. - Ce sont des bouquets à la mode du vieux temps. On les fait plus légers aujourd'hui.

LE VIEUX SERVITEUR. - J'y ai mis les plus belles fleurs de mes jardins.

TSOÉI-NGÔ. - Oui, c'est bien. Et le thé ? Il est là ? Je n'ai plus besoin de toi.

(Le vieux Serviteur sort par la porte de la cour, Tsoéi-ngô la rouvre après lui.)

\title{
SCÈNE II
}

TSOÉI-NGÔ, WÈI-CHÉ, puis le vieux Serviteur.

TSOÉI-NGÔ. - Il est bien parti au moins ? Ce vieux drôle qui se mêle de me surveiller!

Dans le ciel bleu flotte un nuage,

(Elle regarde au dehors.)

Incertitude des pensées.

La brise effleure le feuillage,

Frémissement d'un doux espoir.

Je suis Tsoéi-ngô, la fille du grand Chambellan défunt qui m'a fait épouser Liù Yên, il y a dix ans. Nous avions une belle situation. Pourquoi a-t-il voulu faire la guerre ? Pourquoi m'a-t-il quittée ? 


\section{Trois drames de I'Asie}

Depuis un an il est loin d'ici et depuis six mois je porte le deuil de mon père. Ce n'est pas une existence et je serais morte d'ennui sans les bonnes visites de mon ami Wèi-ché, secrétaire au palais après l'avoir été de mon père. C'est un charmant jeune homme.

(Wèi-ché apparaît à la porte ouverte, très élégant lui aussi.)

WÈI-CHÉ. - De qui parliez-vous donc, madame ?

TSOÉI-NGÔ. - Pas de vous, à coup sûr, car vous êtes un monstre de vous faire attendre ainsi.

WÈI-CHÉ. - L'audience de ce matin était plus longue que de coutume et je brûlais d'impatience.

$$
\begin{aligned}
& \text { (Pendant cette conversation, Tsoéi-ngô } \\
& \text { verse le thé dans deux tasses.) }
\end{aligned}
$$

TSOÉI-NGÔ. - Et que dit-on à la cour ?

WÈI-CHÉ. - Ce thé embaume, moins cependant que la main qui le verse. On dit que les coques de cheveux vont se porter très hautes.

TSOÉI-NGÔ. - Très hautes ? Alors je ne serais plus à la mode ?

WÈI-CHÉ. - Toute coiffure est seyante à la beauté parfaite, mais pourtant...

TSOÉI-NGÔ. - Dites tout de suite que j'ai I'air d'une vieille femme.

(Elle va à la table de toilette et commence à déplacer ses épingles. Wèi-ché la suit.)

TSOÉI-NGÔ. - Comment faut-il faire ?

WÈI-CHÉ. - L'épingle un peu plus en avant. 


\section{Trois drames de I'Asie}

TSOÉI-NGÔ. - Comme ceci ?

WÈI-CHÉ. - L'oreille un peu plus dégagée. C'est parfait. Si l'empereur pouvait vous voir...

TSOÉI-NGÔ. - Et que dit-on encore ?

WÈI-CHÉ. - On dit que notre armée de l'ouest, après de brillantes victoires annoncées à grand fracas, a été battue à plates coutures et qu'on en cache la nouvelle.

TSOÉI-NGÔ. - L'armée de I'ouest ? Celle où était mon mari ?

WÈI-CHÉ. - Votre mari ? Pardonnez-moi, madame, je n'y avais pas pensé. Mais c'est peut-être une fausse nouvelle.

TSOÉI-NGÔ. - Il n'avait qu'à rester ici, et se tenir tranquille, au lieu de me donner ces inquiétudes.

WÈI-CHÉ. - Oui, comment peut-on quitter une épouse aussi belle?

TSOÉI-NGÔ. - Il faut croire qu'il s'ennuyait avec moi.

WÈI-CHÉ. - Madame ! Est-il possible !

TSOÉI-NGÔ. - Et s'il ne revenait pas, savez-vous ce que je ferais ?

WÈI-CHÉ. - Je ne le puis deviner, madame, mais sais bien ce que je souhaiterais.

(La porte de la cour s'ouvre brusquement et le vieux Serviteur apparaît, très ému.)

LE VIEUX SERVITEUR. - Alerte, madame, votre mari est là. TSOÉI-NGÔ. - Mon mari ? Où donc ? 


\section{Trois drames de I'Asie}

LE VIEUX SERVITEUR. - Il a passé par les appartements intérieurs.

WÈI-CHÉ. - Je m'excuse de vous quitter.

(Il sort précipitamment.)

\section{SCÈNE III}

TSOÉI-NGÔ, LIÙ YÊN, le vieux Serviteur.

LE VIEUX SERVITEUR. - Il se sauve. C'est ce qu'il a de mieux à faire.

(Au même instant l'autre porte s'ouvre et Liù Yên apparaît, tel que nous l'avons vu à l'acte précédent, avec son habit de guerre sali et fatigué, le sceau d'or à la ceinture, et le sabre au côté. Il interpelle Tsoéi-ngô. Le vieux Serviteur reste près de la porte de la cour et il ne l'a pas vu.)

LIÙ YÊN. - Je vous trouve enfin. Qui était avec vous ?

TSOÉI-NGÔ. - Personne.

LIÙ YÊN. - J'étais là, derrière cette porte, comme un pauvre qui n'ose entrer et j'ai tout entendu.

LE VIEUX SERVITEUR (à part). - Pourquoi vient-il ainsi, en se cachant, sans courrier pour l'annoncer, sans escorte ? Que lui est-il donc arrivé ?

TSOÉI-NGÔ. - Qu'avez-vous entendu ? J'étais seule.

LIÙ YÊN. - Seule ? Et ces deux tasses ? Pour qui donc ?

TSOÉI-NGÔ. - Qu'allez-vous insinuer là ?

LIÙ YÊN. - Vous me déshonorez. Vous méritez la mort. 


\section{Trois drames de I'Asie}

TSOÉI-NGÔ. - Il ne veut rien entendre et me voilà à sa merci.

LIÙ YÊN. - Ma chère dame, rien n'est plus clair. En mon absence vous receviez les visites d'un ami, et vous étiez bien loin de souhaiter mon retour.

TSOÉI-NGÔ (pleurnichant). - Voilà ce qu'il pense de moi.

LIÙ YÊN. - Elle me fera mourir de colère.

$$
\begin{aligned}
& \text { (Le vieux Serviteur s'avance et Liù Yên } \\
& \text { l'aperçoit.) }
\end{aligned}
$$

LE VIEUX SERVITEUR. - Il faut que je m'en mêle, ou cela finira mal.

LIÙ YÊN. - Que viens-tu faire ici ?

LE VIEUX SERVITEUR. - Seigneur, c'est moi qu'il faut punir.

LIÙ YÊN. - Va-t-en à tous les diables.

LE VIEUX SERVITEUR. - Seigneur, écoutez-moi. Quand le vieux seigneur est mort, il m'a chargé de veiller sur votre honorable épouse et vos précieux enfants. Mais le jardin à fleurs est de l'autre côté du palais, et j'ai de vieilles jambes.

LIÙ YÊN. - Assez de bavardages. Madame, vous allez mourir.

LE VIEUX SERVITEUR. - Il tire son sabre. Appuyée à la porte, elle couvre de la main son visage, comme si son poignet était un bouclier.

TSOÉI-NGÔ. - Vieux serviteur, prenez pitié, sauvez-moi.

LE VIEUX SERVITEUR. - Dites-moi comment.

TSOÉI-NGÔ. - Ce n'est pas moi ! Ce n'est pas moi !

LIÙ YÊN. - Quelle impudence ! 


\section{Trois drames de I'Asie}

\section{LE VIEUX SERVITEUR.}

Si ce qu'il dit est vrai, il a raison de vous punir.

Votre homme a une dignité extraordinaire, un talent exceptionnel.

Il porte à sa ceinture, pour l'expédition de l'Ouest, le sceau d'or et la plaque à tête de tigre.

Il a sa place parmi les dignitaires du palais impérial, Et vous l'avez coiffé d'un pot de chambre.

Et il ne vous tuerait pas, quitte à vous faire un beau tertre funèbre?

(Liù Yên a levé son sabre, elle est tombée à genoux. Tous deux l'ont écouté, immobiles.)

TSOÉI-NGÔ. - Ce n'est pas moi !

LE VIEUX SERVITEUR.

Si ce qu'elle dit n'est pas faux, votre devoir est de I'entendre.

Vous avez échangé la promesse de rester unis jusque dans la tombe.

Est-ce en un jour qu'un tel serment s'oublie?

Pensez à votre nom qui sera déshonoré,

Pensez à vos enfants qui seront orphelins.

(Le vieux Serviteur s'approche de Liù Yên et veut lui arrêter le bras.)

LIÙ YÊN. - Ôte-toi de là.

LE VIEUX SERVITEUR. - Seigneur, votre sabre étincelle comme le glaive qui chasse les démons. Mais plus haut que les démons, plus haut que les dieux qui leur font la guerre, est le séjour de Koan-yin la miséricordieuse. Il n'y a que la pitié qui sauve. Lourd est le poids d'un mort sur l'âme du meurtrier.

LIÙ YÊN (lentement). - Lourd est le poids d'un mort.

(Il abaisse lentement son sabre.)

TSOÉI-NGÔ. - Merci, vieux serviteur, vous me sauvez la vie.

LIÙ YÊN. - Celle à qui il faut dire merci n'est pas ici. 


\title{
Trois drames de I'Asie
}

\section{LE VIEUX SERVITEUR.}

Voyez-la, qui déjà a cessé de pleurer,

Et changeant de visage, rit joliment, Le rose revient à ses joues.

A l'instant cette pointe menaçait son existence, Mais le pardon est descendu comme une rosée bienfaisante,

Et la fleur se redresse.

\author{
SCÈNE IV \\ Les mêmes, un greffier, un sergent. \\ (La porte de la cour s'ouvre.)
}

LE VIEUX SERVITEUR. - Qui vient encore ?

(Entre un greffier de la cour impériale. Il tire de sa ceinture un édit et en donne lecture.)

LE GREFFIER. - Par ordre de S. M. I'Empereur. Le général Liù Yên a contrevenu aux instructions données et par sa désobéissance causé la perte de l'armée. En conséquence le conseil de guerre le déclare déchu de son grade et le condamne à la peine de mort. Que Votre Excellence veuille bien m'excuser si je lui retire le sceau d'or, insigne de son grade.

TSOÉI-NGÔ (riant nerveusement). Ce n'est plus moi, c'est lui qui doit mourir !

LIÙ YÊN. - J'ai mérité la mort. Par ambition, j'ai manqué à la foi promise et délaissé ma famille. Par orgueil, j'ai couru au désastre. Par jalousie, j'ai voulu faire le justicier. Voilà où m'ont conduit les passions humaines. A toutes je renonce pour le peu qui me reste à vivre. 


\section{Trois drames de I'Asie}

(Mais le greffier n'a pas achevé sa lecture. Il poursuit.)

LE GREFFIER. - Considérant toutefois que le coupable avait à venger le meurtre de ses parents et qu'ainsi un bon sentiment a pu contribuer à sa résolution funeste, S. M. I'Empereur en sa mansuétude a commué la peine de mort en celle de la déportation perpétuelle dans le désert du Nord. L'arrêt sera exécuté sur I'heure. Holà ! Sergent !

(Le sergent qui attendait au dehors entre avec la cangue qu'il va passer au cou du condamné.)

LE VIEUX SERVITEUR. - Le sergent apporte la cangue pour la lui mettre au cou, comme à un malfaiteur.

LE GREFFIER. - Toutefois il sera permis au condamné d'emmener sa famille au lieu de son exil.

TSOÉI-NGÔ (effrayée). - D'emmener sa famille ?

LIÙ YÊN. - Ne craignez rien. Qu'on m'apporte de quoi écrire et qu'on amène ici les enfants. Je prends le pinceau et j'écris : «Par le présent acte, je répudie mon épouse Tsoéi-ngô et lui rends la liberté. » Et je signe : « Liù Yên. »

LE SERGENT. - Seigneur Liù Yên, vous deviez être mis à mort, mais l'empereur dont la volonté incarne la vertu du ciel qui aime les créatures vous fait grâce, quand vous aviez déjà le couteau sur la gorge, et vous envoie en exil dans le pays où vont les mauvais soldats. C'est moi qui suis chargé de vous conduire et pour cela excusez la liberté que je prends, il faut que je vous mette la cangue.

(Le vieux Serviteur revient avec les enfants.) 


\section{Trois drames de I'Asie}

LE VIEUX SERVITEUR. - Seigneur, je vous amène les enfants. TSOÉI-NGÔ. - Adieu, mon ami, vous ne voulez plus me tuer maintenant?

LE VIEUX SERVITEUR. - Madame, dans un pareil instant, est-ce là une manière de parler?

Hier haut fonctionnaire, maître des hommes, chef de la paix et de la guerre Aujourd'hui en exil, sous le balai du vent, Je ne sers plus un maître mais un compagnon d'infortune. Mon frère, à part la mort il n'y a pas de grand malheur.

LIÙ YÊN. - Mes enfants, donnez-moi vos mains.

TSOÉI-NGÔ. - Liù Yên, bien qu'ayant la vie sauve, vous êtes un homme mort. Laissez-là mes enfants.

LIÙ YÊN. - Si je ne les emmène pas, à qui les confier ?

TSOÉI-NGÔ. - Le crime que vous avez commis concerne-t-il mon fils et ma fille?

(Elle veut les lui enlever. Il les tire en sens contraire. Mais le sergent qui a pris en main la chaîne de la cangue l'oblige à avancer.)

LIÙ YÊN. - Sergent, un peu plus lentement, je vous prie. Je veux mourir sans quitter mes enfants, et cette mauvaise femme les retient.

LE SERGENT. - J'ai mes ordres. Nous devons arriver dès ce soir à la première étape.

LE VIEUX SERVITEUR. - Sergent, par pitié, n'allez pas si vite.

(Il se place devant lui. Le sergent le frappe de son bâton. Il tombe à terre.) 


\section{Trois drames de I'Asie}

LE VIEUX SERVITEUR. - Il m'a jeté à terre, mais elle a lâché prise. Ils sortent du palais. Je les suis sur la route, mais ils vont plus vite que moi.

Je vois la cangue qui le serre,

On le tire, on l'entraîne.

$\mathrm{O}$ mon frère, quand on vous menait, avec l'éclat du soleil levant, à la terrasse illuminée,

Pouviez-vous penser qu'une dignité si haute ne fût pas immuable?

Aujourd'hui toute influence favorable a disparu Quand peut-on espérer le pardon pour vos fautes ?

Mon frère est loin déjà. Frère!

LIÙ YÊN (de loin). - Frère !

\section{LE VIEUX SERVITEUR.}

C'est sa voix, mais lointaine. Je reçois son adieu indistinct

Par delà les feuillages tombants des saules.

Je cherche à voir et ne les vois plus,

En vain je perce du regard la brume de I'horizon. Frère !

LIÙ YÊN (de très loin). - Frère !

\section{LE VIEUX SERVITEUR.}

De plus en plus mes yeux s'égarent à le suivre, Le vent de la forêt m'apporte sa voix plaintive. 


\section{Trois drames de I'Asie}

\section{ACTE IV}

\section{SCÈNE PREMIÈRE}

LIÙ YÊN, le Sergent, le Bûcheron, les deux Enfants.

Dans les montagnes du Nord. On voit paraitre, cheminant péniblement, le cortège qui a quitté le palais à l'acte précédent : le sergent en tête, tenant la chaîne de la cangue, suivi de Liù Yên, à qui donnent la main, de part et d'autre, ses deux petits enfants.

\section{LE SERGENT.}

Il faut escalader la cime

Pour découvrir le ciel.

Il faut traverser la montagne

Pour trouver le désert.

Plus vite un peu, voyons! Vous dormez!

LIÙ YÊN. - Sergent, voyez comme le chemin est difficile, le roc aigu, et la pente glissante.

LE SERGENT. - M'en moque. J'ai mon horaire.

LIÙ YÊN. - C'est cette cangue qui me gêne.

LE SERGENT. - Je ne puis vous la retirer avant d'être arrivé à destination.

LIÙ YÊN. - C'est loin encore?

LE SERGENT. - Trois jours. On est en retard, déjà. C'est les enfants qui gênent.

LIÙ YÊN. - Vous n'avez pas d'enfants, sergent ?

LE SERGENT. - Si fait, et des jolis. Ils m'attendent au quartier.

LIÙ YÊN. - Regardez donc ceux-ci. 


\section{Trois drames de I'Asie}

LE SERGENT. - C'est vrai qu'ils ont l'air bien fatigués. Le petit respire comme un soufflet de forge et la petite trébuche à chaque pas. (Il réfléchit un moment.) Eh bien ! vous allez voir que moi aussi je suis capable de sentiment. Puisque nous voilà seuls, dans la montagne où personne ne peut nous voir, je vais vous laisser là et m'en revenir. Voyez, je prends la clé et j'ouvre votre cangue. Vous êtes libres, sauvez-vous.

LIÙ YÊN. - Merci, frère. J'avais le mors à la bouche, la selle sur le dos. C'est un bienfait que je n'oublierai jamais.

LE SERGENT. - Ça va mieux maintenant ? Votre chemin est par ici, le mien par là. Sauvez-vous vite, que je ne vous voie plus. Adieu.

(Il s'en va. Liù Yên reste seul avec les deux enfants.)

LIÙ YÊN. - Nous sauver, c'est facile à dire. Mais nous n'en pouvons plus. La neige commence à tomber. Où trouver un refuge en cette solitude ? La neige couvre le sol et je ne vois plus le sentier. Si seulement quelqu'un venait à passer pour nous remettre dans la bonne direction.

(De l'autre côté de la scène on voit paraître, la hache à la ceinture et une charge de bois aux épaules, un bûcheron.)

\section{LE BÛCHERON.}

Sur la haute montagne

Le souffle humain ne trouble plus l'espace

Et I'on a pour voisin I'univers.

Ce que les autres savent, je l'ignore.

Ce qu'ils ignorent, je le sais.

Bûcheron de la montagne, je rentre au logis avec cette charge de bois sous le vent et la neige, par le froid glacial. 


\section{Trois drames de I'Asie}

Le vent souffle en tourbillons, La neige vole en duvet de tous côtés, Montagne et mer, le froid blanc emprisonne la vieillesse du monde.

\section{(Liù Yên, de l'autre côté de la scène, ne l'a pas vu.)}

LIÙ YÊN. - Mes enfants, un peu de courage, marchez encore. Sous ce vent et cette neige, si nous nous arrêtons un instant, c'est notre mort.

(Le Bûcheron continue à chanter.)

\section{LE BÛCHERON.}

Au promontoire des blancs nuages

J'entends un démon solitaire qui crie sur le désert.

Les fées du ciel battent le vent et mettent en mouvement

la nature,

Les génies brandissent leur sabre et maintiennent la terre Immobile sous I'ouragan.

LIÙ YÊN. - C'est vous qui m'entraînez maintenant. Doucement ! Doucement ! A la descente, il est mauvais de se presser.

LE BÛCHERON. - Je vois, dans le froid aigu, s'avancer en se donnant la main un pauvre homme, des enfants.

LIÙ YÊN. - Je meurs de froid.

\section{LE BÛCHERON.}

Ils luttent de toutes leurs forces, L'un en soulevant les épaules, L'autre les poings aux jambes, Contre le vent qui s'élève et la neige qui frappe, sur la route de la terre au ciel.

$$
\begin{aligned}
& \text { (Les enfants parlent maintenant à leur } \\
& \text { père.) }
\end{aligned}
$$

LES ENFANTS. - Papa, j'ai bien faim. 


\section{Trois drames de I'Asie}

LIÙ YÊN. - Mes enfants, marchez encore un peu. Là-bas, il y aura à manger.

LE BÛCHERON.

L'enfant s'arrête, son père s'inquiète, Le père dit à son enfant Qu'il y a là de quoi manger, qu'on y sera dans un instant. Bientôt le vent glacé de la nouvelle lune va courir par ici.

(Les enfants tombent, saisis par le froid. Liù Yên s'affaisse avec eux et les protège de son corps.)

LIÙ YÊN. - Nous sommes tous les trois tombés, saisis par le froid. Qui sauvera mes enfants?

LE BÛCHERON.

J'ai vu trois malheureux qui s'avançaient, Au moment d'arriver, ils sont tombés à terre. Holà, monsieur, réveillez-vous, réveillez-vous, voyons! Je vais les relever de mes mains bien vite, Leur soutenir la tête un peu, Celui-ci a le corps déjà raidi, Celui-là griffe des mains ses jambes. J'ouvre leurs vêtements Pour voir si leur âme n'est pas trop loin déjà. Je vais sauver ces deux enfants, Les réchauffer contre mon cœur. L'homme a les dents serrées, Mais je crois qu'il s'éveille.

LIÙ YÊN. - Pour un peu, nous étions morts de froid. Qui donc nous a sauvés?

LE BÛCHERON. - C'est moi qui passais par ici. LIÙ YÊN. - Sans vous, mon frère, que serait-il advenu de nous ? LE BÛCHERON. - Liù Yên, où allez-vous ? 


\section{Trois drames de I'Asie}

LIÙ YÊN. - C'est étrange, comment sait-il mon nom ? A ne rien vous cacher, je vous dirai qu'à l'instant, la cangue au cou, je suivais le chemin de l'exil avec mes deux enfants. Le sergent m'a laissé aller, mais j'ai trouvé tant de neige et de froid que je suis tombé sur place. Si vous n'étiez pas venu, mon frère, nous étions morts tous trois. Mais nous n'avons rien sur le dos, rien dans le ventre et avons perdu la route. Frère, où faut-il aller ?

LE BÛCHERON. - Bientôt vous trouverez la Voie que vous avez quittée. Maître, vous avez perdu la Voie, je vous apprendrai la Voie, vous montrerai la Voie.

LIÙ YÊN. - Frère, je ne comprends rien à ce que vous me dites là.

LE BÛCHERON. - La Voie dont je parle, je ne la connais pas moi-même. Mais au bas de la montagne vous trouverez une cabane et dans la cabane un docteur qui pourra vous instruire.

LIÙ YÊN. - Frère, expliquez-vous.

LE BÛCHERON.

Descendez tout droit par ici, Jusqu'au ruisseau, que traverse un pont.

Dans la solitude blanche de neige où se perdent les pas

La brume laisse entrevoir la cabane,

Sapins et cyprès I'entourent.

LIÙ YÊN. - Ce docteur est-il bon ou méchant ? Frère, dites-le moi.

\section{LE BÛCHERON.}

Ce docteur à deux mains ébranle la montagne, D'un regard il chasse les mauvais esprits, De son sabre il ébranle les constellations, De sa poitrine il résiste au fleuve furieux, 


\section{Trois drames de I'Asie}

Le ciel lui a donné un aspect terrible

Pour soumettre le Tigre, dompter le Dragon.

Maître, après le versant de la montagne, de l'autre côté du ruisseau, vous verrez cette cabane de chaume, vous demanderez la route à ce docteur.

La porte n'a pas de battant, La chambre est sans serrure, Les nuages sont obscurs, l'eau bondissante, Le vent frais, la neige tournoie, La porte à claire-voie s'appuie au treillage de bambous.

Par delà la pointe de la montagne,

La source s'infléchit à l'ombre du bois touffu.

Quand vous verrez cette belle et secrète demeure d'Immortel, ce sera la Voie.

Maître, ne vous trompez pas sur la Voie. Saisissez bien. (Il disparaît. Liù Yên se remet en marche avec les deux enfants.)

LIÙ YÊN. - Mes enfants, vous venez d'entendre ce qu'il a dit. Sur le versant de la montagne, il y a une maison, une maison habitée. On y trouve à manger, à se vêtir, à passer la nuit. Allons-y tout droit, ce sera notre salut.

(Ils sortent de scène.)

\section{SCÈNE II}

La Vieille, LIÙ YÊN, les Enfants.

Dans la cabane et devant la cabane du docteur. La partie antérieure de la scène représente l'intérieur de la cabane, avec le même ameublement que l'auberge du premier acte : une table avec deux chaises, un fourneau, un lit de camp, mais cette fois muni d'un oreiller. A l'arrière de la scène se trouve le chemin avec le pont sur le torrent. Une vieille femme est dans la cabane.

\section{LA VIEILLE.}




\section{Trois drames de I'Asie}

Sous les apparences changeantes le destin reste le même,

Sous des apparences pareilles le destin a changé.

Je tenais jadis une auberge sur la grand-route de l'ouest. Mais j'ai suivi mon fils qui s'est retiré du monde et habite avec lui dans cette solitude. Bien qu'il ait renoncé au monde, mon fils est de caractère violent. Chaque jour il use ses forces à la chasse dans la montagne. Le soir tombe. Il va bientôt rentrer, je prépare la collation pour son retour. L'eau ne bout pas encore. Il faut ajouter du bois sur le feu.

(Elle active le feu dans le fourneau. Liù Yên avec les deux enfants apparaît au dehors.)

LIÙ YÊN. - Nous voici au bas de la montagne. J'aperçois un pont sur un torrent, et de l'autre côté une cabane couverte de chaume. Comme le torrent est profond ! Le pont est fait d'un seul tronc d'arbre. Comment passer ? Si je prends le petit d'abord, j'ai peur que les bêtes sauvages n'attaquent la petite fille. Si je fais passer d'abord la petite fille, j'ai peur pour le petit garçon. C'est par lui que je vais commencer. Attends ici, petite fille.

LA PETITE FILLE. - Papa, une grande bête vient pour me mordre.

LIÙ YÊN. - Mon enfant, n'aie pas peur, je reviens tout de suite. Je laisse ici le petit garçon. Attends-moi, je vais chercher ta sœur.

LE PETIT GARÇON. - Papa, une grande bête vient pour me mordre. 


\section{Trois drames de I'Asie}

LIÙ YÊN. - Voilà, nous arrivons. Nous sommes réunis de nouveau. Et voici la maison qui va nous accueillir. Suivez-moi, nous allons trouver de quoi manger. Il n'y a pas de marteau pour frapper. La porte n'est pas fermée. Il n'y a personne ?

LA VIEILLE. - Qui m'appelle?

LIÙ YÊN. - Un père avec ses deux enfants perdus dans la montagne. Je cherche un abri pour la nuit. A l'aube nous nous remettrons en route.

LA VIEILLE. - Vous tombez mal. Je crains de ne pouvoir vous garder ici, tant mon fils est terrible. Chaque jour il cherche sa vie à la chasse dans la montagne. Quand il n'y a plus de vin et qu'il en voudrait, il est capable de tuer quelqu'un.

LIÙ YÊN. - Madame, vous ignorez qu'à la suite de mes malheurs j'ai renoncé à toutes les passions humaines. Si le maître du logis veut me battre, je ne me défendrai pas. S'il m'insulte, je ne me mettrai pas en colère.

LA VIEILLE. - S'il en est ainsi, vous pouvez entrer.

(Ils entrent, cependant que le docteur se montre au dehors, l'arc sur l'épaule, le coutelas à la ceinture, en costume de chasse.)

\section{SCÈNE III}

Les mêmes, le Docteur.

LE DOCTEUR. - J'ai vidé quelques coupes et me sens un peu ivre. Je rentre à la maison, où ma mère a dû me faire à manger, et me donnera à boire, j'espère. 


\section{Trois drames de I'Asie}

Le creux du sentier devant la solitude, Le danger de la montagne en ces escarpements ! Je ne convoite pas les palais où les fonctionnaires, chacun à son rang,

Ont leurs mets servis dans l'argent ou le bronze, leurs lits à couvertures de soie.

Il ne me faut qu'un peu de sang, assez de sang pour teindre mon turban.

(Il s'approche de la porte pendant que Liù Yên et les enfants parlent.)

LES ENFANTS. - Papa, je meurs de faim.

LIÙ YÊN. - Madame, ne pourriez-vous nous faire une bouillie de millet? Nous avons si grand faim !

\section{Liù Yên.)}

(Le Docteur entre brusquement et bouscule

LE DOCTEUR. - Qu'est-ce que vous venez faire ici ?

LIÙ YÊN. - Quel démon est-ce là ?

LE DOCTEUR. - Qui vous permet de me questionner ? Je suis le chasseur d'hommes, si vous voulez le savoir, le chasseur d'hommes, c'est moi.

LIÙ YÊN. - On m'avait parlé d'un docteur.

LE DOCTEUR. - Qu'est-ce que vous alliez réclamer à ma mère ? LIÙ YÊN. - Un peu de bouillie pour mes enfants, qui ont faim.

LE DOCTEUR. - Ils n'auront plus faim bientôt. Viens ici, petit. Je vais le jeter dans le torrent.

LIÙ YÊN. - Vous ne ferez pas cela. Je vais vous le reprendre.

LE DOCTEUR. - Espèce de malappris. Je suis chez moi ici. Mêlez-vous de ce qui vous regarde. Voilà, c'est fait. Les bêtes de 


\section{Trois drames de I'Asie}

I'eau ont faim aussi, il fallait y penser. Et maintenant, au tour de la petite.

LIÙ YÊN. - Voulez-vous laisser cette enfant ?

\section{LE DOCTEUR.}

Si la fillette devient une grande personne, Ce sera une fille ingrate, Une acariâtre fille à marier.

Ne pas la tuer, et pourquoi donc?

Le peu qu'elle a de vie est en mes mains, elle n'y échappera pas.

Voilà, elle a rejoint son frère.

LIÙ YÊN. - Au secours, au secours !

LE DOCTEUR. - Oui, au secours, je viens à votre secours. Ne cherchez pas à fuir. Ce couteau vous délivre.

(Il frappe au cou Liù Yên qui porte la main à sa blessure et tombe sur le lit de camp.)

LIÙ YÊN. - Ah ! je suis mort.

\section{SCÈNE IV}

LIÙ YÊN, TCHOUNG-Lî, la Patronne.

Liù Yên sur le lit de camp a repris exactement la position où il était quand il s'est endormi. Tchoung-lî rentre en scène et prend place sur la chaise. La vieille active le feu du fourneau. C'est le même tableau qu'à la fin du premier acte. Cependant Liù Yên s'agite en son sommeil. On devine qu'il rêve. Il tend les bras comme pour repousser un danger, et bientôt va porter la main à son cou, avec le même geste qu'à la scène précédente.

TCHOUNG-LÎ.

Je suis ici bien tranquille

A veiller sur son sommeil.

La vieille femme a versé dans l'eau la farine

Et ajouté les condiments. 


\section{Trois drames de I'Asie}

L'âne boiteux à l'ombre du saule détend ses jambes

Et ne demande qu'à rester là, paresseusement étendu.

L'homme écarte de son cou un chatouillement,

Coup mortel qui met fin à son rêve.

Et voici qu'il s'éveille.

LIÙ YÊN. - Où étais-je donc ?

TCHOUNG-Lî. - Liù Yên, éveillez-vous.

LIÙ YÊN. - Ai-je dormi longtemps ?

TCHOUNG-LÎ. - Dix minutes ou dix années.

LIÙ YÊN. - Le repas est-il prêt ?

LA PATRONNE. - Attendez, s'il vous plaît, que j'active le feu. Je vais chercher du bois. (Elle sort.)

LIÙ YÊN. - Comme j'ai dormi !

TCHOUNG-Lî.

En votre rêve avez-vous vu, En votre cœur avez-vous compris ?

De ce sommeil de dix années

L'éclat d'une arme vous réveille

Et vous êtes vivant comme autrefois.

Liù Yên, vous souvient-il du grand chambellan ?

LIÙ YÊN. - Je crois voir et entendre encore le grand chambellan, et ses conseils que je n'ai pas suivis. Ce n'était donc pas vrai ?

TCHOUNG-Lî. - Vous étiez en personne dans son palais, comme vous êtes en cette auberge. Il se trouvait là et vous adressait la parole, comme je suis ici et vous parle en ce moment.

LIÙ YÊN. - Je me souviens de la bataille perdue et de ce qui m'attendait au retour. Tout cela n'est donc pas arrivé ?

TCHOUNG-LÎ. - Pourquoi en doutez-vous ? 


\section{Trois drames de I'Asie}

LIÙ YÊN. - Parce que je me retrouve ici.

TCHOUNG-LÎ. - Mais vous étiez ailleurs.

LIÙ YÊN. - Une jeune fille lave la toile au bord de l'eau. Une barque est près d'elle.

TCHOUNG-Lî. - Elle y fut, en effet, ayant devancé, sur mon ordre, le rendez-vous de l'avenir.

LIÙ YÊN.

Je reçois son adieu indistinct

Parmi le feuillage tombant des saules.

Où est le vieux serviteur, qui seul avait pitié de moi ?

TCHOUNG-Lî. - Il n'est plus là, mais l'écho de ses paroles ne peut s'éteindre en votre cœur.

LIÙ YÊN. - Mes enfants, un peu de courage, marchez encore ! Sur le conseil du bûcheron, je les conduis à la cabane, je les mène à la mort.

TCHOUNG-LÎ. - Ils sont retournés dans le monde du possible, d'où ils venaient, à mon appel.

LIÙ YÊN. - Je commence à comprendre.

TCHOUNG-LÎ. - Vous avez obtenu la faveur de prendre à l'essai votre existence, parcourant d'un trait l'espace de dix ans. L'expérience est faite.

LIÙ YÊN. - L'expérience est faite, et je renonce au monde.

TCHOUNG-Lî.

Le millet n'est pas cuit encore,

Et l'ambition n'a plus d'attrait,

La gloire a perdu son éclat,

Le plaisir son mensonge, 


\section{Trois drames de I'Asie}

Le cœur sa jalousie

Et l'esprit son orgueil.

La joie, la colère, le chagrin, la crainte, l'amour, la haine et le désir :

Toutes les passions ont quitté votre cœur.

Une étincelle qui jaillit, une flamme qui vacille entre deux océans de ténèbres,

Telle est la vie humaine.

Liù Yên, avez-vous saisi ?

LIÙ YÊN. - Maître, votre disciple a saisi.

\section{TCHOUNG-LÎ.}

Votre purification est accomplie,

Toutes vos fautes sont effacées

Bientôt vous pourrez sans peine, sans remords,

$S^{\prime}$ il faut marcher, marcher,

$S^{\prime}$ il faut demeurer, demeurer,

$S^{\prime}$ il faut rester oisif, rester oisif,

$S^{\prime}$ il faut être fort, être fort.

Sous une ancienne dynastie un autre général d'armée ayant perdu, comme vous, une bataille, s'est retiré dans la solitude, et c'est là qu'il a connu la Vérité. C'est pourquoi il est revenu, de son séjour d'immortalité, en ce monde de poussière pour vous sauver.

LIÙ YÊN. - Maître, vous seriez donc... Mais il a disparu. De cette délivrance je ne puis le remercier. extase.)

(Il va sur le devant de la scène et répète, en

Et l'ambition n'a plus d'attrait,

La gloire a perdu son éclat,

Le plaisir son mensonge,

Le cœur sa jalousie

Et l'esprit son orgueil. 


\section{Trois drames de I'Asie}

\section{SCÈNE V}

Les mêmes, le Prince empereur de la Floraison orientale.

Au fond de la scène apparaît le Prince empereur de la Floraison orientale, entouré de sept Immortels, parmi lesquels Tchounglî, vêtus de blanc pur. Tchoung-lî se détache un peu en avant et appelle Liù Yên.

TCHOUNG-LÎ. - Liù Yên !

(Liù Yên se retourne et tombe à genoux.)

TCHOUNG-Lî. - Me reconnaissez-vous ? Je suis Tchoung-lî et voici mes compagnons, les Immortels, faisant escorte à Sa Majesté le Prince empereur de la Floraison orientale, qui vous dira lui-même quel sera votre sort désormais.

LE PRINCE EMPEREUR. - Puisque vous avez compris, en dix années de rêve, la vanité du monde, puisque sous le froid mortel vous avez appris l'angoisse de vivre, puisque dans I'horreur des passions le vrai visage du siècle vous est apparu, votre destin est accompli, et vous devez maintenant prendre place, vous huitième, parmi les Immortels qui m'entourent.

Vous n'étiez pas de naissance ordinaire, de complexion obscure.

Par erreur sur votre nature vous avez souffert parmi les hommes.

Le maître Tchoung-lî vous a sauvé entre les rangs de la multitude.

Un rêve vous a montré le néant de la vie.

A votre réveil, vous avez compris.

Aujourd'hui ayant fait vos preuves devant notre assemblée souveraine,

Admis à l'immortalité, vous partagerez notre séjour sur la montagne qui touche au ciel. 
Trois drames de I'Asie

@ 


\title{
VIKRÂMA ET OURVÂSI
}

\author{
ou

\section{LE ROI ET L'APSÂRA}

Drame en cinq actes

donné pour la première fois

par la Radiodiffusion nationale de France

le 6 novembre 1942.

\section{PERSONNAGES}

Vikrâma, roi des Indes

Manâva, son écuyer

Ayous, son fils

Un brahmane

Un héraut

Ourvâsi, apsâra du ciel d'Indra

Nayâni, apsâra messagère

La reine, épouse de Vikrâma

Nipounî, suivante de la reine

Une brahmanî
MM. Henri POLLAN. Jean HEUZÉ.

Le petit LACHAMBE.

André WASLEY.

Louis LORSY.

$M^{\text {mes }}$ Yvonne GAUDEAU.

Geneviève AUGER.

Christine AUDAN.

Paulette MARINIER.

Germaine DUARD.

Mise en ondes de Louis SEIGNER. 


\section{Trois drames de I'Asie}

\section{ACTE PREMIER}

\section{SCÈNE PREMIÈRE}

OURVÂSI, NAYÂNI.

Près de la cime d'une montagne boisée. Deux apsâras apparaissent, marchant avec précaution, descendant du sommet où elles viennent de se poser.

OURVÂSI. - Ainsi nous voilà sur la terre. Comme il fait noir !

NAYÂNI. - C'est que vos yeux sont accoutumés à la splendeur de notre monde. Messagère entre les dieux et les hommes, ce n'est pas la première fois que je dois m'orienter sous cette lueur incertaine, que ceux d'ici appellent le jour, et je sais m'y reconnaître. Donnez-moi votre main.

OURVÂSI. - On enfonce dans une chose humide qui sent la pourriture.

NAYÂNI. - C'est ce qu'ils appellent la terre. Elle est faite avec la dépouille de ce qui meurt.

OURVÂSI. - J'ai peur.

NAYÂNI. - Il faut partir.

OURVÂSI. - J'ai peur ; c'est délicieux.

NAYÂNI. - Il faut partir, petite sœur. Nous sommes ici aux confins de deux mondes, dans la région dangereuse où les dêtyas, esprits du mal, se livrent à leurs déprédations.

OURVÂSI. - Et plus bas ?

NAYÂNI. - Plus bas vivent les hommes. 


\section{Trois drames de I'Asie}

OURVÂSI. - Allons les voir.

NAYÂNI. - Folle enfant, j'ai eu tort déjà de céder à votre caprice, mais n'irai pas plus loin. N'entendez-vous pas?

OURVÂSI. - J'entends au-dessus de nous comme le bourdonnement éloigné d'un essaim d'abeilles sauvages.

NAYÂNI. - Ce sont les gandharvas, musiciens de notre ciel, qui accordent leurs instruments pour la danse $\mathrm{du}$ soir. Qu'adviendrait-il à l'assemblée des dieux et des génies, protecteurs des trois mondes et réunis dans le ciel d'Indra, maître de la foudre, si à la danse des apsâras qui manifeste leur pensée et la transmet aux existences il venait à manquer celle qui entre toutes détient en sa personne le plus haut des secrets, la toute gracieuse, légère, fugitive et fragile Ourvâsi ?

OURVÂSI. - Quelques pas seulement, voulez-vous, de ce côté où la pente est facile.

NAYÂNI. - Ourvâsi, prenez garde !

(Elles sortent par un côté de la scène. De l'autre arrive, sur un char attelé de chevaux ailés et conduit par l'écuyer Manâva, le roi Vikrâma.)

SCÈNE II

VIKRÂMA, MANÂVA.

VIKRÂMA. - Arrêtons un instant.

MANÂVA. - Avant de redescendre ?

VIKRÂMA. - Avant d'aller plus haut. 


\section{Trois drames de I'Asie}

MANÂVA. - Seigneur, c'est impossible. Voyez, nous sommes tout près de la voûte du ciel, que nulle créature terrestre ne peut franchir. Et déjà l'air nous manque.

VIKRÂMA. - Nous sommes montés trop vite, il ne s'agit que de reprendre haleine.

MANÂVA. - Et maintenant partons, I'heure du dîner approche.

VIKRÂMA. - J'ai vaincu en combat singulier le roi des serpents Ananta et fait amitié avec Garouda, roi des oiseaux, qui m'a donné ce char ailé. Crois-tu que ce soit pour rentrer tranquillement au logis après la promenade qui met en appétit ? Je veux courir ici quelque aventure, aussi vrai que je m'appelle Vikrâma, roi de Pratisthâna.

(On entend du côté où sont sorties les deux apsaras, des cris d'appel.)

\section{SCÈNE III}

Les mêmes, NAYÂNI, OURVÂSI.

NAYÂNI et OURVÂSI. - Au secours ! au secours ! seule.)

NAYÂNI. - Seigneur, qui que vous soyez, à I'aide ! Ma compagne a été enlevée par un dêtya errant en ces parages.

VIKRÂMA. - Par un dêtya ! Et qui êtes-vous ? 


\section{Trois drames de I'Asie}

NAYÂNI. - Deux apsâras venues du ciel. Il s'est enfui de ce côté.

MANÂVA. - Ne craignez rien, notre char a des ailes.

(Ils partent. Nayâni reste à les regarder.)

NAYÂNI. - Déjà ils ont pris leur essor. Comme ils vont vite ! Glissant sur les rayons du soleil qui décline, le char disperse les nuages, poussière de la route, et la bannière royale au-dessus d'eux est raidie par le vent de la course. Je ne les vois plus. L'esprit du mal est prompt mais ils sauront l'atteindre. Je I'ai bien reconnu, c'est le roi Vikrâma, le vainqueur d'Ananta, I'allié de Garouda, vaillant entre les hommes. Mais I'homme le plus fort est sujet au destin. Je vois un point noir à I'horizon qui grossit, il me semble. Est-ce le char ? Oui, je distingue maintenant les grandes ailes qui battent I'air. Mais est-elle avec lui ? Le char s'approche. Il me fait de la main un signe favorable. Gloire à Indra qui donne au juste la victoire.

(Elle court au devant du char qui s'arrête. Vikrâma en descend, portant Ourvâsi dans ses bras.)

NAYÂNI. - Le char s'arrête. Le roi descend. Il porte Ourvâsi dans ses bras. Qu'est-il arrivé ?

VIKRÂMA. - La trop grande frayeur la prive de pensée.

NAYÂNI. - Ourvâsi, vous n'avez plus rien à craindre. Ourvâsi, ne m'entendez-vous pas?

VIKRÂMA. - Ourvâsi, reprenez courage. Le maître du tonnerre, toujours armé, veille à la garde des trois mondes; les ennemis du ciel sont en fuite. 


\section{Trois drames de I'Asie}

NAYÂNI. - Ecrasé par la crainte, son cœur s'est resserré comme la fleur se ferme.

VIKRÂMA. - Elle revient, mais lentement, de son sommeil. Ainsi devant la lune qui se lève se retirent à regret les ombres de la nuit. Ainsi la flamme des feux du soir traverse par bouffées les tourbillons de fumée noire. Ainsi le Gange insensiblement dépose le limon terrestre et reprend sa clarté.

NAYÂNI. - Ses yeux s'ouvrent. Ourvâsi, nous sommes là, et vous êtes sauvée.

OURVÂSI. - Par la volonté d'Indra ?

NAYÂNI. - Par le courage d'un prince qu'il protège.

OURVÂSI. - Où est-il ?

(Elle se met vivement debout.)

NAYÂNI. - Comme elle s'est vivement redressée. Je crois qu'elle est guérie.

(Vikrâma s'avance et s'incline profondément devant elle.)

VIKRÂMA. - Céleste créature, c'est moi qui eus I'honneur de vous sauver et m'en sens très indigne, car je ne suis qu'un homme. Mon nom est Vikrâma, roi de Pratisthâna. Et Manâva est l'écuyer qui m'a conduit.

$$
\begin{aligned}
& \text { (Ourvâsi le regarde un moment sans } \\
& \text { répondre.) }
\end{aligned}
$$

NAYÂNI. - Ils échangent un long regard.

OURVÂSI. - Comment pourrai-je reconnaître un tel bienfait ? 


\section{Trois drames de I'Asie}

VIKRÂMA. - J'ai eu déjà ma récompense. Jamais je n'ai porté une aussi douce charge, et mon regret unique est de m'en dessaisir.

NAYÂNI. - Ourvâsi, mon enfant, il est temps de partir.

OURVÂSI. - Mais je ne puis partir. Voyez ! Ma guirlande de fleurs est prise aux enroulements de cette liane.

NAYÂNI. - Rien n'est plus difficile que de détacher une guirlande de fleurs qui d'elle-même s'est laissé prendre.

(Elle détache la guirlande.)

OURVÂSI. - Ma robe est de travers. Il faut m'aider à la mettre droite, je n'ai pas la force.

(Nayâni s'empresse encore, pendant qu'Ourvâsi s'offre complaisamment aux regards de Vikrâma.)

NAYÂNI. - Tournez-vous de ce côté. Et maintenant par là. Etesvous satisfaite?

OURVÂSI. - Adieu, seigneur Vikrâma. Je n'oublierai jamais mon bref séjour sur terre.

VIKRÂMA. - Adieu, divine Ourvâsi. Pourrai-je vous revoir dans une autre existence?

OURVÂSI. - Mes colliers sont-ils bien fermés ? Mes bracelets bien rangés?

NAYÂNI. - Elle porte les mains à son cou, puis à ses bras. Que cherche-t-elle ? Venez, petite sœur, nous serons en retard, mais on vous pardonnera, parce que vous êtes plus belle que jamais.

(Elles disparaissent.) 


\section{Trois drames de I'Asie}

MANÂVA. - Nous aussi nous serons en retard, si vif que soit notre attelage. Mais il y aura fête au palais, quand on saura notre victoire. Déjà je crois voir les jardins illuminés, entendre le son joyeux des tambourins et des cymbales, et les acclamations de la foule massée à l'extérieur. Que fera Votre Majesté pour répondre aux vœux de son peuple ? Ordonnera-t-elle un grand festin ? Un service d'actions de grâces au temple ? Ou des combats nautiques ? Ou des danses sacrées ? Il ne répond pas. En vérité les grands de la terre sont de singuliers personnages. En voici un qui vient d'accomplir un nouveau et magnifique exploit. En son palais splendide il rentre couvert de gloire. Cependant son front reste barré d'un morne souci, son regard accablé sous le poids du regret. Que peut-il regretter ? Où veut-il en venir ? C'est à n'y rien comprendre. 


\section{Trois drames de I'Asie}

\section{ACTE II}

\section{SCÈNE PREMIÈRE}

Le héraut, invisible.

La scène reste vide. On entend une voix qui vient du ciel. C'est celle d'un héraut qui proclame la volonté d'Indra.

LE HÉRAUT. - Ceci est la volonté du seigneur Indra, dieu du nuage et de la foudre, préposé au gouvernement des trois mondes, qui tient sa cour dans le premier ciel. L'apsâra Ourvâsi a commis une faute grave dans la danse du soir, au moment de figurer les mouvements qui commandent aux cœurs des hommes. Au geste de l'adoration, anjali hasta, elle a substitué le gadja hasta qui signifie le don de soi-même. Un grand frémissement a parcouru la terre et l'on ne sait ce qu'il fût advenu, si le tonnerre d'Indra n'avait aussitôt conjuré les volontés rebelles. Pourtant, en sa clémence, il n'a pas voulu en frapper la coupable, qui venait d'échapper à un grand danger, et la condamne seulement à l'exil sur la terre, auprès de son sauveur, pour y rester aussi longtemps que l'arbre n'aura pas vu le fruit.

\section{SCÈNE II MANÂVA, NIPOUNÎ.}

Dans le jardin du palais. On y voit entrer l'écuyer Manâva.

MANÂVA. - Comme chaque matin je viens ici pour recevoir les ordres de mon maître. Il n'y a pas eu de fête au palais. Et même 


\section{Trois drames de I'Asie}

il m'a défendu de rien dire sur ce qui nous est arrivé hier, dans la montagne. C'était pourtant un beau combat. Le monstre avait le corps d'un lion, les ailes d'un aigle et la tête d'un homme. Et la jeune fille qu'il tenait en ses griffes était blanche de peur. Quel beau récit on pourrait faire ! Quel dommage de s'en priver ! Quelqu'un vient. Ce n'est pas lui, c'est Nipounî, suivante de la reine et confidente de ses plus fidèles pensées. Que vient-elle faire ici ? Me questionner peut-être ? Ou plutôt me faire parler malgré moi, car c'est une fine mouche. Elle perdra son temps. J'aurai bouche cousue.

NIPOUNÎ. - Seigneur écuyer, je vous souhaite une heureuse journée.

(Manâva s'incline en silence.)

NIPOUNÎ. - Aussi heureuse que celle d'hier, ou davantage si possible. (Même jeu.) Vous ne répondez rien ? Vous vous inclinez en silence ? Avez-vous entendu, au début de la nuit, ce grand coup de tonnerre ? (Il fait signe que non) Vous faites signe que non. C'est donc que vous êtes sourd. (Même jeu.) Vous dites que vous n'êtes pas sourd ? Alors vous dormiez bien. Ce n'est pas comme votre maître. La reine m'a confié qu'il n'a presque pas fermé l'œil de la nuit. Cela n'a pas l'air de beaucoup vous surprendre ? Vers le matin cependant il s'était assoupi ; et je vais vous confier un secret, un grand secret ; vous me promettez, n'est-ce pas, de le garder, comme vous savez si bien faire quand vous voulez ? La reine ayant doucement posé la main sur son front il a murmuré, dans son rêve, un nom qui n'était pas celui de son épouse.

MANÂVA. - Ourvâsi ? Il a appelé la reine Ourvâsi ? 


\section{Trois drames de I'Asie}

NIPOUNÎ. - Comme vous dites. Et cette femme...

MANÂVA. - Ce n'est pas une femme, c'est une apsâra du ciel d'Indra descendue sur la terre, enlevée par un monstre, et nous l'avons sauvée. Le monstre avait le corps d'un lion, les ailes d'un aigle et la tête d'un homme. Et la jeune fille était blanche de peur.

NIPOUNÎ. - Voici ton maître. Je me sauve et te dis grand merci, car je sais maintenant ce que je voulais savoir.

(Elle s'en va.)

MANÂVA. - Je me suis laissé jouer comme un enfant.

(Vikrâma entre en scène.)

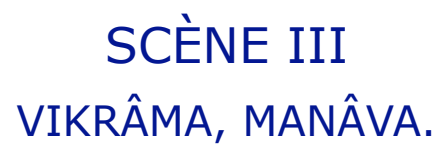

VIKRÂMA. - De quoi parlais-tu donc avec cette rusée ?

MANÂVA. - De rien, Seigneur. De I'orage de cette nuit, du beau temps qu'il va faire.

VIKRÂMA. - Et de nos aventures, tu n'as rien dit, au moins ?

MANÂVA. - Rien de plus que vous-même.

VIKRÂMA. - Alors je suis tranquille. Ecoute donc mes instructions pour la journée. Marchons un peu, la promenade du matin calme l'agitation des esprits que la nuit a troublés.

(Il le prend par le bras et ils quittent la scène. Ourvâsi presque aussitôt s'y glisse d'un pas timide, avec un geste d'adieu à une personne invisible.) 


\section{SCÈNE IV \\ OURVÂSI.}

OURVÂSI. - Merci, compatissante Nayâni, de m'avoir montré la route. Sans vous, je ne serais jamais arrivée. C'est le jardin de son palais, il va venir. Mais comment m'aventurer à lui adresser la parole sans être sûre de son cœur ? Sur cette feuille de palmier je vais écrire ce que je n'ose lui dire. (Elle détache une feuille de palmier et de la pointe du petit poignard passé à sa ceinture trace quelques lignes d'écriture.) Il revient. Je plie la feuille, la dépose sur ce banc, et me cache dans ce bosquet.

(Vikrâma revient seul, à pas lents.)

\section{SCÈNE $V$ \\ VIKRÂMA, OURVÂSI.}

VIKRÂMA. - Il est presque midi. Déjà alangui par la chaleur du jour, le paon descend dans le lac à demi desséché où vient s'abreuver comme un serpent solidifié la racine de l'arbre. L'abeille assoupie s'endort dans le calice du lotus, à l'ombre des pétales qui se referment. Au bord de l'eau le canard sauvage s'abrite parmi les joncs. Et le perroquet dans sa cage demande par ses cris qu'on lui apporte à boire. C'est I'heure de rentrer au palais où m'attend l'ombre et la fraîcheur. Je ne puis m'y résoudre. Il me semble être moins éloigné d'elle auprès des 


\section{Trois drames de I'Asie}

fleurs, et je vois tout au moins le ciel où elle réside, et dont le seuil d'azur nous sépare à jamais. Étendu sur ce banc, je veux contempler son séjour inaccessible et lui adresser ma prière. Tiens ! cette feuille de palmier n'y était pas tout à I'heure. Elle est pliée comme une missive. Je la prends et je lis ; ce sont des vers.

(Il s'assied sur le banc et lit.)

J'ai quitté la splendeur céleste où n'était pas mon ami.

Mais j'ai peur sur la terre : il ne me répond pas.

Faut-il plonger au fond des eaux ?

Faut-il interroger Yâma, roi des enfers ?

J'ai quitté la splendeur céleste... Quelle folle espérance ! Ourvâsi n'est pas revenue, elle ne peut revenir. Un jour ne s'est pas écoulé depuis qu'elle m'a quitté, et je me sens vieilli d'un siècle. Elle veut se jouer de moi. Ourvâsi, cruelle Ourvâsi, qui peut-être me regardez maintenant de votre lumineux séjour, observant mon chagrin, souriant de mes larmes, je vous demande en dernière faveur d'écouter ma réponse.

Si je savais où trouver mon amie, J'affronterais pour elle les génies de la terre et des eaux, Les monstres des enfers.

Mais pourquoi la chercher, quand son image est dans mon cœur?

(Ourvâsi sort du bosquet où elle s'était cachée et de ses mains clôt les yeux de Vikrâma.)

Oh ! que m'arrive-t-il ? Qui m'a fermé les yeux ?

Distrait, je contemplais les richesses de ce monde. Un instant de bonheur et tout s'est effacé ; Un éclair a jailli et j'ai perdu la vue.

Délivré de la terre je regarde en moi-même 


\section{Trois drames de l'Asie}

Le ciel de ma pensée, aveugle par amour.

Oh ! qui que vous soyez, ange, femme ou démon, ne les retirez pas, ces mains, ces petites mains, douces comme l'oiseau, fraîches comme les fleurs, mais dont aucune fleur n'a le parfum vivant et suave, ne les retirez pas encore, je vous en prie, car je crois les reconnaître, et si c'est un mensonge, je mourrai de l'apprendre.

OURVÂSI. - Non, vous pouvez rouvrir les yeux. Comment vous mentirais-je ?

VIKRÂMA. - Ourvâsi ! Vous êtes là ! Près de moi ! Sur la terre !

OURVÂSI. - Oui, je suis là, sur la terre, près de vous, et je vous dirai même que j'y suis en pénitence.

VIKRÂMA. - Je vous remercie d'être venue, même malgré vous. OURVÂSI. - Figurez-vous qu'hier soir, à la danse des mondes, j'ai commis une grosse faute. Au lieu du geste de l'adoration, comme ceci, voyez-vous (elle joint les mains), j'ai fait le signe du don de soi-même, comme cela (elle laisse pendre la main au bout du bras baissé). Il en est résulté un désordre terrible, le seigneur Indra était très en colère. Si vous aviez entendu ce coup de tonnerre !

VIKRÂMA. - Nous I'avons entendu jusqu'ici. A quoi pensiez-vous donc?

OURVÂSI. - A quoi je pensais ? C'est vous qui me demandez cela ? J'étais distraite, et vous n'en saurez pas davantage, monsieur le trop curieux. Toujours est-il que le seigneur Indra, après avoir ainsi déchargé sa colère, m'a punie parce qu'il le 


\section{Trois drames de I'Asie}

fallait, mais j'ai bien vu qu'il n'était plus fâché. Il m'envoie en exil sur cette terre.

VIKRÂMA. - En exil ici ! Seigneur du ciel, combien d'actions de grâces...

OURVÂSI. - Mais il y a encore une condition, une condition très dure, que je n'ose pas vous dire. Il le faut cependant. Je n'oserai jamais.

VIKRÂMA. - Vous me mettez à la torture.

OURVÂSI. C'est que le temps de mon exil, je le passe...

VIKRÂMA. - Où donc?

OURVÂSI. - Il ne faut pas vous fâcher. Il faut me dire bien franchement si cela vous convient, si vous pouvez et voulez accepter cela. Le temps de mon exil, je dois rester auprès de vous.

VIKRÂMA. - Et c'est là ce que vous ne vouliez pas me dire.

(Il l'attire à lui.)

OURVÂSI. - Non, ne m'embrassez pas, répondez-moi d'abord.

VIKRÂMA. - J'ai déjà répondu. Vous ne savez donc pas ? Vous n'avez pas compris?

OURVÂSI. - Je voulais être sûre. Mais si vous me gardez, vous ne me ferez jamais de peine ? C'est promis ?

VIKRÂMA. - Moi, faire de la peine à celle que j'adore !

OURVÂSI. - C'est que, voyez-vous, j'ai bien I'air maintenant d'une femme comme les autres. Et cependant je garde ma nature. Filles de la joie originelle, nous sommes faites pour vivre 


\section{Trois drames de I'Asie}

en un monde de lumière où ne subsistent plus que les sentiments purs. Mais ici je sens bien que l'air est vicié par les passions égoïstes. Si l'une d'elles nous atteint, dépit, soupçon, rancune ou jalousie, si légère que soit la morsure, le venin est mortel, notre forme se flétrit et la déchéance est si prompte, que nous ne pouvons même nous arrêter à l'existence humaine et sommes précipitées dans le troisième monde, celui de la vie animale ou végétale. Vous ne voudriez pas, n'est-ce pas, me voir changée en plante ou en bête ? Seule pourrait me sauver alors la Pierre ardente, c'est un talisman très puissant mais très rare.

VIKRÂMA. - Que parlez-vous de talisman ? C'est mon amour qui vous protège. Et nous n'aurons l'un par l'autre aucune peine, jusqu'au jour où vous me quitterez.

OURVÂSI. - Vous quitter, mon ami ?

VIKRÂMA. - Sans doute. L'arrêt qui vous condamne a bien fixé un terme à votre exil ?

OURVÂSI, embarrassée. - Un terme ? Oui, peut-être. Je n'ai pas bien compris. Mais pourquoi y penser ?

VIKRÂMA. - C'est pour combien d'années ?

OURVÂSI. - Le nombre des années n'a pas été fixé. Mais qui est cette belle dame qui vient à nous ? Que sa démarche est élégante ! Que son visage est noble et fier !

(La reine s'approche et tranquillement dévisage Ourvâsi.)

SCÈNE VI

Les mêmes, la Reine. 
LA REINE. - Alors c'est là votre nouvelle conquête ? Je vous en félicite, et vous avez fort sagement fait en la tirant des griffes du monstre, car elle a des grâces qui ne sont pas de cette terre, et I'on respire auprès d'elle le parfum du ciel. Ne craignez rien, mon cher époux, je connais mes devoirs de femme légitime et puis vous envier vos plaisirs, mais non pas vous les prendre. Je vous laisse maintenant à vos doux entretiens et suis sûre que nous deviendrons bonnes amies, quand vous n'aurez plus peur de moi, mademoiselle Ourvâsi.

(Elle se retire.)

OURVÂSI. - Elle sait déjà mon nom ! Vous lui avez tout raconté, pour qu'elle vienne se moquer de moi. Oh ! quelle peine affreuse ! Je ne puis respirer. Un froid de glace me monte au cœur. Une force inconnue m'attire vers la forêt. Adieu, mon prince, souvenez-vous...

(Elle disparaît.)

VIKRÂMA. - Ourvâsi ! Où est-elle ? Ourvâsi ! Ourvâsi ! Sans toi je ne puis vivre. Pour la deuxième fois je saurai te sauver. 


\title{
Trois drames de I'Asie
}

\author{
ACTE III \\ SCÈNE PREMIÈRE \\ VIKRÂMA. \\ Dans la forêt où Vikrâma s'est engagé \\ à la recherche d'Ourvâsi.
}

VIKRÂMA.

Est-ce le jour ? Est-ce la nuit ?

Jamais un rayon de soleil,

Les branches ferment le passage

Et le referment après moi.

Ma prison n'a pas de murailles

Mais une foule de gardiens

Qui sans me regarder m'observent

Et se taisent à mon approche.

Est-ce la vie ? Est-ce la mort ?

Les formes dans l'ombre s'effacent,

Le terrain cède sous mes pas,

Je ne sais plus le lieu ni l'heure,

Je ne sais plus trouver ma trace

Et interroge le silence,

Perdu dans la forêt profonde

A la recherche de mon amour.

Est-ce la mort ? Est-ce la vie?

Est-ce la nuit ? Est-ce le jour?

C'est bien vers la forêt qu'elle était attirée. Mais où la retrouver ? Comment la reconnaître ? Ourvâsi ! Ourvâsi ! céleste créature que j'ai sauvée, que j'ai perdue, ne m'entendez-vous pas ? Rien ne répond. On croirait que le silence à m'entendre se contracte et se resserre encore.

Pas à pas, les mains étendues, J'avance pareil à l'enfant 


\section{Trois drames de I'Asie}

Qui joue à trouver la cachette.

Elle me voit, elle m'écoute

Et je ne puis la découvrir.

Est-elle près ou loin d'ici ?

Fille du ciel, prenez pitié

Car je ne suis qu'un maladroit.

Il faut sortir de la cachette,

Il faut finir ce jeu cruel.

Il semble que le jour décline, car un souffle de brise a fait frémir l'épais feuillage, et les oiseaux que la chaleur tenait assoupis, la tête sous I'aile, se réveillent. Un merle siffle doucement. Un nid de mésanges gazouille. Le paon jette son cri de guerre. Bel oiseau qui te joues du cobra venimeux comme le chat de la souris, de la haute branche où tu es à l'affût peux-tu me dire si tu vois ma bien-aimée ? Il abaisse vers moi sa tête fine, faisant miroiter sur son cou les reflets de l'arc-en-ciel, et par trois fois, en cadence, il a battu des ailes. C'est un signal sans doute, mais comment le comprendre ? Malheur d'appartenir à la race des hommes, exclu de ce troisième monde où maintenant elle vit et respire. Une barrière infranchissable nous sépare.

A leur tour, les êtres qui sur le sol cheminent sortent de leurs refuges, ranimés par la fraîcheur. L'antilope furtive prend le sentier connu pour se désaltérer au creux où s'attarde encore un peu de l'eau des pluies.

Elle était comme toi légère et bondissante,

De grâce détournée

Toujours prête à s'enfuir,

Mais le regard plus doux encore.

$\mathrm{Si}$ le sort la fait vivre en ces lieux solitaires,

N'est-ce pas une de tes sœurs?

Dis-moi si tu l'as vue. 


\section{Trois drames de l'Asie}

L'antilope m'entend, elle s'arrête de boire et reste un instant étonnée, sans toucher l'eau des lèvres. Mais rassemblant ses jambes fines elle a rejoint d'un bond sa compagne qui l'attendait sur l'autre bord, et lui murmure en leur langue inconnue quelques mots à l'oreille. Toutes deux de côté me jettent un bref regard et s'enfoncent dans la forêt. Je ne sais rien encore.

Que me veulent ces fleurs ? Je ne les avais pas remarquées. On croirait qu'elles viennent d'éclore et toutes, tendant vers moi de tous côtés les branches qui les portent, fixement me regardent avec leurs frais visages. Est-ce pour $\mathrm{m}^{\prime}$ intriguer ? Serait-elle parmi vous ? Fleur tendre du jasmin, fleur frissonnante du manguier, fleur rougissante de l'açoka, fleur souriante du camélia, vous lui ressemblez toutes, est-elle parmi vous ? Je vais de l'une à l'autre, mais chacune, quand j'approche, laisse fléchir sa tige et confuse n'ose pas soutenir mon regard, faisant ainsi l'aveu qu'elle n'était pas assez belle pour recevoir celle que j'aime. Il faut aller plus loin encore. La forêt s'épaissit. Mais de ce côté passe un reste de jour. C'est la clairière ouverte comme un lac où le flot des herbes s'élève plus haut que la taille d'un homme. Penché en avant et les mains jointes au-dessus de ma tête comme la proue d'un navire, faisant le geste du plongeur, lentement je progresse et sépare sans bruit l'amas serré des tiges. C'est ici le séjour de l'éléphant sauvage. Chasseur inoffensif, je recherche sa trace et ne veux pas que de loin, m'ayant deviné, il m'évite. Je le vois. Il est seul. A l'ombre des grands arbres, loin du troupeau il médite en silence et rêve les yeux ouverts. Sans bouger plus que s'il fût taillé dans un bloc de pierre grise, il me regarde sans me voir et me laisse approcher. 
Souverain maître des forêts

Tu n'as pas d'ennemis sur terre,

Car devant toi tremble le tigre

Et se brise l'arbre géant.

Mais tu les laisses en repos,

Préférant à la crainte lâche

Le beau respect.

C'est pourquoi dans le ciel tu prêtes

Ton front et ton intelligence

Au dieu des sages, Ganéça.

Je ne t'apporte aucune offrande

Sinon la peine de mon cœur.

Que t'importe règne et couronne?

Tu es plus grand que prince et roi.

Je ne suis devant toi qu'un homme,

Mais tu voudras peut-être entendre

Un malheureux.

Il semble m'écouter. Que vois-je ? Non, je ne me trompe pas. Lentement, lentement il incline la tête, la tourne un peu, et reste ainsi. Est-ce un signe d'assentiment ? Un conseil qu'il me donne ? Une direction, peut-être, qu'il m'indique ? Je la suis et je trouve un hallier très obscur.

En ce repaire du sanglier,

Sur les pieds et les mains je me traîne,

Pareil à l'enfant abandonné,

Comme lui seul au monde.

Ce n'est pas un jouet que je cherche,

Ce n'est pas un trésor,

Mais celle qui pour m'abandonner

A fui dans l'autre monde.

La forêt pèse sur mes épaules, Mon front se heurte aux branches.

Je rampe sous le poids du remords,

L'angoisse étreint mon cœur.

Ce bonheur, fallait-il le maudire ?

Cet espoir, faut-il I'abandonner

De la voir en ce monde? 


\section{Trois drames de I'Asie}

Il me semble avoir vu une rouge lueur. Est-ce, traversant I'ombre, un des derniers rayons du soleil qui décline ? Un lambeau de chair vive, relief du repas du tigre ? Je m'approche, la lumière est plus vive. Une pierre qui brille, pareille à un rubis, mais ceux de cette terre ne jettent pas ces feux étincelants. Estce toi, Pierre ardente, talisman merveilleux, le seul qui puisse rompre l'enchantement fatal ? Je m'en empare et ses rayons luisent encore au travers de mes mains. Les ronces autour de moi s'écartent, laissant la place libre au tronc de ce jeune arbre qui d'un seul jet s'élance, lisse et droit, jusqu'au ciel. Une liane I'entoure. Que la feuille en est tendre ! Jetée autour de lui, elle infléchit ses rameaux comme des bras craintifs qui ne veulent pas lâcher prise, et sa tige se plie, flexible et confiante comme une jeune fille qui avoue sa faiblesse. Elle n'a pas de fleurs, mais à l'aisselle de chaque feuille un bouton rose pointe, promesse virginale. Aucune femme n'eut jamais une grâce si pure, aucune, si ce n'est celle que j'ai perdue. Tremblante de chagrin, de peur et d'espérance, liane languissante, liane caressante, je voudrais te saisir, parce que tu lui ressembles et je croirais alors la tenir encore entre mes bras. Mais je n'ose, parce que tu es trop délicate et ma main est trop rude. Cependant une force invincible m'attire. Non, ne crains rien, liane, je ne te touche pas. Vois, mes mains se rejoignent au delà de toi-même et tu n'as rien senti. Je veux t'envelopper, te garder, te défendre. Mais que m'arrive-t-il ? Est-ce un rêve ? Arbre et liane ont disparu. Ourvâsi dans mes bras. Ses yeux sont clos. Elle respire. 


\section{Trois drames de I'Asie}

VIKRÂMA, OURVÂSI.

OURVÂSI, comme en rêve. - Trouvera-t-il la route ? VIKRÂMA. Je l'ai trouvée. Je suis là.

OURVÂSI. - Je ne puis pas bouger. Comment lui dire ?

VIKRÂMA. - Comme elle est pâle et froide.

OURVÂSI. - Le talisman. La Pierre ardente.

VIKRÂMA. - J'approche de son front la Pierre ardente. Sous sa rouge clarté les couleurs lui reviennent. Elle rouvre les yeux. Elle s'éveille. Ourvâsi !

OURVÂSI. - Comme tu as tardé ! Quel lourd sommeil ! Non, laisse, laisse-moi te regarder d'abord.

VIKRÂMA. - Tu te souvenais toujours ?

OURVÂSI. - Ma seule conscience était ce souvenir.

VIKRÂMA. - Un jour de plus et j'étais mort.

OURVÂSI. - Pardonne-moi !

VIKRÂMA. - Pardonne-moi !

OURVÂSI. - Ecoute. Tous les oiseaux de la forêt, réunis à la cime des arbres, ont fait ensemble, avant la nuit, leur prière au soleil. Quand le dernier rayon a disparu, le concert de leurs voix jetées en adieux jusqu'au plus haut des airs s'est tu subitement. VIKRÂMA. - C'est pour que mieux je puisse entendre ta voix douce et contenue comme le murmure du ruisseau. 


\section{Trois drames de I'Asie}

OURVÂSI. - C'est en une telle solitude que le divin Krishna au temps jadis a rencontré Râdha, son amoureuse. Elle était prosternée devant lui, qui la main étendue sur sa tête inclinée la bénissait et l'attirait à lui.

VIKRÂMA. - Mais elle n'était pas une fille du ciel.

OURVÂSI. - C'était une bergère, mais la force de son amour a consumé tout ce qui demeurait en sa nature humaine de grossier et d'impur. C'est ainsi qu'elle s'est brûlée vive sur l'autel de son maître et qu'elle est devenue dans le monde céleste la compagne du dieu.

VIKRÂMA. - Puissé-je mériter par un tel sacrifice... OURVÂSI. Il ne faut pas de sacrifice, mon ami. Il ne faut rien qu'un grand amour.

VIKRÂMA. - Sais-tu maintenant combien je t'aime ?

OURVÂSI. - Tu as trouvé le talisman ? Montre ! La belle pierre !

VIKRÂMA. Je I'ajoute aux colliers, je l'ajoute aux joyaux. Penche la tête ! Toi seule es digne d'en être parée. Elle brille au milieu des diamants et des perles, éclairant doucement la forme de ton corps.

OURVÂSI. - Elle ne me quittera plus.

VIKRÂMA. - Et tu ne me quitteras plus ?

OURVÂSI. - La pierre ardente nous protège.

VIKRÂMA, - Il est temps de rentrer au palais pour la nuit.

OURVÂSI. - Je ne rentrerai pas au palais pour la nuit.

VIKRÂMA. - Te dire adieu déjà ? 


\section{Trois drames de I'Asie}

OURVÂSI. - Je veux rester ici, à vous attendre.

VIKRÂMA. - Ici, dans la forêt ?

OURVÂSI. - Croyez-vous que j'aie peur ? Les êtres du troisième monde sont mes frères et mes sœurs, ils ne me feront aucun mal. Je n'ai peur que des hommes.

VIKRÂMA. - Ce n'était rien pourtant, qu'un bavardage de valets. OURVÂSI. - Et des femmes plus encore. Excusez-moi, seigneur, de vous parler ainsi, et croyez bien que rien dans ma pensée n'offense une personne à qui je dois l'obéissance et le respect. C'est une belle et noble épouse. Sa bonté m'est connue. Mais je ne veux pas la mettre à l'épreuve. Auprès d'elle, le souffle me manque.

VIKRÂMA. - Je vais donc tout quitter pour passer près de vous le reste de mes jours. Avec joie je renonce au fardeau des richesses, aux actions inutiles, aux conseils superflus, aux entretiens frivoles, aux amitiés menteuses, au pouvoir sur les hommes.

OURVÂSI. - Il ne faut pas y renoncer. Comme le soldat à son poste vous devez garder votre rang et rester sous les armes, sans devancer l'appel du destin.

VIKRÂMA. - Ne plus vous voir !

OURVÂSI. - Vous me verrez toujours, et la tâche accomplie viendrez retrouver, le cœur libre, celle qui retirée en la forêt sauvage y sera demeurée tout le jour en prières pour notre bonheur, anachorète de l'amour.

VIKRÂMA. - Vous serez seule. 


\section{Trois drames de I'Asie}

OURVÂSI. - Donc sans trouble et sans crainte.

VIKRÂMA. - Nous sommes seuls tous deux. Indicible bonheur. OURVÂSI.

Le soir aux reflets verts s'immobilise dans l'attente, Et le parfum des fleurs en pluie invisible retombe. Pas une feuille ne bouge, elles écoutent le ciel. Sentant la nuit venir, la terre a mis son voile blanc Où va, sans le rompre, danser le rayon de la lune.

VIKRÂMA. - La brume monte et je discerne à peine ton visage.

OURVÂSI. - Mais les yeux que l'amour éclaire ont reconnu le bien-aimé.

VIKRÂMA. - La lune à pas comptés parcourt le ciel, le front penché.

OURVÂSI. - Moissonneuse qui recueille à pleins bras les gerbes du silence.

VIKRÂMA. - Tout se tait maintenant.

OURVÂSI. - C'est I'instant de prêter l'oreille.

VIKRÂMA. - Le silence est profond.

OURVÂSI. - Mais il faut écouter par delà le silence.

VIKRÂMA. - J'écoute, et crois entendre, mais sans entendre, un chant qui n'est pas un chant, des accords dans l'espace ou au fond de mon cœur.

OURVÂSI. - C'est la musique des gandharvas, musiciens célestes. Elle vient jusqu'à toi, parce que tu as le cœur pur. Dans le séjour d'Indra c'est I'heure du concert et des danses du soir. 


\section{Trois drames de I'Asie}

J'écoute et me souviens. Mais maintenant c'est vous qui êtes mon seigneur et mon maître. Prenez place, et voyez. Dans la clairière de la forêt, sous la clarté du ciel où est réunie I'assemblée des dieux, aux sons de I'harmonie qui traduit leur pensée et gouverne les mondes, je vais danser pour vous la danse des étoiles. 


\section{ACTE IV}

\section{SCÈNE UNIQUE \\ OURVÂSI, NAYÂNI.}

Le quatrième acte se passe environ une année plus tard, au même lieu de la forêt. Une cabane y a été bâtie avec des troncs d'arbres, couverte en feuilles de palmier. C'est là que réside maintenant Ourvâsi.

OURVÂSI. - Vous regardez mon ermitage ? C'est lui qui me l'a édifié de ses mains, faisant œuvre de bûcheron, de charpentier et de couvreur et sans le secours de personne, afin que le secret soit gardé. Il se méfie maintenant des bavards.

NAYÂNI. - La voûte du ciel suffisait, et I'ombre des feuillages.

OURVÂSI. - Je n'ai pas voulu l'empêcher, tant il prenait plaisir à travailler pour moi. C'est lui qui avait raison. Maintenant qu'il est loin, tout me parle de lui, les poutres et la table, le toit qui me protège, le lit où je repose. Chacun de ces objets figure auprès de moi sa constante pensée, m'entoure et m'enveloppe de sa sollicitude.

NAYÂNI. - Il ne sait rien encore ?

OURVÂSI. - Je ne lui ai rien fait savoir.

NAYÂNI. - Pourtant vous lui envoyez chaque jour un message par l'oiseau voyageur.

OURVÂSI. - J'ai craint d'amollir son courage. Il ne faut pas qu'un chef d'armée pense trop au foyer.

NAYÂNI. - Pourtant vous voulez bien qu'il pense à vous. 


\section{Trois drames de l'Asie}

OURVÂSI. - Ce n'est pas l'épouse qui fait le foyer, c'est l'enfant. NAYÂNI. - C'est vrai chez les humains, je l'avais oublié.

OURVÂSI. - Surtout s'il est unique.

NAYÂNI. - Unique en effet. La reine ne lui a pas donné d'héritier. Il saura désormais à qui léguer l'autel des sacrifices, l'œuvre à continuer, la charge du pouvoir, et ce qui pour les êtres du deuxième monde est plus précieux encore, le souvenir que garde un fils reconnaissant au père qui l'a instruit, à la mère qui I'a nourri. Quelle sera sa joie !

OURVÂSI. - Plus bas ! Je crois que l'enfant dort. Approchezvous, tout doucement.

NAYÂNI. - Il a le front bombé, les épaules carrées et les poings fermés, comme prêt à la lutte. Il s'éveille et son regard s'arrête sur nous. Est-ce qu'il nous voit ? Il a l'air de nous interroger.

OURVÂSI. - Il est toujours ainsi, comme étonné de se trouver en ce monde.

NAYÂNI. - Il ne pleure jamais ?

OURVÂSI. - Il ne pleure jamais, et jamais ne sourit. Tant de sérieux et de gravité chez un si petit enfant.

NAYÂNI. - N'est-ce pas l'âge où l'existence entière pèse d'un bloc sur l'âme inerte, avant de s'effeuiller jour après jour et de se morceler en volontés et en désirs ? Le destin qui l'attend est lourd et redoutable, puisque c'est celui d'un fils de roi.

OURVÂSI. - Croyez-vous qu'il va bientôt revenir ? 


\section{Trois drames de I'Asie}

NAYÂNI. - C'est la bonne nouvelle que je venais vous annoncer, avant que vos moyens terrestres aient pu vous l'apprendre. La ville capitale des ennemis est prise, et ils ont fait leur soumission.

OURVÂSI. - Il va rentrer, victorieux ! Chacun, pour son triomphe, tressera des couronnes, et moi, quand il viendra, je m'avancerai, et comme le fidèle va porter à son dieu l'offrande, je lui présenterai, sur mes mains jointes, notre enfant. Il sourira de la surprise et me dira merci.

NAYÂNI. - Et vous remonterez au ciel, où vous serez la bienvenue. Combien vous nous avez manqué depuis votre départ! Mais tout est oublié maintenant. Le seigneur Indra m'a priée de vous dire qu'il vous juge assez punie pour cette inadvertance et ne garde en son cœur aucune trace de la sévérité qu'il a dû montrer contre vous. Les régents des huit directions de l'espace sont à leur poste et vous attendent. Les musiciens célestes préparent pour vous recevoir le plus beau de leurs concerts.

OURVÂSI. - Il faut que je quitte la terre ?

NAYÂNI. - Votre exil se termine.

OURVÂSI. - Je ne le savais pas.

NAYÂNI. - Tel était cependant le texte de l'arrêt. L'avez-vous oublié ? Votre peine doit durer aussi longtemps que l'arbre n'a pas vu le fruit.

OURVÂSI. - Aussi longtemps que l'arbre n'a pas vu le fruit ? O sotte que j'étais ! Je n'avais pas compris et je n'y pensais plus. 


\section{Trois drames de I'Asie}

NAYÂNI. - C'est cependant bien clair. Le roi voit l'enfant, le garde auprès de lui, rien ne vous retient plus, vous regagnez, légère et la tâche accomplie, notre monde de lumière.

OURVÂSI. - Le laisser là !

NAYÂNI. - Que voulez-vous dire ?

OURVÂSI. - Vous ne pouvez pas me comprendre, vous ne savez pas ce que c'est que d'aimer un mortel. Rivé pour toute son existence terrestre à la chaîne des causes, condamné à l'action qui use la pensée, exposé aux dangers du monde matériel, guetté à tout instant par les passions mauvaises, il n'est pas un instant qu'il ne craigne de perdre, tant sa condition est précaire, et tant d'angoisse se mêle au délice d'amour qu'on en devient insatiable, comme d'un poison qui égare l'esprit. Si vous saviez combien est douce une tendresse menacée, combien le cœur s'attache au sentiment qui le déchire!

NAYÂNI. - Ce sont les pièges de la condition terrestre. Ils perdront leur pouvoir et vous resterez stupéfaite d'avoir pu, même un instant, vous y laisser prendre.

OURVÂSI. - Ce roi glorieux, ce guerrier redoutable, ce chef puissant et sage, je console son chagrin, j'apaise son inquiétude, j'essuie la sueur de son front, je le tiens dans mes bras comme un enfant qui pleure. L'autre, c'est notre enfant, mais lui, c'est mon enfant à moi seule, qui ne connaît que moi. Comment l'abandonner?

NAYÂNI. - Il le faudra, un jour ou l'autre.

OURVÂSI. - Pas encore ! 


\section{Trois drames de l'Asie}

NAYÂNI. - Et qu'importe qu'un jour ou cent années se passent ?

Tout ce qui doit périr est mort dès sa naissance, vous le savez bien.

OURVÂSI. - Pas encore !

NAYÂNI. - Vous voilà devenue créature terrestre, engagée dans l'action, vouée à la personne et victime de l'illusion du temps.

OURVÂSI. - Peu importe ce que je suis. Je ne sais qu'une chose. Je ne dois pas le quitter encore, parce qu'il serait trop malheureux. Il faut lui cacher cet enfant.

NAYÂNI. - Ici, c'est impossible.

OURVÂSI. - Il faut l'emmener loin d'ici.

NAYÂNI. - C'est lui que vous ne verrez plus.

OURVÂSI. - Je serai seule à en souffrir. Nayâni, vous avez toujours été pour moi de bon conseil et malgré mes caprices vous étiez près de moi comme une grande sœur. Dites-moi ce qu'il faut faire. Aidez-moi ! Sauvez-moi !

NAYÂNI. - Je connais, loin d'ici, un pieux brahmane et son épouse, retirés de ce monde, passant leurs jours dans la prière et l'étude. Un fils leur était venu, après bien des années de mariage, presque au même jour que celui-ci, mais il n'était pas assez solidement accroché à l'existence terrestre et un souffle a suffi pour l'emporter. Dans leur affliction profonde volontiers ils accepteraient un enfant adoptif et lui donneraient tous les soins qu'ils réservaient à l'autre. Je vous dirai leurs noms...

OURVÂSI. - Ne me dites rien ! Je ne veux rien savoir. 


\section{Trois drames de I'Asie}

NAYÂNI. - Cependant...

OURVÂSI. - J'aurais trop à combattre I'envie de le revoir.

NAYÂNI. - Alors vous me le confiez ?

OURVÂSI. - Je crois qu'il s'est rendormi. Laissez-moi le bercer une dernière fois.

Dors, mon enfant, dors, mon roi.

Sans bouger je te regarde

De peur qu'une larme

Ne tombe sur toi.

Dors, mon enfant, dors, mon bien.

Puisse ton séjour sur terre

N'être qu'un beau rêve

Moins bref que le mien.

Dors, mon fils, pardonne-moi.

Tu seras loin de ta mère

Plus heureux peut-être

Que le fils d'un roi.

Ne le réveillez pas !

NAYÂNI. - Je serai bientôt arrivée.

OURVÂSI. - Prenez bien garde à lui. Elle est partie. Mon seigneur peut venir. Désormais je suis seule, seule au monde pour lui. 


\section{ACTE V}

Le cinquième acte se passe douze années plus tard et très loin de là, dans une autre forêt, au bord d'un grand fleuve.

\section{SCÈNE PREMIÈRE}

Le Brahmane.

Une chaumière dans la forêt. Devant la porte, un vieux brahmane est seul, assis dans l'attitude de la méditation, un livre dans les mains.

LE BRAHMANE, lisant.

« L'homme qui connaît Dieu et met en lui sa confiance ne doit ni se réjouir de la prospérité, ni s'affliger de l'adversité.

Les plaisirs apportés par les sens auront pour fruit inévitable la peine qui doit venir. Le sage qui connaît le commencement et la fin des choses n'y prend aucune joie.

Celui qui peut s'opposer à la violence du désir et de la colère, en cette existence terrestre recueille le plein bonheur.

L'homme qui possède le plein bonheur reçoit la lumière en son cœur et participe à la nature incorruptible de I'Etre suprême.

\section{SCÈNE II}

Le Brahmane, la Brahmanî. 


\section{Trois drames de I'Asie}

(La Brahmanî paraît sur la porte et
l'appelle.)

LA BRAHMANÎ. - Mon seigneur et mon maître, pardonnez à votre humble servante si elle ose interrompre votre pieuse lecture. Ayous n'est pas là ?

LE BRAHMANE. - Il n'est pas là.

LA BRAHMANÎ. - Je croyais qu'il devait écouter la leçon du saint livre.

LE BRAHMANE. - Il ne l'écoutait plus. Je I'ai laissé partir.

LA BRAHMANÎ. - C'est notre enfant, nous sommes responsables de son éducation.

LE BRAHMANE. - Notre enfant, oui vraiment, et il nous est aussi cher que si nous lui avions donné l'existence terrestre, puisqu'il a pris auprès de nous la place de celui que nous avons perdu. Et je n'ai rien oublié de ce que j'ai promis jadis à la jeune fille inconnue qui nous l'a confié. Vous l'avez nourri comme une mère, je l'ai instruit comme un père. Mais il doit suivre sa nature.

LA BRAHMANÎ. - Il ne pourra prier s'il n'étudie la religion.

LE BRAHMANE. - Prier, c'est agir encore. Aucune action par ellemême n'est bonne ni mauvaise, nécessaire ou bien inutile. Toute valeur est dans la pensée.

LA BRAHMANÎ. - Je suis inquiète. Ce matin, pendant qu'il dormait encore, j'ai voulu regarder ses vêtements, et savez-vous ce que j'ai trouvé, caché sous les étoffes ? 


\section{Trois drames de I'Asie}

LE BRAHMANE. - Un arc avec des flèches. Il a passé la journée d'hier, dans la forêt, à choisir la branche, la courber, ajuster la corde, durcir au feu les pointes.

LA BRAHMANÎ. - Comment le savez-vous ?

LE BRAHMANE. - Et aujourd'hui, profitant du moment où vous alliez remplir le seau à la rivière, il s'est glissé dans la maison, a pris son arc et il est parti.

LA BRAHMANÎ. - Sous vos yeux.

LE BRAHMANE. - Non, derrière mon dos. Il m'avait demandé poliment la permission de faire un tour de promenade, et

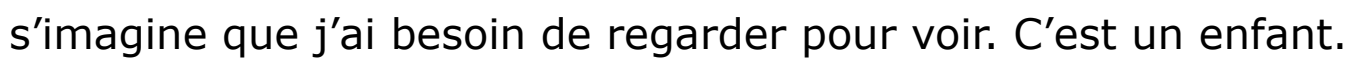

LA BRAHMANÎ. - S'il allait rencontrer une bête féroce.

LE BRAHMANE. - II n'a pas peur.

LA BRAHMANÎ. - Mais il n'a que douze ans.

LE BRAHMANE. - Mais voyez comme il est fort et brave pour son âge.

LA BRAHMANÎ. - Et s'il allait causer la mort d'un être, verser le sang d'une créature?

LE BRAHMANE. - Il sortirait de notre caste et voilà tout.

LA BRAHMANÎ. - Et voilà tout ! Vous en parlez bien légèrement.

LE BRAHMANE. - Autrefois le roi Vardjouna, parvenu dans la plaine de Koutouxétra, pour livrer la bataille qui devait décider du sort de son empire, fit conduire son char entre les deux armées, et ne voyant, de part et d'autre, que des parents et des frères, il fut pris de désespoir et dit à Krishna, conducteur de son 


\section{Trois drames de I'Asie}

char : «Quand je vois, impatients de combattre, mes parents et mes frères, mon cœur se trouble et mes membres fléchissent, mes cheveux se hérissent et tout mon corps frissonne d'horreur. Mon entendement est confondu par les obligations terribles que m'impose mon devoir, et je ne vois rien qui puisse calmer ma douleur, quand même j'obtiendrais l'empire de la terre et le commandement des armées du ciel. » Mais Krishna répondit : «Sur le champ de bataille, d'où te vient cette faiblesse folle et indigne d'un homme ? Elle est honteuse, contraire au devoir du soldat et te conduit au déshonneur. Tous les corps sont périssables et le sage ne s'afflige jamais, pour les vivants ni pour les morts. C'est la sensibilité de nos organes qui nous procure ces impressions changeantes ; il faut s'en rendre maître. Que le plaisir et la douleur, le gain et la perte, la victoire et la défaite, la vie et la mort te laissent indifférent et ainsi tu seras prêt pour la lutte, la raison libre et le cœur intrépide. Pour un homme de la caste des Xatrias le premier devoir est de combattre. »

LA BRAHMANÎ. - Il est vrai que nous ne savons pas qui est le père de cet enfant.

LE BRAHMANE. - Mais nous savons qu'il a le corps robuste, le regard fier, un courage précoce et que dans nos livres sacrés ce qu'il préfère à tout le reste, ce sont les beaux combats.

LA BRAHMANÎ. - Vous croyez donc qu'il appartient à la caste guerrière, que c'est un Xatria ?

LE BRAHMANE. - Sinon par la naissance, du moins par tous les traits de son visage et de son caractère. Et parmi les guerriers, il faut qu'il soit un chef. N'avez-vous pas observé la décision de 


\section{Trois drames de l'Asie}

son esprit, son air de commandement ? Le jour où il pourra quitter notre solitude pour vivre parmi les hommes vous verrez son glorieux destin.

LA BRAHMANÎ. - Hélas ! il faudra donc nous séparer de lui ?

LE BRAHMANE. - Vous n'êtes pas la première qui ait dû l'éloigner d'elle.

LA BRAHMANÎ. - Mais l'autre n'avait pas eu le temps de le connaître.

LE BRAHMANE. - Ni la joie, comme vous, de le voir grandir.

LA BRAHMANÎ. - Où est-il maintenant ? J'ai peur.

LE BRAHMANE. - Vous n'avez rien à craindre. C'est un enfant heureux. Aussitôt qu'il paraît le jour semble plus clair. Son sourire répand la joie dans nos cœurs. On croirait qu'il nous vient d'un monde de lumière.

LA BRAHMANÎ. - Que je voudrais savoir le secret de sa naissance!

LE BRAHMANE. - Mais le jour où vous l'apprendrez ne sera-t-il pas celui de l'adieu ?

LA BRAHMANÎ. - Il devrait être de retour.

LE BRAHMANE. - Il reviendra. C'est I'heure d'adresser au Maître du monde notre prière.

«Tu es le père de toutes choses animées et inanimées. Tu es le très sage instructeur du monde qui t'adore. »

LA BRAHMANÎ. «Je me prosterne et j'implore ta miséricorde, ô Seigneur ! 


\section{Trois drames de I'Asie}

»Car tu peux me pardonner comme le père pardonne au fils, I'ami à I'ami, I'amant à sa bien-aimée. »

\section{SCÈNE III \\ VIKRÂMA, OURVÂSI.}

A quelque distance de là, sur la berge du fleuve qui est un fleuve sacré. Vikrâma et Ourvâsi viennent de s'y plonger, gardant, selon l'usage indien, leurs pagnes de mousseline, que sécheront bientôt les rayons du soleil. Ils sont assis l'un près de l'autre sur la rive.

VIKRÂMA. - Ourvâsi, vois ce fleuve qui sans arrêt s'écoule et cependant reste le même.

OURVÂSI. - C'est ainsi que s'écoulent les instants de la vie dans le fleuve d'amour.

VIKRÂMA. - Il a lavé nos corps des souillures terrestres et cependant reste limpide.

OURVÂSI. - Et nous avons été purifiés de même en plongeant chaque jour au flot incorruptible qui a sa source dans nos cœurs. VIKRÂMA. - Chaque soir je venais à toi, alourdi et flétri par les soucis du jour. Il m'avait fallu discuter, délibérer, décider et juger. Les uns me résistaient, les autres me flattaient, d'autres encore imploraient mon aide et mon secours. Tous laissaient en mon esprit la trace et la marque de leurs pensées. Tu étais là, qui m'attendais. D'un long regard tu m'enveloppais et je croyais entrer dans un bain de lumière. Tu posais tes mains sur mon front et toutes ces impuretés se détachaient aussitôt, dissoutes et évaporées comme le limon dans le torrent, comme la 


\section{Trois drames de I'Asie}

poussière que balaie le vent du sud. Tout était éclairci parce que tu me rendais à moi-même, ou plutôt à nous deux, prenant vie I'un par l'autre.

OURVÂSI. - Au long de la journée, séparée de toi, ma pensée errait comme le nuage dans le ciel qui ne sait où se poser, comme la barque sur les flots dont l'amarre est rompue. Mais le nuage au soir rencontrait la montagne et se résolvait en pluie bienfaisante. La barque reprenait sa course droite et prompte, ayant retrouvé son rameur.

VIKRÂMA. - Te souvient-il du premier jour?

OURVÂSI. - Oui, j'étais bien troublée.

VIKRÂMA. - Tu n'osais pas me dire que tu resterais près de moi. OURVÂSI. - Parce que je le désirais.

VIKRÂMA. - Sais-tu que depuis lors treize années ont passé !

OURVÂSI. - Peut-être. Me trouves-tu changée ?

VIKRÂMA. - Certainement, je te trouve changée. Et cela ne date pas d'hier. C'était la première année, lorsque je suis, tu te rappelles, revenu de la guerre. D'un bond tu étais venue te jeter dans mes bras, rieuse et caressante, petite amie qui veut être embrassée, enlevée, emportée, et tout à coup, baissant la tête et comme un peu confuse, tu ne m'offrais plus que ton front.

OURVÂSI. - Tu as remarqué cela ?

VIKRÂMA. - Ce n'était qu'un instant. Mais souvent, depuis lors, j'ai vu passer une ombre en ton regard qui devenait ainsi plus sérieux et plus tendre. Je m'approchais et elle se dissipait 


\section{Trois drames de I'Asie}

aussitôt, chassée par un éclair de joie. Tu retrouvais alors ta grâce aussi légère qu'un rayon de soleil, comme le premier jour.

OURVÂSI. - Comment me préférais-tu ?

VIKRÂMA. - Autrefois Gôpala Krishna, en son séjour sur terre, eut pour amies les deux filles de Nanda, qui s'appelaient Sarasvâti et Nisdâli. Toutes deux étaient auprès de lui, et la première jetait les bras autour de son cou en faisant sonner ses bracelets, pendant que l'autre, pensive, le contemplait. Il leur dit : «Tu es belle, Sarasvâti, toi dont les lèvres ont le parfum de l'ambre et de toutes les fleurs ; tu es belle, Nisdâli, toi dont les paupières voilent les yeux profonds et qui sais regarder en toimême. Toutes deux je vous aime et ne puis décider entre vous. »Plus heureux que lui, je trouve unies en toi Sarasvâti et Nisdâli, et encore bien d'autres, toutes les femmes de la terre, les douces, les audacieuses, les craintives, les ardentes, les langoureuses, les triomphantes, et, au-dessus d'elles toutes, celle qui n'est pas de ce monde et m'apporte la lumière du ciel.

OURVÂSI. - Et moi, mon ami, je ne trouve en toi que toi-même, et que m'importent auprès de toi les hommes et les dieux ?

VIKRÂMA. - Sais-tu pourquoi j'ai fait atteler mon char et t'ai prise avec moi ?

OURVÂSI. - Parce que tu savais que j'en serais heureuse. Est-il besoin d'un autre motif ?

VIKRÂMA. - Pourquoi nous avons fait un si lointain voyage et nous sommes baignés dans le fleuve sacré ? 


\section{Trois drames de l'Asie}

OURVÂSI. - Pour que notre prière ensuite soit agréable aux dieux.

VIKRÂMA. - Oui, j'ai dit en effet que j'allais porter mes offrandes au grand temple qui s'élève non loin d'ici, afin de rendre grâces pour la prospérité de mon royaume. Mais je n'ai pas tout dit. Je viens ici pour m'engager par un vœu secret et solennel, mais il faut que tu consentes à le formuler avec moi.

OURVÂSI. - J'y consens et demande que ton vœu, quel qu'il soit, s'accomplisse.

VIKRÂMA. - Écoute-moi. Te souviens-tu de tes paroles, quand je t'ai retrouvée, changée en liane, dans notre forêt ? Je voulais sans tarder me retirer du monde pour rester près de toi mais tu m'en as empêché, parce que les devoirs de ma charge m'y retenaient encore. «Comme le soldat à son poste, me disais-tu, il faut garder son rang et rester sous les armes, sans devancer I'appel du destin. » Je suis resté, mais aujourd'hui il me semble que mon combat terrestre est terminé. J'ai étendu jusqu'aux deux mers les bornes de mon empire, les peuples réunis sous mon autorité vivent en paix, et j'ai obtenu la faveur de rencontrer des ministres fidèles, qui savent écouter les plaintes et rendre la justice. N'ai-je pas mérité mon repos comme le bon ouvrier qui a fait sa journée ?

OURVÂSI. - Vous ne voulez plus être roi ?

VIKRÂMA. - Je veux pour le temps qui me reste à vivre n'être plus qu'un homme, seul avec ses pensées, seul avec son amour. OURVÂSI. - Vous seriez toujours près de moi. Quel rêve ! 


\section{Trois drames de I'Asie}

VIKRÂMA. - Tous les liens se détachent, toutes les chaînes tombent. Une seule me tient encore. Qui va me succéder ? Je n'ai pas d'héritier. De grands désordres sont à craindre et des compétitions redoutables. Le peuple en souffrirait et ce serait par ma faute.

OURVÂSI. - Alors, vous gardez le pouvoir.

VIKRÂMA. - Pour l'instant, mais je fais vœu de me retirer avec vous dans la solitude, voués à la méditation, servant et priant Dieu, si la faveur m'est accordée d'avoir un fils qui devienne après moi souverain légitime.

OURVÂSI. - Un fils ! Vous demandez un fils !

VIKRÂMA. - Et vous comprenez maintenant pourquoi vous deviez être associée à mon vœu.

OURVÂSI. - Non, je ne comprends pas, je ne veux pas comprendre. Ne souhaitez pas cela. Prenez plutôt une autre femme !

VIKRÂMA. - Que proposez-vous là ! Pauvre enfant, elle a peur. Mais vous avez promis et vous verrez ensuite quel sera notre bonheur.

OURVÂSI. - Notre bonheur !

VIKRÂMA. - Vous frissonnez. Venez, le soleil est moins vif, il est temps de partir.

SCÈNE IV

MANÂVA. 


\section{Trois drames de I'Asie}

(A peu de distance, dans une clairière de la forêt, Manâva cherche de tous côtés un objet perdu. Il s'adresse au public.)

MANÂVA. - Où ai-je pu la mettre ? Quel étourdi je fais ! Vous me voyez bien embarrassé. J'ai conduit jusqu'ici, sur notre char rapide, Son Altesse royale avec la princesse Ourvâsi. La voiture est restée à la lisière de la forêt. Nous avons poursuivi à pied. Ils sont allés, par delà ces arbres, prendre le bain rituel dans le fleuve sacré et de peur de le perdre m'ont confié un bijou auquel ils tiennent beaucoup. Et maintenant c'est moi qui l'ai perdu. Obligé de m'absenter un moment, vous n'auriez pas voulu que je le garde avec moi. Il n'y a pas de quoi rire. Je vous assure que c'est très grave. Si je ne le retrouve pas, qu'est-ce qu'ils vont dire ! C'est un gros rubis qu'ils appellent la Pierre ardente. L'ai-je caché sous cette pierre ? Ou bien dans le creux de cet arbre ? Ah ! je le vois, qui brille là-bas, posé tout simplement sur un quartier de roc. Comment ne l'ai-je pas aperçu plus tôt ? Misère de ma vie ! Un faucon l'a vu avant moi ! Il l'a pris pour un morceau de chair. Il s'abat ; il I'enlève. Je peux toujours courir. Mon arc et mon carquois sont restés dans la voiture. Maudit oiseau ! Il s'élève en tournoyant et la chaîne d'or qui pend à son bec trace des anneaux de feu. Mais que lui arrive-t-il ? Voilà qu'il tombe tout d'un coup, battant des ailes. Une flèche I'a frappé. Qui donc l'a tirée ? Je le ramasse et reprends mon bien.

\section{SCÈNE V}

MANÂVA, AYOUS, puis le Brahmane et la Brahmanî.

(Un jeune garçon accourt, l'arc à l'épaule.) 


\section{Trois drames de I'Asie}

AYOUS. - Monsieur, je vous demande pardon. C'est ma flèche. Cet oiseau m'appartient.

MANÂVA. - L'oiseau peut-être, mais non pas le joyau qu'il nous avait volé.

AYOUS. - Il faudrait le prouver.

MANÂVA. - Mon cher petit ami, depuis quand as-tu cessé d'être nourri de lait?

AYOUS. - Longtemps avant que vous ayez appris la politesse.

MANÂVA. - Je te casserai les os et les jetterai dans la mer.

AYOUS. - Je n'en crois rien.

MANÂVA. - Je te briserai les dents et te les ferai rentrer dans la gorge, que tu ne puisses plus dire des insolences.

(La Brahmanî entre en scène, éperdue, suivie du Brahmane, plus calme.)

LA BRAHMÂNI. - Ayous! Mon petit Ayous! Tu étais là ! Nous te cherchons depuis des heures.

MANÂVA. - C'est votre enfant, madame ? Il faut croire qu'il oublie quelquefois l'excellente éducation que vous lui avez donnée. Depuis que j'ai eu le plaisir de faire sa connaissance, il n'a cessé de m'abreuver d'injures.

LE BRAHMANE. - Vous êtes sûr ?

MANÂVA. - Oh ! pardon, seigneur brahmane, je ne vous avais pas aperçu. Et tous mes compliments. Vous avez fait de votre fils un adroit chasseur. 


\title{
Trois drames de I'Asie
}

\author{
SCÈNE VI \\ Les mêmes, VIKRÂMA, OURVÂSI. \\ (Vikrâma entre en scène à son tour, suivi par \\ Ourvâsi.)
}

VIKRÂMA. - Qu'y a-t-il, Manâva ? Pourquoi cette dispute ?

MANÂVA. - C'est cet enfant qui veut me prendre le bijou parce que je n'ai pas tué le faucon. Le faucon avait pris dans ma main le bijou.

VIKRÂMA. - Pas possible ! Expliquez-moi, braves gens, I'affaire à votre tour. Parlez-moi sans crainte, votre roi vous écoute. Comment t'appelles-tu, petit archer ? Quel est ton âge ?

AYOUS. - Je m'appelle Ayous. J'ai douze ans.

VIKRÂMA. - Douze ans ! Voyez comme il est grand et fort. C'est votre enfant?

LE BRAHMANE. - C'est notre fils, monseigneur. Mais ce n'est pas moi qui lui ai appris à tirer de l'arc.

VIKRÂMA. - Ce n'était pas nécessaire, car il tire fort bien, je crois. Explique-toi, mon garçon, dis ce qui est arrivé !

AYOUS. - J'ai désobéi à mes parents et je me suis caché d'eux. J'ai eu tort et leur demande pardon. Je m'étais fabriqué en cachette un arc avec des flèches et je suis allé ce matin m'exercer dans la forêt. J'ai vu un oiseau qui s'envolait avec une chaîne d'or au bec. J'ai tiré et j'ai eu la chance de l'abattre. Je ne connais pas la personne qui l'a ramassé. 


\section{Trois drames de I'Asie}

VIKRÂMA. - Enfant, ta franchise me plaît. Donc sans toi le bijou était perdu.

AYOUS. - Je ne sais pas. Ce qui est sûr, c'est qu'on ne l'aurait pas retrouvé ici.

VIKRÂMA. - Je te dois beaucoup. Quelle sera ta récompense ?

AYOUS. - Je demande que mes parents me pardonnent.

VIKRÂMA. - Cela ne dépend pas de moi.

LE BRAHMANE. - Nous t'avons déjà pardonné.

AYOUS. - S'il m'était permis de solliciter une grâce encore, je voudrais devenir soldat dans l'armée royale.

VIKRÂMA. Je ne demande pas mieux, car tu me parais destiné à faire un bon soldat, et même à devenir un chef. Encore faut-il que tes père et mère $y$ consentent.

LE BRAHMANE. - Il est déjà sorti de notre caste, ayant versé le sang.

LA BRAHMANÎ. - Mais partir pour la guerre ! Risquer sa vie ! Tuer des hommes!

LE BRAHMANE. - Vous oubliez que nous n'avons pas le droit de nous opposer à sa volonté.

LA BRAHMANÎ. - C'est vrai.

VIKRÂMA. - Pourquoi donc ?

LE BRAHMANE. - Parce qu'il n'est pas notre fils.

OURVÂSI, effrayée. - Il n'est pas leur fils ! 


\section{Trois drames de I'Asie}

VIKRÂMA. - Il est vrai qu'il ne vous ressemble pas, ni d'esprit ni de corps. Mais qui donc est son père ?

LE BRAHMANE. - Nous ne le savons pas. Nous l'avons adopté.

LA BRAHMANÎ. - Quand il venait de naître.

OURVÂSI. - Quand il venait de naître !

VIKRÂMA. - Sa mère vous I'avait confié ?

LE BRAHMANE. - Non, seigneur, ce n'était pas sa mère. Une mère ne peut pas remettre elle-même à des étrangers son enfant.

LA BRAHMANÎ. - Nous ne I'avions pas vue venir. Elle était devant nous comme un oiseau se pose. Et elle s'est envolée de même.

VIKRÂMA. - Ourvâsi ! Vous semblez défaillir. Quel mal vous a saisie ? Vos yeux se ferment. Je suis là, près de vous, je ne vous quitte pas.

OURVÂSI, d'une voix faible. - C'est moi qui dois partir. L'arbre a vu le fruit.

LA BRAHMANÎ. - Et voilà qu'elle descend de nouveau parmi nous.

VIKRÂMA. - Qui donc ?

LA BRAHMANÎ. - Celle qui nous a apporté l'enfant. Veut-elle nous le reprendre? 


\title{
Trois drames de I'Asie
}

\author{
SCÈNE VII \\ Les mêmes, NAYÂNI.
}

(Nayâni apparaît.)

@

NAYÂNI. - Seigneur roi Vikrâma, me reconnaissez-vous ? Ne vous souvient-il pas de ce mont solitaire où je vous appelais au secours de ma sœur Ourvâsi ?

VIKRÂMA. - Messagère céleste, soyez la bienvenue. Avec respect je vous écoute.

NAYÂNI. - Vous êtes en grande peine pour elle, et nous aussi, au ciel d'Indra, nous avons eu bien du regret. Mais comment ne pas l'aimer, dans le souci qu'elle nous donne ? Ourvâsi, prenez courage, vous savez bien que votre grande sœur ne vous contrariera jamais.

OURVÂSI. - Il faut leur expliquer.

NAYÂNI. - Je vais leur dire tout ce que vous n'osez avouer. L'arrêt de notre seigneur Indra, maître de la foudre et gouverneur des trois mondes, la condamnait à rester sur la terre aussi longtemps que l'arbre n'aurait pas vu le fruit. $\mathrm{Ne}$ comprenez-vous pas ? Le fruit, c'est cet enfant. Elle vous l'a donné, pendant que vous étiez à la guerre, et a voulu le cacher à vos yeux, pour demeurer auprès de vous.

VIKRÂMA. - Ourvâsi, vous avez fait cela !

OURVÂSI. - Me pardonnerez-vous ?

VIKRÂMA. -Vous pardonner ! Quand vous avez souffert de perdre votre enfant plutôt que de nous séparer! 


\section{Trois drames de I'Asie}

OURVÂSI. - Mais maintenant il faut partir.

NAYÂNI. - Voulez-vous m'écouter un peu sans m'interrompre ? Car je n'ai pas tout dit. Seigneur Vikrâma, votre prière est exaucée et votre vœu doit s'accomplir. Vous avez désormais un héritier légitime à qui vous pouvez sans inquiétude et sans remords remettre le pouvoir ; aucun désordre n'est à craindre ; tous lui obéiront. La dernière des chaînes qui vous retenait est tombée. Délivré de l'action, maître de vos pensées, vous irez, compagnon des arbres, sous le vêtement d'écorce, au plus profond de la forêt.

VIKRÂMA. - Pour y passer loin d'elle le restant de mes jours à méditer sur mon malheur.

NAYÂNI. - Vous êtes insupportable. Je n'ai pas tout dit encore. Le puissant Indra, en sa clémence et pour vous témoigner combien votre renoncement aux biens et aux maux de la terre lui est agréable, permet à Ourvâsi de demeurer auprès de vous aussi longtemps que doit durer votre vie en ce monde, dans cette solitude qui n'en sera pas troublée car vous ne formez plus qu'un seul être en deux corps. Vous ne dites plus rien ?

VIKRÂMA. - Permettez que devant vous je me prosterne, en signe d'adoration et de reconnaissance pour le beau message que vous nous apportez.

OURVÂSI. - Unis par la volonté d'Indra, nous ferons tout notre possible, joignant nos forces et nous aidant I'un l'autre, pour mériter sa confiance et son bienfait.

NAYÂNI. - Adieu, seigneur roi. Adieu, petite sœur. 


\section{Trois drames de I'Asie}

(Elle disparaît.)

LE BRAHMANE. - Elle nous a transmis les instructions du Maître des trois mondes. Pieusement nous les avons recueillies en nos cœurs et maintenant, il faut élever nos pensées vers Celui qui a dit :

Il n'y a rien au-dessus de moi et toutes choses dépendent de moi comme les perles du fil qui les retient.

Je suis I'humidité dans l'eau, la lumière dans le ciel, l'adoration dans les prières, le son dans l'air, la nature humaine dans I'homme,

Le doux parfum sur terre, la splendeur dans les astres, la vie en toute chose.

Je suis la voie, le consolateur, le créateur, le témoin, l'immobile, l'asile et l'ami.

Je suis la génération et la dissolution, le lieu où résident joutes choses et l'inépuisable semence de la nature.

Je suis la clarté du soleil, le froid de la pluie. Je suis le fouet du vent, la roue du tonnerre, le cours égal du fleuve et l'inquiétude de la mer.

Je suis le sacrifice et je suis l'encens. Je suis l'invocation et celui qu'on invoque. Je suis le père, la mère, l'aïeul et le conservateur du monde. Je suis l'être et le non-être. Je suis la mort et l'immortalité. »

Viens ici, jeune enfant, toi que j'ai cru mon fils, toi qui vas recueillir un si lourd héritage. N'en sois pas effrayé. Pourvu que 


\section{Trois drames de l'Asie}

tu gardes le cœur pur, l'esprit droit, et qu'ayant pris en toute circonstance le parti de la justice tu n'en attendes aucun profit, tu feras ton salut.

Approchez, ô grand roi qui renoncez à votre royaume pour devenir un solitaire comme moi, approchez, fille du ciel qui avez éveillé en son cœur cette nostalgie d'un autre monde ; vous partirez tous deux, pareils à des enfants qui se tiennent par la main pour aller à leurs jeux, et votre vie en effet ne sera plus qu'un jeu où chacun de vous sera pour l'autre la plus belle des images, celle que l'on ne se lasse pas de contempler, l'image de Celui qu'on ne peut voir, entendre, ni nommer ; vous n'aurez plus à craindre le tourment de l'absence, l'inquiétude, le doute, ni le désir d'une récompense puisque vous l'aurez obtenue et n'en pourrez être frustrés; dans la sécurité de vos consciences et la plénitude de votre félicité vous accomplirez votre salut.

Approchez, vous aussi, qui serez retenus dans le monde terrestre, chacun par le labeur qui lui est ordonné, il vous suffira de I'accomplir sans vous laisser corrompre par l'ambition, I'envie ou la cupidité, et vous parviendrez au salut.

Car celui qui s'acquittant des devoirs de sa vie n'en veut tirer aucun avantage n'est pas souillé par le péché ; mais il demeure intact au milieu du monde comme le lotus dans les eaux.

Et vous, bons comédiens qui avez joué de votre mieux ce drame, chacun attentif à son rôle, si modeste fût-il, s'oubliant soi-même, et soucieux uniquement de la vérité qu'il fallait mettre au jour, c'est par ce dévouement, cette abnégation que vous parviendrez au salut. 


\section{Trois drames de I'Asie}

Et vous enfin, qui de près ou de loin nous avez écoutés, saisissant au vol nos discours, nous n'avons eu d'autre intention que de vous encourager, par un illustre exemple, dans la voie du salut.

Car cette voie est ouverte à tout homme qui sait dominer ses passions et fixer sa pensée. C'est par la connaissance qu'on parvient à la délivrance. Le Maître souverain de tout ce qui existe et de ce qui n'existe pas l'a dit :

« Tous les hommes me sont précieux mais j'estime le sage comme moi-même, parce qu'il met en moi sa confiance.

Quand même tu serais le plus grand des pécheurs, tu pourras traverser l'abîme du péché sur la barque de la sagesse.

Ainsi se termine I'histoire de Vikrâma, roi des Indes, et d'Ourvâsi, apsâra du ciel d'Indra. 


\section{LE CHAGRIN AU PALAIS DE}

\section{HAN}

Drame en cinq actes

donné pour la première fois en cette version nouvelle par la Radiodiffusion nationale de France

le 13 novembre 1942.

\section{PERSONNAGES}

Yuên-ti, empereur de la Chine.

Maô Yên-chéou, ministre

Le Conseiller de droite

Le Conseiller de gauche

Le Chambellan

Le Secrétaire du ministre

Le Khan des Tartares

Olochan, guerrier tartare

Baldour, guerrier tartare

Deux soldats tartares.

Tchao-kiun

Première suivante

Deuxième suivante
MM. Julien BERTHEAU.

CHAMARAT.

Lucien PASCAL.

R. GIRARD.

BOURDEL.

J.-L. ALLIBERT.

André WASLEY.

André VARENNES.

DESMOULINS.

$M^{\text {mes }}$ Denise BOSC.

Renée DARGENT.

Janine DEHELLY.

Mise en ondes de René ROCHER. 


\section{Trois drames de l'Asie}

\section{ACTE PREMIER}

\section{Le palais impérial}

\section{SCÈNE PREMIĖRE}

L'Empereur, le Conseiller de droite, le Conseiller de gauche, le Chambellan.

Dans la salle du trône, l'empereur est assis ayant auprès de lui, debout, les deux conseillers de droite et de gauche. Devant lui, le chambellan prêt à recevoir ses ordres.

\section{L'EMPEREUR.}

Entre les quatre mers règne la paix profonde, Les peuples sont soumis et le ciel les protège.

Chaque saison apporte en son temps ses bienfaits.

Et le palais de Han se réjouit

De la prospérité des cent familles.

Monsieur le conseiller de droite, Monsieur le conseiller de gauche, vous avez entendu le rapport que vient de me présenter mon premier ministre le seigneur Maô Yên-chéou. Comme l'exige la coutume il a quitté la salle afin que vous puissiez parler librement.

Seul Monsieur le chambellan nous écoute, prêt à exécuter les ordres qui lui seront donnés. Avez-vous une observation à faire ? Un avis à proposer ? Que rien ne vous retienne. Le droit de remontrance vous appartient, et je sais, tout empereur que je suis, le respect que je dois à votre âge ainsi qu'à vos vertus de fidélité, de dévouement et de sagesse. Monsieur le conseiller de gauche? 


\section{Trois drames de I'Asie}

LE CONSEILLER DE GAUCHE. - J'ai entendu. La récolte a été belle et le plus pauvre aura de quoi ne pas mourir de faim, cependant que le grain afflue aux greniers de l'État. Les familles s'accroissent et les filles y naissent plus nombreuses encore que les fils.

L'EMPEREUR. - Que voulez-vous dire?

Le CONSEILLER DE GAUCHE. - Rien, sinon que la faveur du ciel est la récompense visible du bon gouvernement.

L'EMPEREUR. - Comment oserais-je accepter un pareil éloge ? Mon mérite est bien faible.

LE CONSEILLER DE GAUCHE. - Le rapport que nous venons d'écouter apporte un témoignage indiscutable. Mais je ne suis pas sûr qu'il nous ait tout appris. De son voyage d'inspection dans les provinces Monsieur le premier ministre n'a-t-il vraiment tiré que ces renseignements de statistique?

L'EMPEREUR. - Vous voulez parler du présent qu'il m'a offert à son retour?

LE CONSEILLER DE GAUCHE. - On dit que dans chaque ville et dans chaque village les beautés les plus rares, par ses soins choisies...

L'EMPEREUR. - Vous êtes bien renseigné, mais ici je vous arrête. Ce qui se passe dans les jardins intérieurs n'est pas soumis à vos conseils. Vous savez mes soucis. Ne touchez pas à mes plaisirs.

LE CONSEILLER DE GAUCHE. - Il arrive qu'un ministre favorise à l'excès les plaisirs de son maître pour échapper à sa vigilance. 


\section{Trois drames de l'Asie}

L'EMPEREUR. - Maô est un ministre habile. Ma confiance lui est acquise. Mais si un jour je l'en découvre indigne, soyez assuré que le châtiment sera prompt et exemplaire. Monsieur le conseiller de droite?

LE CONSEILLER DE DROITE. - Avec joie j'ai appris que dans toute l'étendue de l'empire fleurissent les arts de la paix. Je voudrais être assuré qu'il en est de même hors de nos frontières. L'EMPEREUR. - Qui oserait nous attaquer?

LE CONSEILLER DE DROITE. - Le voisin pauvre est un danger pour le riche. Les tribu du désert ont toujours convoité I'opulence de nos villes et la fertilité de nos champs. Ce sont de hardis cavaliers, des archers redoutables.

L'EMPEREUR. - N'avons-nous pas un traité d'alliance avec eux ?

LE CONSEILLER DE DROITE. - L'avons-nous observé nousmêmes ? Leur chef suprême, qu'ils appellent le grand Khan des Tartares, ne devait-il pas recevoir pour épouse une princesse de la maison impériale qui l'unirait à nous par des liens de parenté ? L'EMPEREUR. - S'il réclame son droit nous ne serons pas pris de court. Votre collègue à l'instant montrait de l'inquiétude au sujet des jardins intérieurs. Il ne sera pas difficile de lui trouver là une épouse et nous n'aurons, comme on dit, que l'embarras du choix. Messieurs les conseillers, je ne vous retiens plus. Monsieur le chambellan!

(Les conseillers se retirent et le chambellan s'approche.)

LE CHAMBELLAN. - Aux ordres de Votre Majesté ! 


\section{Trois drames de I'Asie}

L'EMPEREUR. - Trop sages conseillers ! Ils ont répandu malgré moi l'ombre sur mes pensées. C'est l'heure où dans la nuit des jardins les pavillons disséminés s'éclairent et les jeunes filles font leurs apprêts dans l'espérance de recevoir ma visite. Elles sont si nombreuses que je ne les connais pas toutes. Mais j'ai leurs noms ici, et leurs portraits que le ministre m'a remis, faits par son secrétaire, un peintre très habile. Non, monsieur le chambellan, il ne faut pas me les montrer ce soir, car la nuit est trop belle et c'est elle seule que je veux contempler.

LE CHAMBELLAN. - Je vais faire alerter l'escorte et avancer la voiture.

L'EMPEREUR. - Je ne veux pas d'escorte, ni rien qui me signale. Vous serez, si vous y consentez, mon compagnon de promenade. LE CHAMBELLAN. - C'est un trop grand honneur pour ma pauvre personne.

L'EMPEREUR. - Nous irons, au hasard, par les jardins nocturnes où les fleurs s'obscurcissent et les parfums s'exaltent. Nous aurons pour musique le murmure de la brise sur les feuillages que caresse la lune. Nos pas muets sur I'herbe molle prendront soin de ne pas troubler la jeune fille dans sa chambre, éveiller I'oiseau dans son nid. Venez avec moi. Dites, vous souvient-il de celle dont hier, regardant le portrait, nous cherchions en vain la beauté ?

LE CHAMBELLAN. - Celle qui avait les yeux écarquillés, le front ridé ? Son nom, je m'en souviens, était Wâng, son prénom Tchao-kiun. 
L'EMPEREUR. - Wâng Tchao-kiun. N'oubliez pas. Si le Khan des Tartares fait valoir ses droits, nous lui donnerons pour épouse, et il sera tenu d'accepter avec reconnaissance, la princesse Tchaokiun.

(Ils sortent en riant.)

\section{SCÈNE II}

TCHAO-KIUN, deux Suivantes.

Dans le parc impérial. Un pavillon un peu surélevé et fermé jusqu'à hauteur d'appui. Porte ouverte au milieu. Par devant, un chemin. Clair de lune. Tchao-kiun est assise dans le pavillon. Les suivantes s'empressent à sa parure qu'elle observe dans un miroir. Elle est inquiète et nerveuse.

TCHAO-KIUN. - J'ai trop de rouge ici. Cette épingle est mal placée. Plus en arrière. Assez ! Et d'ailleurs, à quoi bon tout cela?

PREMIÈRE SUIVANTE. - Ne vous plaît-il pas de vous sentir belle?

TCHAO-KIUN. - Triste beauté qui n'attire pas le regard ! Fleur sans parfum qui meurt dans l'ombre de la forêt ! Oiseau sans voix dont nul n'entendra jamais l'appel printanier !

DEUXIÈME SUIVANTE. - Il n'est pas possible que l'empereur ne découvre tôt ou tard le trésor caché au fond de ses jardins.

TCHAO-KIUN. - Pourquoi ne m'a-t-il jamais mandée auprès de lui ? Non, laissez-moi, ne me tourmentez plus.

(Elle se lève et écarte les suivantes.)

PREMIÈRE SUIVANTE. - Si c'était pour ce soir cependant ? 


\section{Trois drames de I'Asie}

DEUXIÈME SUIVANTE. - Nous serions punies pour notre négligence.

PREMIÈRE SUIVANTE. - La nuit est claire comme une nuit prédestinée.

TCHAO-KIUN, se rasseyant. - Faites donc votre ouvrage et perdez votre peine.

(Les suivantes s'empressent.)

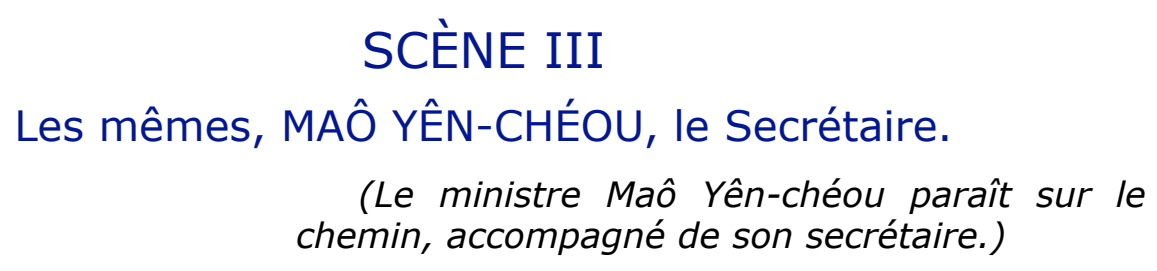

MAÔ YÊN-CHÉOU. - Vous n'étiez jamais venu jusqu'ici ?

LE SECRÉTAIRE. - Je ne savais même pas que le parc impérial s'étendît aussi loin.

MAÔ YÊN-CHÉOU. - C'est un lieu d'exil plus abandonné que le désert au delà des frontières et I'habileté de votre pinceau ne trouverait pas I'occasion de s'y exercer.

LE SECRÉTAIRE. - Ce pavillon est habité ?

MAÔ YÊN-CHÉOU. - Voyez.

LE SECRÉTAIRE, s'approchant. - Une jeune fille que I'on apprête pour la nuit.

MAÔ YÊN-CHÉOU. - Bien inutilement.

LE SECRÉTAIRE. - Elle est délicate et tremblante comme une fleur de pavot qui vient de déplier ses pétales. 


\section{Trois drames de I'Asie}

MAÔ YÊN-CHÉOU. - Ne la reconnaissez-vous pas ?

LE SECRÉTAIRE. - Il me semble...

MAÔ YÊN-CHÉOU, tirant à demi un rouleau de sa manche. - Ce portrait ?

LE SECRÉTAIRE. - Oui, c'est de son portrait que j'ai fait sur votre ordre la plus infidèle copie. Wâng Tchao-kiun, je me souviens maintenant. J'ai honte.

MAÔ YÊN-CHÉOU. - Honte ! Ses parents m'avaient refusé cent onces d'argent.

LE SECRÉTAIRE. - Ils pensaient qu'il lui suffirait de paraître pour que la faveur impériale lui fût accordée.

MAÔ YÊN-CHÉOU. - Ils comptaient sans le ministre.

Cœur de vautour et serres d'aigle, La ruse pour les grands, pour les petits la contrainte, Mensonge, flatterie, avarice, luxure, Telles sont les vertus dont le profit est assuré.

Les pesants lingots d'or sont à ma volonté ; je ne crains ni les flots de sang répandu ni la rigueur des lois; ma vie durant je veux richesse et puissance. Et que m'importent, après ma mort, les malédictions des hommes?

LE SECRÉTAIRE. - Mais ne craignez-vous pas que le destin...

MAÔ YÊN-CHÉOU. - Il n'est pas de destin pour l'esprit qui sait prévoir. Deux hommes seulement me font obstacle encore : les deux grands conseillers de droite et de gauche. Je saurai les compromettre et vous m'y aiderez. Je vais vous exposer mon plan. 


\section{Trois drames de I'Asie}

(Ils se remettent en route.)

LE SECRÉTAIRE. - Non, cette fois je ne veux plus vous obéir. Des hommes dont tout l'empire honore la droiture ! MAÔ YÊN-CHÉOU. - Vous m'avez trop obéi déjà. Votre vie est entre mes mains.

(Ils sortent, les suivantes cependant ont terminé et se sont retirées.)

\section{SCÈNE IV}

TCHAO-KIUN.

TCHAO-KIUN. (S'approchant timidement de la porte.) - J'avais cru entendre. Ce n'est rien. Un lézard a glissé dans I'herbe, ou la cime des arbres lointains a salué le vent du soir. Je suis seule, toujours seule, sans même un souvenir pour nourrir ma douleur. Celui qui est mon maître et que j'attends jamais n'a désiré me voir ; j'ignore son visage et sa voix. Si mes parents avaient su, lorsqu'ils m'accompagnaient jusqu'à la porte du village avec des larmes de regret et de bonheur ! Si mes compagnes avaient deviné, qui me regardaient monter dans le palanquin doré, et les bras joints sur leurs poitrines se trouvaient en secret plus désirables que moi ! La femme du laboureur ne meurt pas sans avoir écouté les paroles de tendresse et de reconnaissance. La femme du soldat donne le jour à un fils qu'elle nourrit et qui plus tard brûlera l'encens devant sa tablette funéraire. Je disparaîtrai comme une ombre et mon nom même sera oublié. Je n'ai d'autre compagnon que ce luth qui répond en son langage obscur à mes paroles plaintives. 


\title{
Trois drames de l'Asie
}

\author{
(Elle promène ses doigts sur le luth et \\ prononce doucement.)
}

Fleurs choisies, fleurs cueillies, fleurs perdues, J'entends une flûte chanter parmi les rayons de lune.

Ma mère vit en rêve une clarté céleste Qui s'abaissait sur elle et se perdit tout aussitôt. Du jour où je suis entrée en ce palais glorieux Il s'est changé pour moi en une prison noire.

Fleurs fanées, fleurs passées, fleurs meurtries, J'entends une flûte pleurer parmi les rayons de lune. Je ne baisserai pas ces stores tressés de perles, Je cherche à percer l'ombre légère des bambous. La lune a tendu ses rideaux de lumière. Un seul pas me perdrait en ces jardins immenses.

Fleurs jetées, fleurs foulées, fleurs broyées, La flûte a cessé de pleurer parmi les rayons de lune. Au loin j'entends vibrer des cordes de guitare. Est-ce le cortège impérial qui s'avance? Est-ce la nuit bénie où les étoiles fiancées Se joignent ayant traversé à gué la Voie lactée, Pendant que les jeunes filles sur le pas des portes Usent leurs yeux à passer dans l'aiguille le fil En signe de noces prochaines?

(Elle tire encore quelques sons du luth, perdue en ses pensées.)

\section{SCÈNE V}

TCHAO-KIUN, I'Empereur, le Chambellan.

(L'empereur et le chambellan paraissent sur le chemin.)

L'EMPEREUR. - C'est d'ici que venait l'écho de ce luth.

LE CHAMBELLAN. - Pourquoi Votre auguste Majesté n'a-t-elle pas voulu d'escorte? 


\section{Trois drames de l'Asie}

L'EMPEREUR. - Ce n'est pas avec les armes qu'on va surprendre les secrets de la nuit.

LE CHAMBELLAN. - C'est peut-être un esprit qui joue du luth, ou bien l'âme d'un mort.

L'EMPEREUR. - Qui que ce soit, des notes aussi pures n'ont pas un pouvoir maléfique.

LE CHAMBELLAN. - On n'entend plus rien.

L'EMPEREUR. - La musique reprend.

LE CHAMBELLAN. - Je crains une surprise en cet endroit désert et vais dire aux soldats de la garde de se tenir près d'ici.

\footnotetext{
(Il s'éloigne. L'empereur s'approche du pavillon, mais s'arrête.)
}

L'EMPEREUR. - Quelle puissance me retient ? (Il avance d'un pas et aperçoit Tchao-kiun.) Ah ! une fée joue du luth, nimbée de rayons. Elle ne m'aperçoit pas. Je n'ose avancer, de peur qu'elle ne s'enfuie, et cependant toute ma vie se retire de mon corps pour s'élancer vers elle.

(Tchao-kiun, interdite, s'arrête de jouer.)

Elle se tait. Elle devine une présence profanatrice. Un prince de jadis aperçut une jeune fille au bord d'un torrent. Elle chantait : « Le matin je garde les nuages ; le soir je ramène la pluie. » Il voulait l'interroger mais elle disparut aussitôt et il parcourut toute la terre sans la revoir jamais.

TCHAO-KIUN. - J J'entends parler dans les ténèbres.

L'EMPEREUR - Il ne faut pas que le rameau frissonne. Il ne faut pas effrayer la colombe. Pour la première fois je ne suis plus le 


\section{Trois drames de I'Asie}

maître et mon désir n'est plus un ordre. Il fallait pour cela sortir de ce palais.

TCHAO-KIUN. - Un palais ?

L'EMPEREUR - Palais des vains plaisirs, prison d'orgueil et de mensonge où me tenait captif la gloire de mes ancêtres les Hán.

TCHAO-KIUN. - $\quad$ L'empereur ! Est-ce un rêve ?

L'EMPEREUR - Je crois reconnaître la déesse de la miséricorde qui habite au sommet d'un mont inconnu, plus blanche que la neige et plus brillante que la lune. Elle incline la tête pour entendre les prières murmurées. Celui qui une fois a contemplé son visage, la mort recule devant lui. Celui qui I'aime dans son cœur obtient la paix pour toujours.

TCHAO-KIUN. - Je ne suis pas une déesse, et me sens bien coupable de n'être pas venue aussitôt rendre hommage à Votre Majesté.

(Elle veut descendre vers lui.)

L'EMPEREUR - Comme elle a bien dit cela ! Non, restez où vous êtes, pour que je vous regarde encore.

TCHAO-KIUN. - Mon nom est Wâng Tchao-kiun.

(Le chambellan revient.)

\section{SCÈNE VI \\ Les mêmes, le Chambellan.}

LE CHAMBELLAN. - Wâng Tchao-kiun. Est-ce possible ? 


\section{Trois drames de l'Asie}

L'EMPEREUR. - Vous l'avez entendue.

TCHAO-KIUN. - Qu'y a-t-il là d'étrange ?

LE CHAMBELLAN. - Si belle ! Comment expliquer cette erreur ?

L'EMPEREUR. - Dites-moi, mon enfant, est-ce volontairement que vous vous étiez enlaidie?

TCHAO-KIUN. - Je ne sais pas ce que Votre Majesté veut dire.

L'EMPEREUR. - Un portrait qui était loin de vous ressembler m'avait été remis.

TCHAO-KIUN. - Puis-je savoir par qui ?

L'EMPEREUR. - Par Maô Yên-chéou, mon ministre.

TCHAO-KIUN. - Par le ministre !

L'EMPEREUR. - Ce souvenir ne vous paraît pas agréable. Avezvous quelque chose à lui reprocher ? Parlez sans crainte, nous sommes devant une énigme qu'il faut à tout prix éclaircir.

TCHAO-KIUN. - Je ne sais rien.

L'EMPEREUR. - C'est bien lui qui vous avait choisie ?

TCHAO-KIUN. - Oui, monseigneur.

L'EMPEREUR. - Et vos parents ont consenti ?

TCHAO-KIUN. - Bien à regret, mais ils sont chargés d'enfants, ce sont de pauvres laboureurs.

L'EMPEREUR. - Il les a, j'espère, indemnisés comme il fallait pour un trésor si rare? 


\section{Trois drames de I'Asie}

TCHAO-KIUN. - Tout au contraire, il leur a demandé cent onces d'argent s'ils voulaient que leur fille fût jamais honorée de la faveur impériale.

L'EMPEREUR. - Cent onces d'argent ! Et vos parents ne les ont pas données?

TCHAO-KIUN. - Ils n'ont pu, monseigneur. Et alors...

L'EMPEREUR. - Et alors ?

TCHAO-KIUN. - Monsieur le ministre $\mathrm{m}^{\prime} \mathrm{a}$ bien dit que je vieillirais délaissée au fond de ce jardin, et il me semblait en effet que tel devait être mon sort.

L'EMPEREUR. - Le misérable ! Monsieur le chambellan, voici mon sceau impérial. Retournez au palais. Il faut qu'on le recherche, s'en empare et l'arrête sur l'heure. Et demain, justice sera faite. Messieurs les conseillers verront que je tiens ma promesse.

LE CHAMBELLAN. - J'exécute avec respect les ordres de Votre Majesté.

(Le chambellan s'éloigne.)

L'EMPEREUR. - Tchao-kiun, qu'avez-vous ? Vous semblez défaillir.

(Il entre dans le pavillon et doucement lui prend les mains.)

TCHAO-KIUN. - A peine ai-je passé quelques instants près de vous, et je cause déjà la mort d'un homme.

L'EMPEREUR. - Il était infâme. Ne tremblez pas. Je voudrais seulement remplacer cette mantille mouillée de larmes, 


\section{Trois drames de I'Asie}

réchauffer ces bas traversés par la rosée nocturne. Demain, dès l'aube, les torches allumées sur la terrasse d'argent en répandant de tous côtés leurs fleurs de pourpre annonceront au loin I'heureuse nouvelle. Alors vous entrerez avec moi dans le palais intérieur ; aux sons des cloches, des tambours, des flûtes et des guitares, vous serez présentée aux ancêtres et nous viderons ensemble la coupe des fiançailles. Mais, cette nuit, je veux, en ce pavillon solitaire, écouter encore ce luth qui m'a conduit vers vous.

(Tchao-kiun reprend son luth. L'empereur debout l'écoute.)

L'EMPEREUR, comme à lui-même. - A l'appel de la mélodie les esprits des lacs et des rivières, des monts et des forêts, des côtes élevées et des plages basses se sont présentés. Puis les génies de la terre ont quitté les grottes et les profondeurs, les génies du ciel ont laissé les astres et les espaces. Enfin les âmes des vivants et des morts sont venues apporter en offrande les pensées et les songes.

Je vois les murs s'évaporer, les arbres se dissoudre, la terre s'éloigner et se perdre, nous glissons doucement dans la brume de lumière, remontant le cours des rayons, et les déesses qui ont pour demeure la lune interrompent leur danse légère pour nous saluer de la main. Elle me guide et je la suis, sans oser un mouvement, retenant mon souffle et mon regard. Elle est si douce que le ciel frémit à son approche.

\section{SCÈNE VII}

Les mêmes, MAÔ YÊN-CHÉOU, le Secrétaire. 


\section{Trois drames de I'Asie}

(Maô Yên-chéou et le secrétaire reviennent. Trois soldats les suivent de près.)

MAÔ YÊN-CHÉOU, à voix basse. - Je connais une issue par ici. Nous sommes sauvés si nous y parvenons.

LE SECRÉTAIRE. - J'entends marcher.

MAÔ YÊN-CHÉOU. - Les soldats sont sur nos talons.

LE SECRÉTAIRE. - Nous sommes perdus. Je savais bien que la punition viendrait.

MAÔ YÊN-CHÉOU. - Pour vous peut-être, pour moi non.

(Il pousse le secrétaire vers les soldats qui le saisissent, le bâillonnent et l'emportent. Maô Yên-chéou s'est jeté à terre à leur passage.)

MAÔ YÊN-CHÉOU. - Demain ils montreront leur beau trophée à l'empereur qui les récompensera comme ils le méritent. Combien il est facile d'abuser les sots ! Mais ne nous attardons pas, et cherchons un autre souverain qui saura mieux reconnaître mon mérite.

$$
\text { (Il s'enfuit.) }
$$

TCHAO-KIUN. - N'avez-vous rien entendu ? J'ai peur. 


\section{Trois drames de I'Asie}

\section{ACTE II}

Dans la steppe mongole où est campée la horde des guerriers nomades, la tente de leur chef. L'entrée est au fond. Elle est d'abord fermée. Le chef est seul. C'est la fin du jour.

\section{SCÈNE PREMIÈRE}

Le grand Khan, puis OLOCHAN et BALDOUR.

\section{LE GRAND KHAN.}

Sur la terre des herbes s'étend notre empire.

Rôdant à l'aventure,

Nous avons chaque jour I'horizon pour frontière,

Notre ville où se dressent nos tentes de feutre.

La chasse est notre jeu,

La guerre notre fête.

La guerre ! Voilà longtemps que nous n'avons pris nos armes de guerre. Mes hommes s'impatientent. Ils viennent me dire qu'ils s'ennuient, que leurs chevaux sont trop gras et que les Chinois qui arrivent ici pour nous vendre du thé ou des étoffes commencent à se montrer insolents. Ils ne perdront rien pour attendre, mais j'entends choisir mon Heure. Qu'y a-t-il ?

(Deux Tartares soulèvent la tenture de feutre, entrent et saluent en s'inclinant, sans retirer leurs bonnets fourrés.)

LE GRAND KHAN. - Salut, Olochan. Salut, Baldour. Votre chef vous écoute.

OLOCHAN. - Salut et gloire au grand Khan des Tartares.

BALDOUR. - Nous rentrons de la chasse.

LE GRAND KHAN. - Bonne chasse ? 


\section{Trois drames de l'Asie}

OLOCHAN. - Pas grand'chose. Quelques oies sauvages. Mais une capture plus rare.

BALDOUR. - Nous avons pris un homme.

LE GRAND KHAN. - Un étranger ?

OLOCHAN. - Un Chinois.

BALDOUR. - Et qui semble un personnage d'importance, si I'on en juge par son costume et sa mine.

LE GRAND KHAN. - Il vous appartient. Gardez-le. Vous pourrez en tirer une bonne rançon.

OLOCHAN. - Il demande à parler à notre chef le grand Khan.

LE GRAND KHAN. - Vous a-t-il dit pourquoi ?

OLOCHAN. - Un message secret.

LE GRAND KHAN. - Ils disent tous cela. Amenez-le quand même. On ne peut pas savoir.

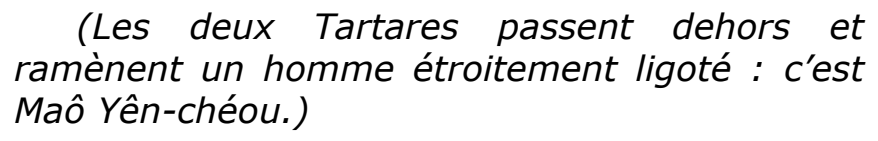

(Les deux Tartares passent dehors et ramènent un homme étroitement ligoté : c'est Maô Yên-chéou.)

\section{SCÈNE II \\ Les mêmes, MAÔ YÊN-CHÉOU.}

LE GRAND KHAN. - Déliez-le.

MAÔ YÊN-CHÉOU. - Salut et gloire au grand Khan des Tartares.

LE GRAND KHAN. - Qui es-tu ? 


\section{Trois drames de l'Asie}

MAÔ YÊN-CHÉOU. - Maô Yên-chéou, premier ministre de I'empereur de Chine.

LE GRAND KHAN. - La preuve ?

MAÔ YÊN-CHÉOU. - La tablette de jade, insigne de mon rang. Je l'avais cachée dans la tige de ma botte de peur qu'on ne me la prenne.

LE GRAND KHAN. - Mes guerriers ne sont pas des voleurs.

MAÔ YÊN-CHÉOU. - Dans le désert on fait parfois de mauvaises rencontres.

LE GRAND KHAN. - Donne ! C'est bien la forme de I'insigne. Le général Lì-lîng en avait un pareil, quand nous l'avons fait prisonnier. Parle.

MAÔ YÊN-CHÉOU. - Mon message est secret.

LE GRAND KHAN. - Ces deux guerriers te gênent ? Non, non, restez, mes braves. Nous ne sommes pas ici en Chine. Le grand Khan des Tartares n'a pas de secret pour ses hommes, ni ses hommes pour lui.

MAÔ YÊN-CHÉOU. - Il s'agit de paix ou de guerre.

LE GRAND KHAN. - Est-ce ton maître qui t'envoie ?

MAÔ YÊN-CHÉOU. - Non.

LE GRAND KHAN. - Tu veux donc le trahir ?

MAÔ YÊN-CHÉOU. - C'est lui qui m'a trahi. J'avais sa confiance et c'est moi qui portais toute la charge du pouvoir. Mais j'ai commis la faute de m'absenter pour un voyage d'inspection dans les provinces qui a duré trop longtemps. A mon retour, les 


\section{Trois drames de I'Asie}

envieux avaient eu le temps de travailler contre moi et l'avaient mis à profit. La lutte des ambitions n'a pas de lois, et aucun scrupule n'a jamais arrêté une intrigue de cour. Mais je ne puis pardonner à l'empereur qui a prêté I'oreille à leurs calomnies, oubliant en un jour tout ce qu'il devait à un vieux et fidèle serviteur. Il m'a fait si mauvais accueil que j'ai eu du soupçon et me suis renseigné. Bien m'en a pris car j'ai pu sortir de l'empire la veille même du jour où je devais être arrêté !

LE GRAND KHAN. - Que peut me faire tout cela ?

MAÔ YÊN-CHÉOU. - Ce que je vais vous montrer vous intéressera davantage. Ce sont les renseignements d'ordre militaire recueillis au cours de mon voyage, que je n'ai pas eu le loisir de lui communiquer.

LE GRAND KHAN. - Ou que tu as eu la précaution de lui dissimuler?

MAÔ YÊN-CHÉOU. - Peut-être. Vous trouverez ici l'état des effectifs, des armes et des vivres, dans nos places fortes du nord et les fortins de la Grande muraille.

LE GRAND KHAN. - Fais voir. Les chiffres semblent exacts ; ils sont d'accord avec d'autres renseignements, auxquels je n'avais pas voulu croire. Est-il possible qu'un grand empire prenne aussi peu de précautions pour sa défense?

MAÔ YÊN-CHÉOU. - La Chine a trop d'orgueil. Elle se croit invincible ; c'est ainsi que l'on prépare les catastrophes. Elle ne daigne même pas vous donner ce qu'elle a promis par le traité 


\section{Trois drames de I'Asie}

d'alliance que cependant vous observez. En vain j'ai supplié l'empereur ; il vous traite de sauvages, et ne veut rien entendre. LE GRAND KHAN. - Tu veux parler de la clause du mariage ? Il ne tenait qu'à moi de réclamer. Si je ne l'ai pas fait, c'est qu'il m'importait peu de recevoir, sous le titre de princesse impériale, une pauvre fille que votre maître a dédaignée, rebut de son palais.

MAÔ YÊN-CHÉOU. - Vous ne recevrez pas une pauvre fille, rebut de son palais. J'ai encore un document à vous soumettre. Que pensez-vous de ce portrait?

\section{(Il présente au grand Khan le portrait de Tchao-kiun.)}

LE GRAND KHAN. - Une beauté céleste ! Mes amis, venez voir.

(Olochan et Baldour s'approchent.)

BALDOUR. - Est-il possible qu'ils aient en leur pays de Chine des femmes aussi belles!

OLOCHAN. - Je donnerais ma vie pour que celle-ci devienne l'épouse de notre chef.

MAÔ YÊN-CHÉOU. - C'est une fille du palais impérial, où je I'ai fait entrer, ayant eu le bonheur de la trouver au fond de sa province, fleur rare qui répand aujourd'hui son parfum dans les jardins intérieurs. C'est là qu'à votre tour vous irez la cueillir. Nous n'avons pas tenu parole; vous déclarez rompu le traité d'alliance et vous prenez les armes. La résistance que vous rencontrerez sera faible et ne pourra vous arrêter. Le pays sera envahi, dévasté. Parvenus à la capitale vous dicterez vos conditions. C'est celle-ci qui doit vous être accordée pour 


\section{Trois drames de I'Asie}

épouse. Celle-ci, non pas une autre. Elle s'appelle Wâng Tchaokiun.

LE GRAND KHAN. - Wâng Tchao-kiun. Oui, le conseil est bon. Olochan et Baldour, ouvrez la porte de la tente. Appelez nos guerriers.

(Les deux Tartares sortent un instant. On entend leur cri d'appel au dehors.)

OLOCHAN. - Guerriers de notre horde, accourez tous, notre chef vous demande.

(Les guerriers arrivent, la tente se remplit, et l'on devine une autre foule au dehors.)

LE GRAND KHAN. - Hommes de la terre des herbes, guerriers de notre horde, fidèles compagnons dont j'ai la garde et qui m'avez toujours suivi, je vous prie d'écouter mes paroles et de me dire ensuite si nous sommes d'accord.

LES TARTARES. - Gloire au Khan des Tartares ! Gloire !

LE GRAND KHAN. - Depuis longtemps plusieurs parmi vous me demandent si la paix va durer encore. Ils me représentent qu'ils s'ennuient, que nos chevaux sont trop gras, que nos armes se rouillent. Est-ce vrai ?

LES TARTARES. - Oui, c'est vrai.

LE GRAND KHAN. - Je comprends votre ennui, je partage votre impatience. Mais déclarer la guerre à un puissant empire est une décision grave. Au cours des règnes précédents nous n'avons pas toujours été vainqueurs, il s'en faut de beaucoup. Les plus vieux parmi vous se souviennent encore du désastre où notre armée fut accablée sous le nombre et quatre-vingts de nos chefs 


\section{Trois drames de l'Asie}

immolés par l'ennemi, offrant leur sang au dieu du sol. Le devoir d'un bon chef est de ne pas exposer à une mort inutile les soldats qu'il conduit. Je crois avoir fait mon devoir en résistant à vos instances. Mais aujourd'hui me sont parvenues des nouvelles qui m'inspirent confiance. L'occasion est favorable et rien ne doit plus nous retenir. Je viens vous demander si vous approuvez la décision que je veux prendre. Cette décision est : la guerre !

LES TARTARES. - La guerre ! la guerre !

LE GRAND KHAN. - C'est bien. Demain dès l'aube nos chevaux seront sellés, et tous en rangs serrés, épaule contre épaule, nous nous avancerons vers le sud comme un rempart mouvant. Nous couvrirons les plaines, nous gravirons les montagnes, nous passerons les fleuves. Nous envahirons les villages et forcerons les portes des cités. Tout être vivant rencontré sur les routes, dans les campagnes, ou caché à l'intérieur des maisons, sera tué par la flèche et la lance. Tout ce que les hommes auront élevé au-dessus du sol, temples, cabanes, étables ou palais, sera détruit par l'incendie. Partout où nous aurons passé, la terre, débarrassée de sa charge, se retrouvera pure, nue, et rouge de sang frais.

MAÔ YÊN-CHÉOU, s'avançant. - Seigneur, mes avis ne vous feront pas défaut. Je vous indiquerai les passes mal gardées, les garnisons peu sûres.

LE GRAND KHAN, continuant. - Mais la terre de ces contrées nous a fidèlement nourris pendant plusieurs saisons. Nous ne la quitterons pas sans lui offrir, à elle la première, le sang d'un homme. Un ministre a trompé son maître et s'est enfui. Le 


\section{Trois drames de I'Asie}

châtiment que l'empereur de Chine, trop faible, n'a pu lui infliger, est échu au Khan des Tartares. Il n'y faillira pas.

MAÔ YÊN-CHÉOU, se jetant à ses genoux. - Seigneur, épargnez ma vie. Grâce ! Ne vous ai-je pas montré l'image, donné le nom, indiqué le chemin ? Est-ce là ma récompense?

LE GRAND KHAN. - Aurais-tu peur?

MAÔ YÊN-CHÉOU, se reprenant brusquement. - Peur ? Non pas. Je voulais seulement vous épargner un crime. Je mourrai donc, victime de vos superstitions ; je ne discuterai pas avec vous, cervelles épaisses et bornées. Sachez seulement que je ne disparaîtrai pas tout entier. Ma haine pour vous me survivra. Elle s'attachera à vous comme la flamme, comme la fièvre, comme la pourriture; elle vous poursuivra sans repos. Et toi, misérable berger d'un troupeau privé de raison, la beauté que tu veux conquérir t'échappera dans l'instant même que tu croiras la tenir. La fleur de la terre chinoise ne se laissera pas cueillir par ta main ignorante, grossière, répugnante.

LE GRAND KHAN. - Que les bourreaux s'avancent et que les signaux de feu s'allument, appelant ceux qui sont en chasse dans la plaine.

(Deux bourreaux s'avancent, armés de larges coutelas, et entraînent Maô Yên-chéou. Lueurs rouges au dehors.)

MAÔ YÊN-CHÉOU. - Approchez. Aiguisez bien vos lames, car voyez, ma peau de vieillard pend autour de mon corps comme les fanons d'un bœuf, et c'est à peine si vous tirerez de moi quelques gouttes de sang glacé. Êtes-vous prêts ? Et vous, barbares, venez, vous qui ne savez que paître avec vos chevaux 


\section{Trois drames de I'Asie}

la terre des herbes, venez voir comment meurt un homme nourri sur la terre de Hán.

@ 


\title{
Trois drames de l'Asie
}

\author{
ACTE III \\ Le palais impérial \\ SCÈNE PREMIÈRE
}

L'Empereur, le Chambellan, TCHAO-KIUN, les Suivantes.

Les jardins du palais. Au fond, à gauche, l'empereur à demi couché devant une petite table contemple Tchao-kiun qui aidée par les suivantes dispose des fleurs en des vases. Le chambellan debout auprès de lui.

L'EMPEREUR. - Depuis l'instant où soudain elle m'est apparue au fond de mon parc abandonné, je ne sais combien de jours, de semaines ou de mois ont passé. Comme si son regard avait dissous la substance de mon corps, je suis devant elle pareil à un nuage qui flotte suspendu aux rayons du soleil. Et c'est vous qui m’avez aidé à découvrir la merveille cachée, vous souvenezvous?

Le CHAMBELLAN, gravement. - Je me souviens.

L'EMPEREUR. - C'est en de tels jardins que l'empereur Mouhwâng, porté par son char aux chevaux ailés, devint I'hôte de la reine d'Occident et goûta un tel bonheur qu'il oublia le chemin du retour.

LE CHAMBELLAN. - Il est écrit que l'empereur Yù le Grand employa treize années à explorer les provinces dont il était maître, partout traçant les routes et réglant le cours des fleuves. Pour gravir les montagnes il s'aidait de crampons; pour 


\section{Trois drames de l'Asie}

traverser la boue il posait le pied sur un van d'osier. Trois fois il aperçut le seuil de sa maison sans le franchir.

L'EMPEREUR. - Quand elle m'accompagne sous les poiriers en fleurs, les cerfs et les biches couchés dans I'herbe grasse ne s'enfuient pas devant nous. Quand je monte avec elle, le soir, à la tour des Signes célestes, les étoiles s'approchent, attirées par le parfum de sa ceinture.

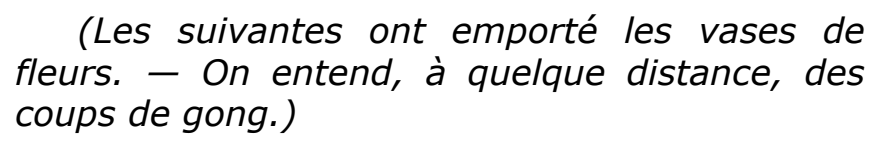

LE CHAMBELLAN. - Le grand tambour de la porte d'émeraude annonce l'arrivée d'un prince vassal.

(On entend des flûtes lointaines.)

L'EMPEREUR. - Je n'entends que des flûtes éloignées, du côté de la porte de nacre.

LE CHAMBELLAN. - Neuf coups ont été frappés ; ce n'est pas un prince vassal, mais l'ambassade d'un royaume étranger.

L'EMPEREUR. - Je reconnais un air des pays du sud. Ce sont les danseuses magiciennes que m'envoie en présent le roi des rivages ensoleillés.

LE CHAMBELLAN. - Je vais avertir les conseillers de droite et de gauche de se tenir prêts à recevoir les étrangers dans la grande salle.

L'EMPEREUR. - Leur danse n'est pas celle de la robe de nuages, ni de l'aile de phénix, ni de la bienvenue à la brise. C'est la danse des cinq couleurs qui répondent aux cinq destinées. 


\section{Trois drames de I'Asie}

LE CHAMBELLAN. - Fasse le ciel que cette ambassade soit pour la paix et non pas pour la guerre.

(Il sort.)

\section{SCÈNE II \\ L'Empereur, TCHAO-KIUN.}

L'EMPEREUR. - Il m'a semblé qu'une ombre d'inquiétude effleurait votre front.

TCHAO-KIUN. - Ces danses, dites-vous, nous feront connaître notre destinée?

L'EMPEREUR. - Oui, nous saurons tout ce que les jours futurs nous réservent de gloire, ou de bonheur paisible, ou bien...

TCHAO-KIUN. - Ou bien ?

L'EMPEREUR. - Pourquoi nommer ce qui ne peut exister ?

TCHAO-KIUN. - Comment être assuré de ce qui n'est pas encore?

L'EMPEREUR. - Rien ne pourra nous séparer parce que tous les siècles qui restent au monde ne suffiront pas à épuiser la tendresse de nos cœurs. Pour dire vos grâces, Tchao-kiun, aussi variées que les jeux du vent et de l'eau courante, que seraient mille années, que seraient dix mille années?

TCHAO-KIUN. - Cette nuit encore j'ai vu en songe des ours luttant contre des tigres ; j'ai vu un fleuve immense d'où s'élevait une musique funèbre et un roc élevé, prince de la vie et de la mort, qu'il me fallait gravir. 


\section{Trois drames de I'Asie}

L'EMPEREUR. - Il arrive que la nuit ne se retire pas tout entière et laisse traîner quelques erreurs sur notre esprit. Mais il faut ouvrir les yeux au jour et les fantômes se dissipent. Les danseuses approchent. J'entends sonner les anneaux d'or et les pendants de perles. Voyez, leurs visages sont blancs comme la fleur du cerisier, et blancs les ornements des robes qui flottent autour d'elles, légères comme un brouillard. Celle qui préside à leur danse tient un nénufar entr'ouvert.

$$
\begin{aligned}
& \text { (Trois danseuses en vêtements blancs } \\
& \text { entrent et dansent.) }
\end{aligned}
$$

\section{L'EMPEREUR.}

L'éclat occidental est pareil à une blanche vapeur, Les fruits de l'automne sont recueillis et mis en lieu sûr. O pureté inaltérable du métal, Argent limpide et clair, Vol paisible de la colombe, Félicité sans trouble.

(Les danseuses disparaissent subitement.)

TCHAO-KIUN. - Mais tel n'est pas notre destin.

$$
\begin{aligned}
& \text { (Trois danseuses en vêtements bleus } \\
& \text { entrent et dansent.) }
\end{aligned}
$$

L'EMPEREUR. - Celles-ci sont parées de bleu et l'une d'elles tient un iris droit comme une lance.

L'azur à l'orient éveille l'univers, Les tigres au printemps s'élancent au dehors. $O$ fécondité des troncs et des ramures, Douceur des naissances heureuses, Prospérité croissante.

(Les danseuses disparaissent.)

TCHAO-KIUN. - Mais tout autre est notre destin.

$$
\begin{aligned}
& \text { (Trois danseuses en vêtements rouges } \\
& \text { entrent et dansent.) }
\end{aligned}
$$




\section{Trois drames de I'Asie}

L'EMPEREUR. - Elles sont rouges et n'apportent plus de fleurs, mais des rubis étincelants.

La splendeur rouge au sud est l'accomplissement total, Les fleurs en été s'épanouissent largement

O force invincible du feu,

Eclat glorieux du tonnerre,

Sang des victimes agréable aux dieux,

Domination victorieuse.

(Les danseuses disparaissent.)

TCHAO-KIUN. - Mais nous n'aurons pas ce destin.

L'EMPEREUR. - Voici la danseuse noire qui fuit devant un démon.

$$
\begin{aligned}
& \text { (Une danseuse et un démon entrent et } \\
& \text { dansent.) }
\end{aligned}
$$

L'obscurité du nord est redoutable et mystérieuse,

Les dix mille êtres tremblent devant l'hiver et cherchent un abri.

O pénétration opiniâtre de l'eau, Chute silencieuse des brouillards, Terre nue, arbres dépouillés,

Cruel renouvellement par la mort et la séparation.

(Les deux personnages dansants se retirent lentement à reculons, fixant de leurs regards l'empereur et Tchao-kiun.)

TCHAO-KIUN. - Et tel sera notre destin.

L'EMPEREUR. - Non, ce n'est pas possible ! Une danse reste encore, la danse jaune, celle de l'unité suprême et de l'éternelle harmonie. C'est celle-là, Tchao-kiun, qui nous est réservée. Elles vont venir, les danseuses vêtues d'or, tenant en leurs mains les fleurs de lotus resplendissantes. Ne les entendez-vous pas?

(Le conseiller de droite et le conseiller de gauche s'avancent, précédés par le chambellan.) 


\section{SCÈNE III}

Les mêmes, les Conseillers, le Chambellan.

L'EMPEREUR. - Qui se permet de venir ici troubler notre repos ?

LE CHAMBELLAN. - C'est un grave danger qui amène auprès de Votre auguste Majesté ses deux conseillers de droite et de gauche.

L'EMPEREUR. - De confiance j'approuve tout ce que votre expérience aura résolu. Un des rois tributaires s'est révolté ? Un prétendant au trône rassemble des partisans ? Que le général en chef réunisse les troupes nécessaires et parte, dès demain, emmenant avec lui les tablettes des ancêtres impériaux et l'effigie du dieu du sol.

LE CONSEILLER DE DROITE. - Ce n'est pas un vassal ni un imposteur qui nous met au défi.

LE CONSEILLER DE GAUCHE. - La guerre nous est déclarée par le Khan des Tartares.

L'EMPEREUR. - Le Khan des Tartares ?

LE CONSEILLER DE GAUCHE. - Déjà il s'est mis en marche avec ses cavaliers armés de l'arc et de la lance et ils poussent devant eux, comme un troupeau, les populations.

L'EMPEREUR. - Mais ils ne franchiront pas les frontières de l'empire. Les forts sont solides et bien gardés. 


\section{Trois drames de I'Asie}

LE CONSEILLER DE DROITE. - Par l'effet d'une longue paix les soldats de l'empire ont désappris le combat, et dans les forts les provisions épuisées ne permettraient pas de soutenir un siège même de quelques jours.

L'EMPEREUR. - Et c'est aujourd'hui, quand le péril brûle, quand la terre de Hán tout entière frémit sous la menace, c'est aujourd'hui que vous venez me dire: Nous sommes sans défense?

LE CONSEILLER DE DROITE. - Le fils du Ciel ne nous avait-il pas interdit de jeter sur son bonheur l'ombre même d'un souci ?

L'EMPEREUR. - Les Tartares cependant ont envoyé des ambassadeurs. Ils veulent négocier. Quelle est la rançon qu'ils demandent.

LE CONSEILLER DE GAUCHE. - Ce n'est pas une rançon qu'ils exigent.

LE CONSEILLER DE DROITE. - Ils viennent seulement nous rappeler une promesse.

L'EMPEREUR. - Une promesse ?

LE CONSEILLER DE DROITE. - Celle que nous n'avons pas tenue.

L'EMPEREUR. - Je n'y pensais plus, ma foi. Que ne le disaient-ils plus tôt ? Le beau prétexte pour partir en guerre! Le Khan des Tartares se tiendra pour honoré de recevoir en mariage une princesse du palais impérial. Elles n'y manquent pas. On n'a qu'à apporter la liste. Je choisirai.

LE CONSEILLER DE DROITE. - Le Khan des Tartares a choisi. 


\section{Trois drames de I'Asie}

L'EMPEREUR. - Comment a-t-il pu choisir ?

LE CONSEILLER DE GAUCHE. - Maô Yên-chéou, votre ministre infidèle, le soir même où $M$. le Chambellan avait reçu vos instructions pour se saisir de sa personne, avait réussi à s'enfuir. L'EMPEREUR. - Oui, je sais.

LE CONSEILLER DE GAUCHE. - Il a trouvé refuge chez nos ennemis et a montré à leur chef un portrait véritable.

L'EMPEREUR. - Tchao-kiun !

LE CONSEILLER DE GAUCHE. - Si la princesse Tchao-kiun lui est accordée, il s'engage à retirer aussitôt ses troupes en leur désert natal, par delà le fleuve Amour, et offre de conclure avec nous un traité de paix perpétuelle.

LE CONSEILLER DE DROITE. - Sinon, ils gagneront toujours vers le sud, égorgeant sur leur passage tous les êtres vivants, et à la place de nos villes et de nos maisons, de nos jardins et de nos champs, il n'y aura plus qu'une prairie immense, pâturage de leurs chevaux.

LE CONSEILLER DE GAUCHE. - Il faut que la réponse parvienne au Khan des Tartares avant le coucher du soleil. Ses envoyés n'ont pas même voulu mettre pied à terre et attendent, droits sur leurs selles, dans la première cour, prêts à partir.

L'EMPEREUR. - Ainsi donc c'est moi qui dois subir la peine et donner la victime. N'avez-vous pas honte ? Vous demandez qu'elle soit bannie et quitte ce palais, passant le reste de ses jours sous la tente de feutre, captive d'un chef sauvage, pour que paisiblement, couverts de fourrures légères, montés sur vos 


\section{Trois drames de I'Asie}

chevaux luisants de graisse, vous alliez vous asseoir aux tables des banquets que viendront égayer musiciennes et danseuses, pour dormir d'un sommeil sans trouble sous vos couvertures épaisses, et prendre votre rang aux séances de vos conseils, fiers de vos dignités et faisant sonner vos insignes de jade comme grelots d'enfant.

LE CONSEILLER DE DROITE. - Il est loisible à Votre auguste Majesté de nous jeter en prison, de nous faire briser les membres, étrangler, ou lentement dépecer sur la place publique. Vous pouvez aussi nous condamner à marcher sur une poutre de cuivre enduite de graisse au-dessus d'un brasier. Le dernier empereur de la dynastie des Yn avait inventé ce supplice et s'en divertissait fort avec la femme qu'il aimait. Cependant il périt luimême par le feu, quand son armée fut défaite et qu'il dut, pour éviter une mort plus infâme, se jeter dans l'incendie allumé sur la terrasse de son palais.

L'EMPEREUR. - Périsse mon palais et périsse l'empire, plutôt que de consentir à perdre sa présence et la voir s'éloigner. Que m'importent grandeurs et peines de la terre, devant cette envoyée du ciel ? Vous ne pouvez comprendre. Elle m'est plus précieuse que mon corps et ma pensée, que les tablettes de mes ancêtres et que la mission qui me fut accordée de gouverner les hommes. Seule divinité que je doive servir et devant qui par trois fois, en signe d'adoration et de reconnaissance, je veux heurter le sol de mon front.

(Il veut se prosterner devant Tchao-kiun, mais elle l'écarte doucement et s'avance.) 


\section{Trois drames de I'Asie}

TCHAO-KIUN. - Vénérable empereur, sages conseillers, s'il est permis à une humble femme d'élever la voix en votre présence, je vous prierai d'abord d'excuser la violence de sa peine, puis d'accepter que moi-même je consente à devenir la victime offerte aux barbares pour la paix de l'empire.

L'EMPEREUR. - Que dites-vous ? M'abandonner, manquer à la fidélité de l'épouse !

TCHAO-KIUN. - Je vous reste fidèle. Croyez-vous qu'il me soit possible d'oublier les sentiments de la chambre nuptiale ? Ils demeureront enfermés en mon cœur comme dans mon tombeau. J'accomplis mon destin.

L'EMPEREUR. - Que voulez-vous dire?

LE CONSEILLER DE DROITE. - Il est temps de partir.

LE CONSEILLER DE GAUCHE. - Votre dévouement vaudra à votre nom d'être inscrit pour toujours dans les annales de l'empire.

TCHAO-KIUN. - Que du moins un dernier regard me soit permis encore. Hélas ! bien que je me dévoue pour le salut du pays et du peuple des cent familles, je ne puis résister, Seigneur, à la douleur de vous quitter.

(Elle cache son visage de sa manche. Les deux conseillers prennent place à ses côtés et lentement s'éloignent avec elle.)

L'EMPEREUR. - Qu'on prépare mon char ! Je veux la suivre au moins jusqu'à la première étape du mauvais voyage. 


\section{Trois drames de I'Asie}

LE CHAMBELLAN. - Seigneur, il ne faut pas que ces barbares soient témoins de vos regrets. Il faut que le chagrin demeure enfermé dans le palais de Hán.

L'EMPEREUR. - Et ce misérable que voici, sans force et sans courage, qui ne peut donner que des larmes, et aussi impuissant à retenir son bonheur que I'homme qui voit fuir un oiseau sur la mer, c'est le fils du ciel devant qui tout front s'incline ici-bas, c'est I'héritier de l'antique royaume de Hán.

(Il s'abat sur la table, la tête dans ses mains. Le chambellan reste auprès de lui.)

L'EMPEREUR, murmurant comme en rêve. - La danse noire ! La danse noire ! Le démon est vainqueur et la fée devient sa proie. 


\title{
ACTE IV \\ La rive du fleuve Amour
}

\author{
SCENE PREMIÈRE \\ TCHAO-KIUN, deux Tartares.
}

Au fond l'étendue des eaux, à droite les premiers escarpements d'un rocher qui s'élève. Deux soldats tartares entrent à gauche.

PREMIER TARTARE, à Tchao-kiun qu'on ne voit pas encore. -

Princesse, il faut mettre pied à terre ici.

DEUXIÈME TARTARE. - Nous avons un fleuve à traverser.

TCHAO-KIUN, apparaissant. - Un fleuve?

PREMIER TARTARE. - Et non de ceux qu'on passe en retroussant ses vêtements. Nous avons des outres en peaux de bœuf et nos chevaux les traînent. Mais pour la princesse étrangère une barque est apprêtée.

TCHAO-KIUN. - Où est-elle ?

PREMIER TARTARE. - Un peu plus haut, cachée dans une crique. TCHAO-KIUN. - Quel est le nom du fleuve?

PREMIER TARTARE. - Vous I'appelez fleuve du Dragon noir, en notre langue c'est le fleuve Amour. jusqu'à cette rive c'est votre empire, qui se prétend le maître. Au delà commence le domaine que nul ne peut nous disputer. 


\section{Trois drames de I'Asie}

TCHAO-KIUN. - C'est donc la dernière fois que je foule du pied la terre chinoise.

PREMIER TARTARE. - Attendez-nous ici pendant que nous cherchons la barque. Vos suivantes vont vous rejoindre.

TCHAO-KIUN. - Me sera-t-il permis d'adresser au dieu du sol que j'abandonne une prière d'adieu ?

PREMIER TARTARE. - Nous avons ordre d'obéir autant qu'il est possible à celle qui sera l'épouse de notre Khan.

TCHAO-KIUN. - Sur ce rocher dressé comme une tour, je vais monter afin de découvrir dans la plaine les maisons et les cités de mon pays, maisons heureuses, cités paisibles, gloire de l'empereur. Hélas ! peut-être me sera-t-il accordé d'apercevoir, brillant confusément à I'horizon comme les pierres d'émeraude dans l'eau trouble d'un étang, les toits du palais que j'ai quitté pour toujours, le vaste, le magnifique, I'heureux, le délicat, le triste, le sombre, le cruel palais de Hán.

(Elle se dirige lentement vers le rocher ; les Tartares l'observent.)

DEUXIÈME TARTARE. - N'est-ce pas une ruse pour nous échapper?

PREMIER TARTARE. - A moins d'avoir des ailes, il lui faudra bien redescendre par où elle est montée.

(Ils s'éloignent.)

\section{SCÈNE II}

TCHAO-KIUN, deux Suivantes. 


\section{Trois drames de I'Asie}

TCHAO-KIUN (debout sur un premier escarpement). - Flots profonds, je me rends à votre appel. Rocher du rivage, prince de la vie et de la mort, me voici et votre attente ne sera pas déçue.

(Les deux suivantes accourent, inquiètes.)

PREMIÈRE SUIVANTE. - Princesse, où allez-vous ?

DEUXIÈME SUIVANTE. - Vous nous abandonnez ?

TCHAO-KIUN. - Pauvres enfants qui avez voulu me suivre, je récompense mal votre dévouement. Mais la destinée de Tchaokiun est séparation.

PREMIÈRE SUIVANTE. - Pourquoi ne voulez-vous pas nous prendre avec vous?

TCHAO-KIUN. - Au pays où je suis mandée chacun se présente sans escorte et sans amis.

PREMIÈRE SUIVANTE. - J'ai peur à vous entendre.

TCHAO-KIUN. - Mais grâce à vous mes dernières paroles sont pour des êtres de ma race, et c'est à toutes mes sœurs du vaste empire que je dis adieu sur vos frais visages attristés.

(Elle pose les mains sur le front des suivantes qui sanglotent comme des enfants.)

TCHAO-KIUN. - Plus heureuses que moi vous allez revoir le palais, le pavillon au fond du parc, le jardin où nous assemblions les fleurs, et vous témoignerez qu'une épouse fidèle donne sa vie comme son cœur.

(Les suivantes sans répondre s'attachent à ses bras.) 


\section{Trois drames de I'Asie}

TCHAO-KIUN. - Ne me retenez pas ; je ne dois plus me faire attendre. droite.)

(Elle s'arrache à leur étreinte et disparaît à

DEUXIÈME SUIVANTE. - Où est-elle ?

PREMIÈRE SUIVANTE. - Elle a disparu dans les nuages.

LA VOIX DE TCHAO-KIUN. - Je suis parvenue à mi-hauteur et le brouillard m'entoure. Ainsi le sort ne m'a élevée que pour me plonger dans les ténèbres.

PREMIÈRE SUIVANTE. - Elle reparaît, mais si haut qu'on la distingue à peine.

LA VOIX DE TCHAO-KIUN. - J'approche du sommet, le soleil brille. Il est trop tard, et ce n'est pas sur cette terre que la proie échappera au démon noir.

DEUXIÈME SUIVANTE. - Nous devions la suivre, même malgré sa volonté.

PREMIÈRE SUIVANTE. - Mais comment gravir ce roc abrupt ? Il faut qu'une force divine soit en elle.

LA VOIX DE TCHAO-KIUN. - Adieu, terre ; adieu, ciel ! Esprits lumineux, protégez-moi. Esprits obscurs, épargnez-moi. Montagnes sacrées, intercédez pour moi. Rivières saintes, pleurez sur moi. Ames des ancêtres, venez à moi, accueillez votre fille, conduisez-moi, ne fût-ce que pour la durée d'un songe, vers celui qui se consume de regrets en son palais désert, afin qu'il retrouve la paix de son cœur.

PREMIÈRE SUIVANTE. - J'ai cru entendre un bruit funeste. 


\section{Trois drames de I'Asie}

DEUXIÈME SUIVANTE. - Ici, c'est ici.

(Elles se penchent sur l'eau.)

PREMIÈRE SUIVANTE. - Je crois voir un reflet de sa robe argentée dans les eaux.

DEUXIÈME SUIVANTE. - Un chant s'élève. D'où vient-il ? Comme il est triste et doux !

PREMIÈRE SUIVANTE. - C'est son âme qui s'attarde un instant avant de nous quitter pour toujours.

(Elles restent prosternées au bord du
fleuve.) 


\title{
Trois drames de I'Asie
}

\begin{abstract}
ACTE V
Le temple des ancêtres au palais impérial

SCÈNE UNIQUE

L'EMPEREUR.

La salle où sont rangées, de part et d'autre, les tablettes commémoratives des souverains défunts; au fond, celle du grand ancêtre, fondateur de la dynastie, Porte à droite. Demijour. Au dehors, très loin, une musique de cloches, de flûtes et de petites orgues fait entendre un hymne religieux. Elle cessera aux premières paroles de l'empereur. Il entre en hâte, comme un homme poursuivi, et referme aussitôt la porte derrière lui.
\end{abstract}

L'EMPEREUR. (s'avançant, la démarche incertaine, comme halluciné). La danse noire ! Même en ce jour de fête, même devant les images des ancêtres, elle m'enveloppe de son cercle maudit. Arrière, démon, arrière ! Où est-il ? Il m'échappe. Si je parvenais à I'arrêter un instant, la fée serait délivrée. Il est là. Non ! ici. Je le reconnais, ce n'est pas un démon, c'est un homme comme moi, un guerrier tartare. Je le vois, je le tiens, il est en mon pouvoir, et resserrant peu à peu l'étreinte de mes bras, voilà que je l'étouffe lentement. Son corps fléchit, sa tête retombe en arrière. - Qu'ai-je fait ? Ce n'est pas le guerrier, c'est la fée que j'avais saisie. Elle est tombée sans un cri. Et ce n'était pas une fée ! Horreur ! Tchao-kiun est devant moi, morte, je l'ai tuée ! Tchao-kiun ! Ses yeux sont clos et je n'aurai pas même eu son dernier regard.

(Il s'agenouille auprès d'un corps imaginaire. La musique religieuse reprend.) 


\section{Trois drames de I'Asie}

L'EMPEREUR (se relevant soudain, comme éveillé d'un rêve). - Où suisje ? Ombres de mes ancêtres, est-ce auprès de vous que je viens chercher un refuge ? Mais vous ne pouvez recevoir ce descendant indigne. Cette musique au loin, je la reconnais. Elle accompagne l'offrande au temple du ciel. Quelle offrande ? Je me souviens. Actions de grâces pour la paix revenue, le calme des foyers, la délivrance de l'empire. Joie des cent familles, à quel prix obtenue! (La musique s'arrête.) Dernier écho des cloches et des pierres sonores. Tout se tait maintenant. Le sacrifice est célébré. Le cortège s'avance et viendra jusqu'ici pour I'hommage aux ancêtres dont je serai I'officiant. Comment pourrai-je élever ma prière, quand une sombre vapeur emprisonne ma vue et que l'inquiétude soulève mes pensées en tempête ?

LA VOIX DU GRAND ANCÊTRE. - Celui qui a charge de gouverner les hommes, d'abord gouverne sa maison.

L'EMPEREUR. - Qui a parlé ? D'où venait cette voix d'outretombe ? Est-ce vous, grand ancêtre ? Oui, ma maison était mal gouvernée, ma vie se consumait en jeux de vanité, en plaisirs sans bonheur. Mais depuis le jour où je suis venu, ici même, vous présenter ma nouvelle épouse et vider avec elle la coupe des fiançailles, n'avais-je pas éloigné les conseillers néfastes ? Ramené dans les chambres intérieures comme aux salles d'audience l'obéissance et le respect ?

LA VOIX DU GRAND ANCÊTRE. - Celui qui prétend commander aux hommes, d'abord doit commander à son cœur.

L'EMPEREUR. - Commander à son cœur ! Que voulez-vous dire ? Celle à qui je me sentais uni jusque par delà le tombeau, 


\section{Trois drames de I'Asie}

je l'ai livrée, je l'ai cédée, je l'ai laissée partir, je l'ai laissée mourir, et je devrais encore arracher de mon cœur jusqu'à son souvenir ? Je vous entends. Cette fidélité conjugale que parmi les cent familles on récompense et on honore est coupable chez le souverain, car tout attachement flétrit, toute préférence déforme, tout désir corrompt une volonté qui doit demeurer unie, fixe et universelle comme le ciel dont nous sommes les fils. Pour ce dernier effort, pour ce dépouillement suprême, ancêtres glorieux qui avez obtenu le repos, accordez à celui qui est le sang de votre sang et le corps de vos corps la force et le courage. Le courage surtout. Le courage ! Le courage !

(Il se place devant la tablette du grand ancêtre, dominé par elle, les mains jointes. La porte s'ouvre à deux battants, laissant passer à flots les rayons du soleil.)

L'EMPEREUR. - Voici que le démon s'enfonce sous la terre, la douce fugitive s'échappe, monte légèrement par les sentiers aériens et va se perdre dans l'unique lumière. Toutes les couleurs cèdent et se fondent en l'éclat du soleil. Le cinquième élément triomphe ; le calme est au ciel et sur terre. Le cortège peut entrer ; l'empereur est digne de le recevoir.

(L'hymne religieux s'élève, de près cette fois. Le cortège apparaît. Ceux qui sont en tête se prosternent. L'empereur élève les mains en signe de bénédiction.)

L'EMPEREUR. - La clarté de l'or au centre du monde rayonne sur toute chose, Éternellement les saisons alternent, la vie et la mort se tiennent par la main.

O puissance inépuisable de la terre, Fraternité profonde des principes opposés, Perfection de l'ordre, tranquillité divine, 


\section{Trois drames de I'Asie}

Le cœur du prince est l'image de l'univers.

@ 